ANGELA FRANCISCA TRINCONI

\title{
Avaliação dos fatores de crescimento \\ insulinóides IGF-1 e IGFBP-3 em mulheres \\ com alto risco para câncer de mama
}

Tese apresentada à

Faculdade de Medicina da Universidade de São Paulo para obtenção do Título de Doutor em Ciências

Área de concentração: Obstetrícia e Ginecologia

Orientador: Dr. José Roberto Filassi

São Paulo

2010 
Dados Internacionais de Catalogação na Publicação (CIP)

Preparada pela Biblioteca da

Faculdade de Medicina da Universidade de São Paulo

reprodução autorizada pelo autor

Trinconi, Angela Francisca

Avaliação dos fatores de crescimento insulinóides IGF -1 e IGFBP - 3 em mulheres com alto risco para câncer de mama / Angela Francisca Trinconi. -- São Paulo, 2010. Tese(doutorado)--Faculdade de Medicina da Universidade de São Paulo.

Programa de Obstetrícia e Ginecologia.

Orientador: José Roberto Filassi.

Descritores: 1.Fator de crescimento insulin-like I 2.Proteína 3 de ligação a fator de crescimento insulin-like 3.Neoplasias da mama 4.Grupos de risco

USP/FM/DBD-244/10 


\section{DEDICATÓRIA}

A todas as pacientes,

que passaram pela minha vida deixando um pouquinho de suas histórias para compor meu aprendizado.

À ciência,

que permitirá ao médico tratar antes de adoecer.

À minha família,

base de força e amor sobre a qual ergui minha vida.

A Aroldo e Mateus,

para que saibam que o final é apenas um novo começo! 


\section{AGRADECIMENTOS}

Ao Prof. Dr. Edmund Chada Baracat por seu interesse e estímulo a todos os pós-graduandos.

Ao Dr. José Roberto Filassi por seu incentivo, dedicação e apoio durante todas as fases de execução desta tese.

Ao Sr. Antonio de Castro Bruni que conferiu credibilidade estatística aos dados colhidos.

Aos colegas do Hospital das Clínicas da Faculdade de Medicina da Universidade de São Paulo e do Instituto do Câncer do Estado de São Paulo que colaboraram com a triagem das pacientes que foram elencadas neste estudo.

À Sra. Maria de Fátima O. Suzano que trouxe ânimo e incentivo durante as fases mais trabalhosas. 

“Viver não é só existir, senão existir e criar, saber gozar e sofrer e não dormir sem sonhar." 


\section{NORMALIZAÇÃO ADOTADA}

Esta tese está de acordo com as seguintes normas, em vigor no momento desta publicação:

Referências: adaptado de International Committee of Medical Journals Editors (Vancouver)

Universidade de São Paulo. Faculdade de Medicina. Serviço de Biblioteca e Documentação. Guia de apresentação de dissertações, teses e monografias. Elaborado por Anneliese Carneiro da Cunha, Maria Julia de A. L. Freddi, Maria F. Crestana, Marinalva de Souza Aração, Suely Campos Cardoso, Valéria Vilhena. $2^{\mathrm{a}}$ ed. São Paulo: Serviço de Biblioteca e Documentação; 2005.

Abreviaturas dos títulos dos periódicos de acordo com List of Journals Indexed in Index Medicus. 


\section{SUMÁRIO}

Lista de abreviaturas, siglas e símbolos

Lista de tabelas

Lista de figuras

Resumo

Summary

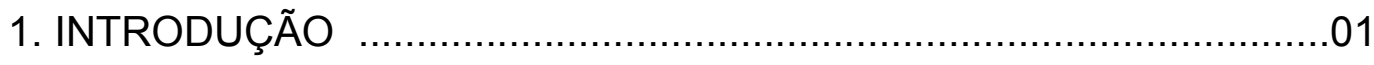

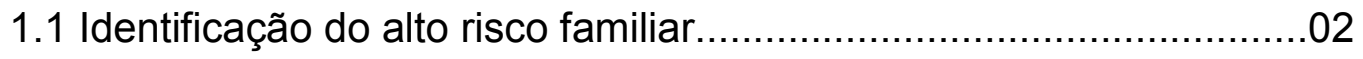

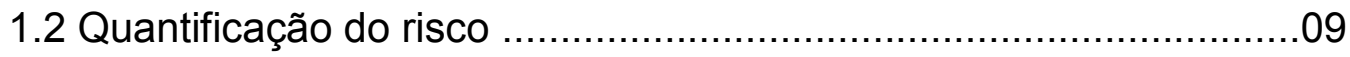

1.3 Identificação do alto risco histopatológico.....................................15

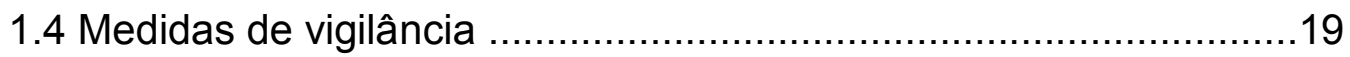

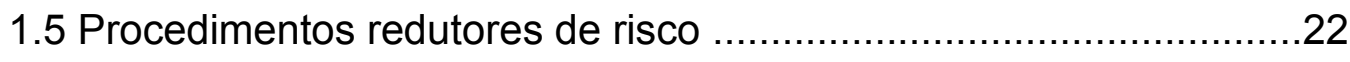

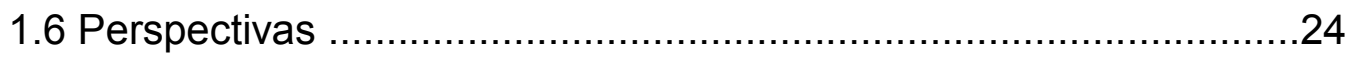

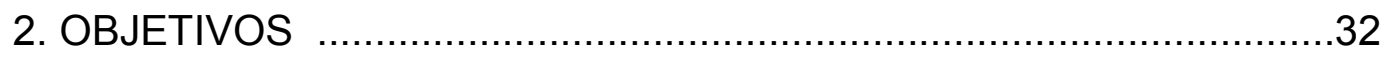

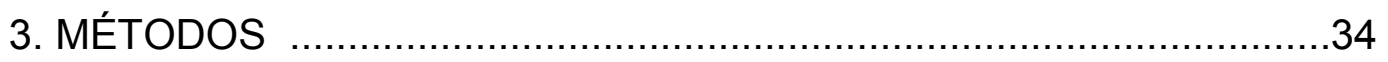

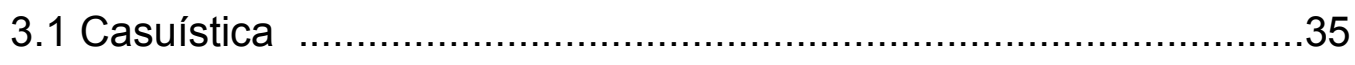

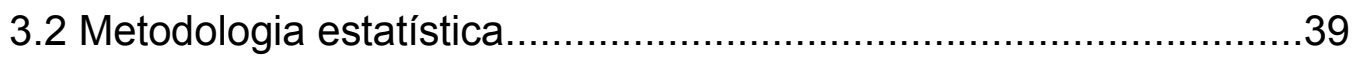




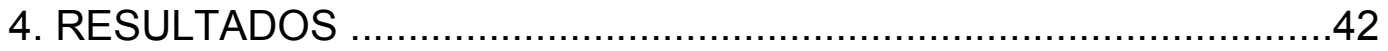

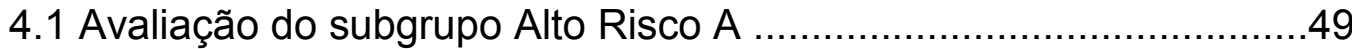

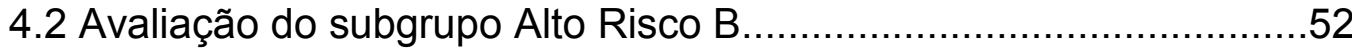

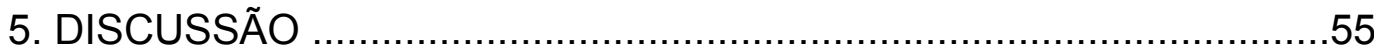

6. CONCLUSÃO

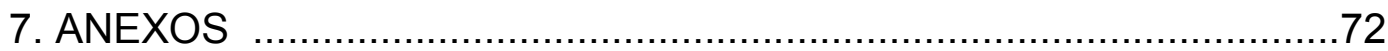

7.1 Anexo A - Termo de consentimento livre e esclarecido....................73

7.2 Anexo B - Formulário de anamnese ...........................................

7.3 Anexo C - Modelo de laudo de dosagem de IGFBP-3.....................80

7.4 Anexo D - Modelo de laudo de dosagem de IGF-1 .......................81

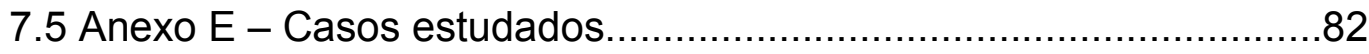

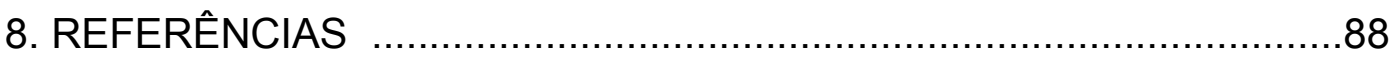




\section{LISTA DE ABREVIATURAS, SIGLAS E SÍMBOLOS}

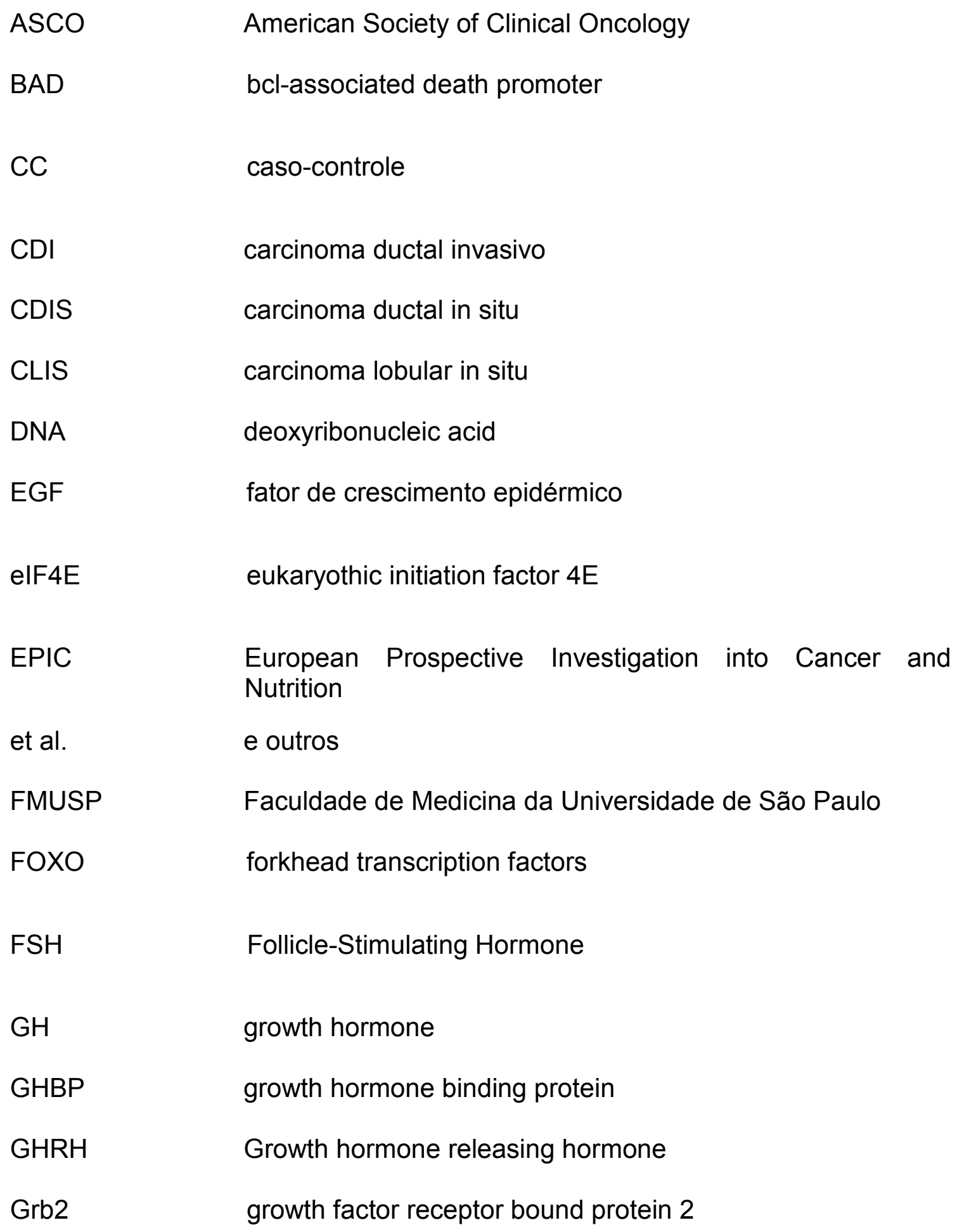




\begin{tabular}{|c|c|}
\hline GSK-3 $\beta$ & glycogen synthetase kinase $3 \beta$ \\
\hline HDA & hiperplasia ductal atípica \\
\hline HLA & hiperplasia lobular atípica \\
\hline IMC & índice de massa corpórea \\
\hline IGF-1 & Insulin-like growth factor 1 \\
\hline IGF-1R & Insulin-like growth factor 1 receptor \\
\hline IGFBP-3 & Insulin-like growth factor binding protein 3 \\
\hline INCA & Instituto Nacional do Câncer \\
\hline IRS1 & proteínas do insulin receptor substrate 1 \\
\hline JAK & janus tyrosine kinase \\
\hline $\mathrm{kg}$ & quilograma \\
\hline । & litro \\
\hline LH & Luteinizing Hormone \\
\hline MA & meta-análise \\
\hline MAPK & mitogen-activated protein kinase \\
\hline $\mathrm{mg}$ & miligrama \\
\hline $\mathrm{ml}$ & mililitro \\
\hline mRNA & Messenger ribonucleic acid \\
\hline n. & número \\
\hline
\end{tabular}


nanograma

NCCN

National Comprehensive Cancer Network

$\mathrm{OZ}$

onça fluida americana(equivale a 29,57 ml)

$\mathrm{PI3K}$

phosphatidylinositol 3-tide-dependent protein kinase

PKB

phosphoinositide-dependent protein kinase

PKB

protein kinase B

pósM

pós-menopausa

préM

pré-menopausa

PRL

prolactina

PTEN

phosphatase and tensin homolog

$\mathrm{RR}$

risco relativo

RE

receptor de estrogênio

$\mathrm{RP}$

receptor de progesterona

RS

revisão sistemática

SERM

selective estrogen receptor modulator

SHV

Src homology collagen

TMX

tamoxifeno

TOR

target of rapamycin 
TSH

$\%$

$\geq$

$\leq$ thyroid-stimulating hormone

porcentagem

maior ou igual a

menor ou igual a 


\section{LISTA DE TABELAS}

Tabela 1 - Síndromes genéticas associadas ao câncer de mama...............05

Tabela 2 - Características dos modelos de Gail, Claus e Tyrer-cuzick.......14

Tabela 3 - Fatores de risco para câncer de mama.....................................15

Tabela 4 - Risco relativo de câncer de mama para os fatores maiores......16

Tabela 5 - Risco relativo para carcinoma invasivo de mama associado com lesões benignas em biópsia prévia

Tabela 6 - Medidas de vigilância recomendadas pela NCCN .21

Tabela 7 - Estatísticas descritivas para as variáveis quantitativas.

Tabela 8 - Associação menopausa e grupos.

Tabela 9 - Distribuição dos \%IGFBP-3 em relação à mediana nos diferentes grupos 45

Tabela 10 - Distribuição dos \%IGF-1 em relação à mediana nos diferentes grupos. .46

Tabela 11 - Distribuição dos \%IGFBP-3 em relação à mediana e risco familiar. 
Tabela 12 - Distribuição dos \%IGF-1 em relação à mediana e risco familiar.

Tabela 13 - Distribuição dos resultados da razão \%IGF-1 / \%IGFBP-3 em relação à mediana e risco familiar.

Tabela 14 - Distribuição dos \%IGFBP-3 em relação à mediana e risco histopatológico 48

Tabela 15 - Distribuição dos \%IGF-1 em relação à mediana e risco histopatológico 48

Tabela 16 - Distribuição da razão \%IGF-1 / \%IGFBP-3 em relação à mediana e risco histopatológico. 48

Tabela 17 - Médias de idade e IMC para o grupo de alto risco A segundo \%IGF-1 em relação à mediana. 49

Tabela 18 - Médias de idade e IMC para o grupo de alto risco A segundo \%IGFBP-3em relação à mediana. 50

Tabela 19 - Médias de idade e IMC para o grupo de alto risco A segundo a razão \%IGF-1 / \%IGFBP-3 em relação

à mediana. .50 
Tabela 20 - Distribuição do \%IGF-1 em relação à mediana e menopausa no alto risco $A$ 51

Tabela 21 - Distribuição do \%IGFBP-3 em relação à mediana e menopausa no alto risco $A$ 51

Tabela 22 - Distribuição da razão \%IGF-1 / \%IGFBP-3 em relação à mediana e menopausa no alto risco $\mathrm{A}$ .51

Tabela 23 - Médias de idade e IMC para o grupo de alto risco $B$ segundo \%IGF-1 em relação à mediana. .52

Tabela 24- Médias de idade e IMC para o grupo de alto rsico B segundo \%IGFBP-3 em relação à mediana .52

Tabela 25 - Médias de idade e IMC para o grupo de alto risco B segundo a razão \%IGF-1 / \%IGFBP-3 em relação

à mediana. .53

Tabela 26 - Distribuição do \%IGF-1 em relação à mediana e menopausa no alto risco $\mathrm{B}$ 54

Tabela 27 - Distribuição do \%IGFBP-3 em relação à mediana e Menopausa no alto risco $\mathrm{B}$ .54 
Tabela 28 - Distribuição da razão \%IGF-1 / \%IGFBP-3 em relação

à mediana e menopausa no alto risco $\mathrm{B}$...............................54

Tabela 29 - Estudos que relacionam IGF-1 e/ou IGFBP-3 e

risco de câncer de mama........................................................66

\section{LISTA DE FIGURAS}

Figura 1 - Modelo de metástase de câncer de mama................................17

Figura 2 - Influência do GH e estrogênios na ação do IGF1 .......................26

Figura 3 - Equilíbrio entre proliferação e apoptose...................................26

Figura 4 - Representação simplificada dos componentes

intracelulares do sistema IGF e suas ações.............................27

Figura 5 - Diagrama de seleção da população estudada...........................37

Figura 6 - Correlações entre as dosagens de IGF-1 e IGFBP-3

e percentual relativo à mediana 


\section{RESUMO}

Trinconi AF. Avaliação dos fatores de crescimento insulinóides IGF-1 e IGFBP3 em mulheres com alto risco para câncer de mama [tese]. São Paulo: Faculdade de Medicina, Universidade de São Paulo; 2010.

INTRODUÇÃO: A crescente incidência de câncer de mama, que cada vez mais acomete mulheres jovens, tem despertado muito interesse no diagnóstico precoce e na busca do tratamento mais eficaz e minimamente agressivo. Da mesma forma, vem aumentando a parcela da população com alto risco para câncer de mama, para a qual as atenções têm se voltado no sentido de se encontrar um caminho que permita prevenir o surgimento da neoplasia. Inspirados por Peyrat, que primeiro associou o câncer de mama com a presença de fator de crescimento insulina like tipo 1 (IGF-1), vários autores se lançaram nesta procura e, apesar de controversa, a literatura internacional tende a mostrar uma relação direta entre IGF-1 e câncer de mama na pré-menopausa. A proteína carreadora de IGF do tipo 3, ou IGFBP-3, também foi adicionada ao rol de sustâncias com possibilidade de promover câncer, porém, não tem demonstrado clara regularidade em seu mecanismo de ação. Tendo como alvo a população com alto risco para câncer de mama, quer histopatológico, quer familiar, e direcionada pelos cálculos matemáticos de Gail e Tyrer-Cuzick, essa tese objetivou avaliar a relação entre IGF-1 e IGFBP-3 em mulheres brasileiras 
atendidas pelo Setor de Mastologia da Disciplina de Ginecologia do Departamento de Obstetrícia e Ginecologia da Faculdade de Medicina da Universidade de São Paulo. MÉTODOS: estudo transversal em que foram comparados os níveis séricos de IGF-1 e IGFBP-3, dosados pelo método imunométrico quimioluminescente, em 3 diferentes grupos: mulheres com câncer de mama não tratado $(n=51)$, mulheres com risco populacional $(n=66)$ e mulheres com alto risco para câncer de mama $(n=108)$. Foram considerados fatores de comparação: idade, estado menopausal e índice de massa corpórea. RESULTADOS: 1) não houve diferenças entre os grupos com respeito ao IMC; 2) foi estatisticamente significativa a diferença das médias de idades dos grupos, sendo as mulheres com alto risco para câncer de mama mais jovens $(p<0,001)$; 3) quanto ao estado menopausal, houve significativa diferença entre os grupos, com predomínio de mulheres pós-menopausa no grupo de pacientes com câncer de mama $(58,8 \%)$, com $p<0,001$; 4) não foi encontrada relação estatisticamente significante entre percentual de IGF-1 em relação à mediana, percentual de IGFBP-3 em relação à mediana e razão dos percentuais de IGF-1 e IGFPB-3 em relação à mediana para os 3 grupos estudados;4) não houve variações nas dosagens de acordo com o tipo de situação determinante do alto risco para câncer de mama (familiar ou histopatológico); 5) não houve alteração estatisticamente significativa das variáveis estudadas, mesmo após subdivisão do grupo de alto risco (risco vitalício entre 20 e $29 \%$ X risco vitalício superior a 29\%). CONCLUSÃO: Não foi observada variação dos níveis séricos de IGF-I e 
IGFBP-3 em mulheres com câncer de mama, com alto risco para câncer de mama ou com risco populacional.

Descritores: fator de crescimento insulin-like 1, proteína 3 de ligação a fator de crescimento insulin-like, neoplasias da mama, grupos de risco. 


\section{SUMMARY}

Trinconi AF. Evaluation of the insulin-growth factors IGF-1 and IGFBP-3 in highrisk breast cancer women [thesis]. São Paulo: School of Medicine, University of São Paulo; 2010

INTRODUCTION: The rising incidence of breast cancer, a disease that is increasingly affecting young women, has aroused a great deal of interest in early diagnosis and the search for a more efficient and minimally aggressive treatment. Likewise, the population at high risk for breast cancer has been growing, and it is now the focus of research efforts in the struggle to prevent neoplasia. Inspired by Peyrat, who was the first to associate breast cancer with insulin-like growth factor type 1 (IGF-1), several authors have taken on the challenge, and the international literature now leans towards a direct relationship, albeit still controversial, between IGF-1 and breast cancer in premenopause. The IGF binding protein 3 (IGFBP-3) has also been added to the list of cancer-causing agents, but its mechanism of action has not shown to be clearly regular. Targeting a population at high risk for breast cancer for histopathologic or familial reasons, and guided by the mathematical calculations of Gail and Tyrer-Cuzick, this thesis aimed at evaluating the relationship between IGF-1 and IGFB-3 in Brazilian female outpatients at the Mastology Sector of the Gynecology Discipline of the Department of Obstetrics and 
Gynecology of the School of Medicine of the University of São Paulo. METHODS: Transverse study to compare the serum levels of IGF-1 and IGFBP3 measured by the chemiluminescent immunometric method. The patients were divided into 3 different groups: women with untreated breast cancer $(n=51)$, women with a population-based risk of breast cancer $(n=66)$, and women at high risk for breast cancer $(n=108)$. The comparison factors were age, menopausal state, and body mass index. RESULTS: 1) there were no differences among the groups with respect to BMI; 2) but there were statistically significant differences among the groups regarding mean age, and the younger women were those at a higher risk for breast cancer $(p<0.001) ; 3)$ as for menopausal state, the groups were significantly different, and the postmenopausal women were prevalent among the patients with breast cancer $(58.8 \% ; p<0.001) ; 4)$ no statistically significant relationship was found between the IGF-1 percentage and the median, the IGFBP-3 percentage and the median, or the IGF-1 and IGFBP-3 ratio and the median in any of the groups; 5) measurements did not vary according to the determinant reason for high breast cancer risk (familial or histopathologic); 6) statistically significant changes in the variables under consideration did not take place, even after subdivision of the high-risk group (lifelong risk between $20 \%$ and $29 \%$ X lifelong risk over $29 \%$ ). CONCLUSION: The serum levels of IGF-I and IGFBP-3 showed no variation among women with breast cancer, at high risk for cancer, or with populationbased risk. 
Key words: insulin-like growth factor 1, insulin-like growth factor binding protein 3 , breast neoplasias, risk groups 
1. INTRODUÇÃO 


\section{INTRODUÇÃO}

Com exceção do câncer de pele, o câncer de pulmão é o câncer mais frequente no mundo, sendo o segundo lugar atribuído ao câncer de mama, que é o mais comum entre as mulheres. A cada ano, cerca de $22 \%$ dos casos novos de câncer em mulheres são de mama.

No Brasil, de acordo com o Instituto Nacional do Câncer (INCA)¹ o número de casos novos de câncer de mama esperados no ano de 2010 é de 49.240, com um risco estimado de 49 casos em cada 100 mil mulheres.

Segundo o National Cancer Institute ${ }^{2}$ a estimativa de casos novos e de óbitos por câncer de mama na população feminina dos Estados Unidos em 2009 era de 192.370 e 40.170, respectivamente. A mesma Instituição ${ }^{3}$ estima que, baseado em dados correntes, $12,7 \%$ das mulheres nascidas hoje (ou 1 em 8) terão diagnóstico de câncer de mama durante suas vidas, nos Estados Unidos.

\subsection{Identificação do alto risco familiar}

Desde o reconhecimento do primeiro gene autossômico dominante relacionado com câncer de mama, uma infinidade de estudos tenta desvendar esta incógnita. O possível papel de alterações genéticas na etiologia do câncer de mama é sugerido pela maior incidência desta neoplasia entre mulheres com 
história familiar de parentes de primeiro e segundo graus afetados. Quando a história familiar é sugestiva de uma predisposição hereditária, mas o número ou a distribuição de câncer não é decisivo, diz-se câncer familiar.

O câncer hereditário é identificado quando famílias têm múltiplos casos de câncer distribuídos segundo modelo Mendeliano de herança ( isto é, dominante, recessivo ou ligado ao X). Estima-se que a prevalência destas mutações seja de 1 em 250-500 indivíduos, com aumento desta prevalência em algumas etnias como Judeus Ashkenazi e descendentes de Islandeses e Finlandeses.

Avalia-se que apenas 5 a $10 \%$ de todos os casos de câncer de mama são hereditários, porém em apenas $25 \%$ deles existe possibilidade de identificação do gene acometido ${ }^{4}$.

No câncer hereditário a história familiar apresenta algumas características marcantes, sendo considerados dados relevantes:

- 2 parentes de primeiro grau com câncer de mama sendo pelo menos um diagnosticado em idade $\leq 50$ anos;

- 3 ou mais parentes de primeiro ou segundo grau com câncer de mama independente da idade no diagnóstico;

- uma combinação de câncer de mama e ovário entre parentes de primeiro e segundo graus;

- um parente de primeiro grau com câncer de mama bilateral;

- 2 ou mais parentes de primeiro ou segundo grau com câncer de ovário 
independente da idade no diagnóstico;

- um parente de primeiro ou segundo grau com câncer de mama e de ovário em qualquer idade;

- câncer de mama em parente do sexo masculino;

- descendência Ashkenazi com 1 parente de primeiro grau ou 2 de segundo grau com câncer de mama ou câncer de ovário;

- pacientes que tenham tido câncer de mama antes dos 40 anos ou câncer de ovário antes dos 50 anos, independente de história familiar;

- vários tipos de câncer em um mesmo indivíduo;

- cânceres mais comuns, porém, fora da faixa de idade usual (próstata ou pâncreas em jovens).

Até o momento foram identificadas 3 síndromes hereditárias de maior relevância: síndrome do câncer de mama e ovário hereditário, síndrome de Cowden e síndrome de Li-Fraumeni.

Algumas de suas principais características encontram-se na tabela 1. 
Tabela 1 - Síndromes genéticas associadas ao câncer de mama ${ }^{4,5}$

\begin{tabular}{|c|c|c|c|c|}
\hline $\begin{array}{l}\text { Sindrome } \\
\text { hereditária }\end{array}$ & Herança & Gene & $\begin{array}{l}\text { Risco de câncer de } \\
\text { mama aos } 70^{\circ}\end{array}$ & $\begin{array}{l}\text { Freqüência } \\
\text { população }\end{array}$ \\
\hline $\begin{array}{l}\text { Câncer de } \\
\text { mama e ovário } \\
\text { hereditário }\end{array}$ & $\begin{array}{ll}\text { Autossômica } & \\
\text { dominante, alta } \\
\text { penetrância }\end{array}$ & 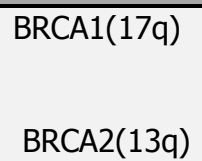 & $\begin{array}{l}65 \% \\
45 \%\end{array}$ & $\begin{array}{l}1 \text { em } 860 \\
1 \text { em } 740\end{array}$ \\
\hline Cowden & $\begin{array}{l}\text { Autossômica } \\
\text { dominante, alta } \\
\text { penetrância }\end{array}$ & $\operatorname{PTEN}(10 q)$ & 30 a $50 \%$ & $1 \mathrm{em} 250.000$ \\
\hline LiFraumeni & $\begin{array}{l}\text { Autossômica } \\
\text { dominante, alta } \\
\text { penetrância }\end{array}$ & TP53(17p) & $\begin{array}{l}\sim 50 \text { a } 60 \% \text { aos } 45 \\
\text { anos }\end{array}$ & $1 \mathrm{em} 5.000$ \\
\hline
\end{tabular}

O BRCA é um gene supressor tumoral que tem a função de manter a integridade do genoma uma vez que possibilita a recombinação de bases homólogas do DNA, repara a quebra da dupla hélice e controla os danos do DNA na fase $S^{6}$. O BRCA1 e o BRCA2, embora modestamente diferentes em suas características, são comumente considerados juntos porque suas similaridades superam suas diferenças.

As mulheres portadoras de mutação no BRCA1 ou 2 têm risco de câncer de mama durante a vida entre 37 e $85 \%$ e de câncer de ovário entre 15 e 40\%. Os homens mutados para BRCA têm risco para câncer de próstata 4 vezes maior que a população geral e 100 vezes de aumento do risco para câncer de mama ${ }^{4}$.

Outros tipos de câncer também estão relacionados à mutações do $\operatorname{BRCA} 1 / 2^{4,5}$

- BRCA1: corpo e colo uterino, pâncreas, tubas uterinas, ovário, 
peritôneo, estômago, cólon e próstata;

- BRCA2: estômago, bexiga, vias biliares, pâncreas, faringe e próstata.

Quanto às características tumorais histopatológicas observa-se:

- BRCA1: fenótipo basal (triplo negativo), pobremente diferenciado, alta contagem mitótica, maior pleomorfismo nuclear, perda da formação tubular, diminuição da capacidade de apoptose, carcinoma ductal invasivo em sua maioria, apesar de ocorrer uma maior incidência de carcinoma medular (13\%) quando comparado com o câncer de mama BRCA2 (3\%) ou o não $\operatorname{BRCA}(2 \%)^{7}$.

- BRCA2: tumores de alto grau que seguem a distribuição de receptores de estrogênio (RE) e de progesterona (RP) dos casos esporádicos assumindo um fenótipo luminal $\mathrm{A}$.

Na Síndrome de COWDEN, também conhecida como a síndrome dos hamartomas múltiplos, o paciente apresenta hamartomas em diversos órgãos (pele, mama, intestino e tireóide) além de outras lesões mucocutâneas e papilomatose oral.

Aproximadamente $80 \%$ dos indivíduos diagnosticados como Cowden têm uma mutação identificada no PTEN ${ }^{8}$, gene localizado no cromossomo $10 \mathrm{q}$, que age como supressor tumoral, já que controla o ciclo celular e a apoptose.

Mulheres acometidas têm 67 a $76 \%$ de risco de apresentar doença mamária benigna ${ }^{7}$ (metaplasia apócrina, fibroadenomas, microcistos, adenose, 
lesões hamartoma-like com colágeno densamente hialinizado, acometendo de modo extenso e bilateralmente as mamas) e de 25 a $50 \%$ de risco durante a vida de ter câncer de mama (geralmente CDI) com uma média de idade no diagnóstico entre 38 a 46 anos $^{6}$.

Adicionalmente ao câncer de mama, os indivíduos com síndrome de Cowden possuem $10 \%$ de risco durante a vida de desenvolver câncer de tireóide (tipicamente folicular e ocasionalmente papilar) e 5 a $10 \%$ de risco de câncer de endométrio ${ }^{4}$. Observa-se também um aumento da prevalência de doenças benignas da tireóide (como bócio multinodular e adenomas) e do útero (miomas).

Também relacionada a mutação no cromossomo 10, a síndrome de Bannayan-Riley-Ruvalcaba ${ }^{9}$ é uma desordem rara, diagnosticada na infância (em contraste com a síndrome de Cowden) sendo mais frequente em pacientes do sexo masculino (baixa penetrância no sexo feminino). Aproximadamente $60 \%$ dos pacientes apresentam mutação no PTEN e a síndrome c0aracterizase pela presença de pólipos hamartomatosos em intestino ( $45 \%$ dos pacientes), macrocefalia com ventrículos cerebrais normais, lipomas (75\%), hemangiomas (40\%), problemas de tireóide, retardo de desenvolvimento neuropsicomotor e sardas no genital masculino. Associa-se com câncer de tireóide (entre 3 e 10\% dos casos) e câncer de mama (entre 30 e 50\%).

A Síndrome de LI-FRAUMENI é responsável por menos de $1 \%$ dos carcinomas hereditários $^{8}$ e se caracteriza pelo surgimento precoce de neoplasias localizadas na mama, sarcomas de tecidos moles, osteossarcomas, 
leucemias, tumores cerebrais e tumores adrenocorticais. Entre 50 e $70 \%$ dos portadores da síndrome de Li-Fraumeni apresentam uma desordem autossômica dominante causada pela mutação no gene $\operatorname{TP} 53^{7}$, que é um gene bem conhecido relacionado à supressão tumoral, localizado no cromossomo 17p13.1, e que está associado ao controle do ciclo celular e apoptose.

Calcula-se que o risco de desenvolver câncer entre os portadores seja de $50 \%$ aos 40 anos e de até $80 \%$ aos 50 anos, diferindo de acordo com o sexo: mulheres têm próximo de $100 \%$ de risco de desenvolver câncer durante a vida e homens, $73 \%$. A média de idade no diagnóstico de câncer em portadores de Li-Fraumeni é de 36 anos.

Outras mutações gênicas associadas ao câncer de mama já foram identificadas, porém, com prevalências muito baixas, a saber:

- Peutz-Jeghers: rara condição autossômica dominante (1 : $25.000-280.000$ indivíduos) que se caracteriza por pólipos (hamartomatosos ou adenomatosos), principalmente intestinais, e pigmentação melânica da pele e mucosas. O risco relativo de câncer pode ser 18 vezes maior do que o verificado na população geral, com 37 - 93\% dos indivíduos acometidos desenvolvendo câncer até a idade de 65 anos. Recentemente foram identificadas mutações no gene STK11/LKB1 localizado no cromossomo 19p13.3, o qual codifica uma proteína facilitadora da apoptose (serina treonina-quinase), resultando 
na perda de sua função e crescimento celular descontrolado ${ }^{4}$. Estas mutações têm sido detectadas em até $70 \%$ dos casos em famílias atingidas e em cerca de $50 \%$ dos casos esporádicos. As mulheres acometidas têm um risco aumentado para câncer de mama, estimado entre 29 e $50 \%$ aos 65 anos de idade, com idade média de acometimento aos 45 anos.

- Ataxia-telangiectasia: rara desordem autossômica recessiva relacionada ao gene ATM (11q), de baixa penetrância, caracterizada por desordem neurodegenerativa associada a ataxia cerebelar, telangiectasias, imunodeficiência e com risco de câncer de mama aos 70 anos de $23 \%(R R=2,23 \text { a } 5,1)^{4,5}$.

- CHEK-2 (1100delC): gene de baixa penetrância que, quando mutado, confere o dobro de risco para câncer de mama. Parece estar relacionado com $1 \%$ dos casos de câncer de mama em mulheres e $9 \%$ dos cânceres de mama em homens ${ }^{4}$.

\subsection{Quantificação do risco}

Com o intuito de avaliar quantitativamente a possibilidade de determinado membro de uma família ser portador de mutação genética e, portanto, avaliar a possibilidade de desenvolver câncer de mama entre outros, foram criados modelos matemáticos. Com a finalidade de estimar a possibilidade de mutação 
de BRCA 1 / 2 podem ser ressaltados os seguintes modelos: BRCAPRO, Myriad, Couch (também conhecido como Penn), FHAT (family history assessment tool), Manchester, Penn II, IBIS e BOADICEA (breast and ovarian analysis of disease incidence and carrier estimation algorithm). Cada modelo calcula o risco com base na inclusão de diferentes tipos de câncer diagnosticados na família. Todos os modelos incorporam a história familiar de câncer de mama e de ovário. Adicionalmente o FHAT inclui câncer de colon e de próstata, enquanto o Manchester, BOADICEA e Penn II incluem câncer de próstata e pâncreas.

Não há, até o momento, modelos estatísticos que possam predizer a probabilidade de mutações nos genes PTEN ou TP53.

A ciência vem descobrindo novas alterações genéticas (mutações, polimorfismos) que podem estar relacionadas com o surgimento do câncer de mama e que não se incluem nesses modelos convencionais, os quais se tornarão gradualmente obsoletos.

Quando há uma grande suspeita de que haja uma herança familiar de mutação genética envolvida com o surgimento de casos de câncer, pode-se lançar mão de testes genéticos.

A análise molecular dos genes BRCA1, BRCA2, PTEN e TP53 é comercialmente oferecida e, de acordo com a American Society of Clinical Oncology $(\mathrm{ASCO})^{10}$, pode ser oferecida quando:

- há história pessoal ou familiar sugestiva de risco hereditário; 
- o teste genético pode ser adequadamente interpretado;

- o resultado ajudar no diagnóstico ou influenciar no controle clínico ou cirúrgico da paciente e familiares.

Possíveis resultados para os testes genéticos:

- POSITIVO VERDADEIRO: a mutação identificada está associada com aumento no risco de câncer;

- NEGATIVO VERDADEIRO: nenhuma mutação é identificada em indivíduo cuja família é sabidamente portadora de mutação;

- SEM SIGNIFICADO: nenhuma mutação é identificada em indivíduo cuja família não é portadora de mutação identificada.

- SIGNIFICADO INCERTO: mutação identificada, mas seu significado clínico é desconhecido.

Há poucos estudos, prospectivos e retrospectivos, sugerindo que o indivíduo não mutado que pertence à família sabidamente mutada pode apresentar risco aumentado para câncer atribuído a modificadores genéticos, quando comparado à população geral ${ }^{7}$. Mais dados são necessários para confirmação.

Os testes genéticos possuem riscos, benefícios e limitações que podem ser assim agrupados:

- o resultado positivo verdadeiro permite saber quando começar a vigilância, o tipo de vigilância necessária e a possibilidade de cirurgia redutora de risco; 
- o resultado negativo verdadeiro descarta a necessidade de exames e/ou cirurgias especiais;

- a certeza do resultado diminui a tensão psicológica;

- o resultado negativo não exclui a possibilidade da história familiar ser atribuída a gene não testado ou a gene cujo teste ainda não é avaliável;

- o teste negativo em paciente sem história familiar ou com história desconhecida não afasta outras possibilidades de neoplasia;

- o resultado pode gerar sentimento de culpa no probando ou por ter passado a mutação para seus filhos ou por ser o único não mutado;

- ônus econômico gerado pela atitude precipitada de realizar o sequenciamento completo;

- discriminação devido ao resultado positivo em ambiente de trabalho, planos de saúde ou socialmente.

Diante do resultado do teste genético o paciente e familiares, além de suporte psicológico, necessitam de acompanhamento médico com aconselhamento quanto a medidas que possibilitem o diagnóstico precoce e/ou estratégias redutoras de risco.

Muitas mulheres são identificadas com alto risco para câncer de mama baseando-se em suas histórias pessoais ou familiares, mas não se enquadram em critérios diagnósticos para síndrome do câncer hereditário. Para estes casos há modelos de avaliação de risco desenhados para estimar o risco de câncer de mama: 
- Modelo de GAIL: estima o risco individual de desenvolver câncer demama invasivo para mulheres entre 35 e 70 anos, utilizando informações sobre fatores de risco bem estabelecidos como idade, idade da menarca, número de biópsias prévias de mama e seus diagnósticos (hiperplasia atípica ou neoplasia lobular), idade no primeiro parto, número de parentes de primeiro grau acometidos e etnia ${ }^{11}$. O modelo de Gail já foi validado e é mais freqüentemente utilizado para estimar o risco de indivíduos que não têm história familiar sugestiva de síndrome do câncer de mama hereditário ou que possuem teste negativo para uma mutação familiar conhecida, sendo também útil para o aconselhamento sobre o uso de Tamoxifeno como um agente quimiopreventivo. Subestima 0 risco de mulheres com predisposição hereditária e daquelas cujos antecedentes são da linhagem paterna ${ }^{7}$.

- Modelo de CLAUS: também já validado, incorpora a história familiar materna e paterna com até dois parentes em $1^{\circ}$ e lou $2^{\circ}$ graus, levando em conta ao idade no diagnóstico de câncer, mas exclui fatores de risco gerais. Em geral, subestima o risco de mulheres que são potencialmente portadoras de predisposição hereditária ${ }^{7,11}$ e não considera o histórico de filhos acometidos (devido ao número restrito de casos).

- Modelo de TYRER-CUZICK: acrescenta outros fatores de risco, tais como antecedente de câncer de ovário pessoal e familiar e câncer de mama na linhagem paterna, além de incorporar parentesco de segundo grau. 
Fatores genéticos e não genéticos são considerados para determinar o risco estimado. Calcula não só o risco para câncer de mama como também o risco de mutação de BRCA. Segundo Amir et al ${ }^{12}$, o modelo de Tyrer-Cuzick é o mais consistente na predição do câncer de mama, porém ainda não está totalmente validado.

As principais características destes modelos encontram-se na tabela 2.

Apesar dos modelos matemáticos, mais uma vez a ciência vem demonstrando a existência de novos fatores de risco que devem ser agregados aos cálculos para estabelecer o valor do risco individual. Novas adaptações são necessárias e novos modelos deverão ser pesquisados para aproximar as estimativas do risco real.

Tabela 2 - Características dos modelos de Gail, Claus e Tyrer-cuzick.

\begin{tabular}{|c|c|c|c|}
\hline $\begin{array}{l}\text { FATOR DE } \\
\text { RISCO }\end{array}$ & GAIL & CLAUS & TYRER-CUZICK \\
\hline Idade & Sim & Sim & Sim \\
\hline $\begin{array}{l}\text { Antecedente } \\
\text { gineco- } \\
\text { obstétrico }\end{array}$ & $\begin{array}{l}\text { - Idade na menarca } \\
\text { - Idade no } 1^{\circ} \text { parto }\end{array}$ & Não & $\begin{array}{l}\text { - Idade na menarca } \\
\text { - Idade no } 1^{\circ} \text { parto } \\
\text { - Idade na menopausa } \\
\text { - terapia hormonal }\end{array}$ \\
\hline $\begin{array}{l}\text { Antecedente } \\
\text { pessoal }\end{array}$ & $\begin{array}{l}\text { - Biópsias prévias } \\
\text { - HDA } \\
\text { - neoplasia lobular } \\
\text { - idade no diagnóstico }\end{array}$ & Não & $\begin{array}{l}\text { - Biópsias prévias } \\
\text { - HDA } \\
\text { - CLIS } \\
\text { - Câncer de ovário }\end{array}$ \\
\hline $\begin{array}{l}\text { Antecedente } \\
\text { familiar }\end{array}$ & - Parentes em $1^{\circ} \mathrm{grau}$ & $\begin{array}{l}\text { - Parentes em } 1^{\circ} \mathrm{e} \\
2^{\circ} \text { graus } \\
\text { - Idade no diagnóstico }\end{array}$ & $\begin{array}{l}\text { - Parentes em } 1^{\circ} \text { e } 2^{\circ} \text { graus } \\
\text { - Idade no diagnóstico } \\
\text { - Câncer de ovário } \\
\text { - considera parentesco paterno } \\
\text { - Ashkenazi }\end{array}$ \\
\hline Outros & Etnia & Não & IMC \\
\hline
\end{tabular}




\subsection{Identificação do alto risco histopatológico}

Estudos epidemiológicos têm identificado uma série de fatores de risco associados com o desenvolvimento de câncer de mama, relacionados na tabela 3 , e que devem ser considerados quando do uso de modelos de risco.

Tabela 3 - Fatores de risco para câncer de mama ${ }^{8}$.

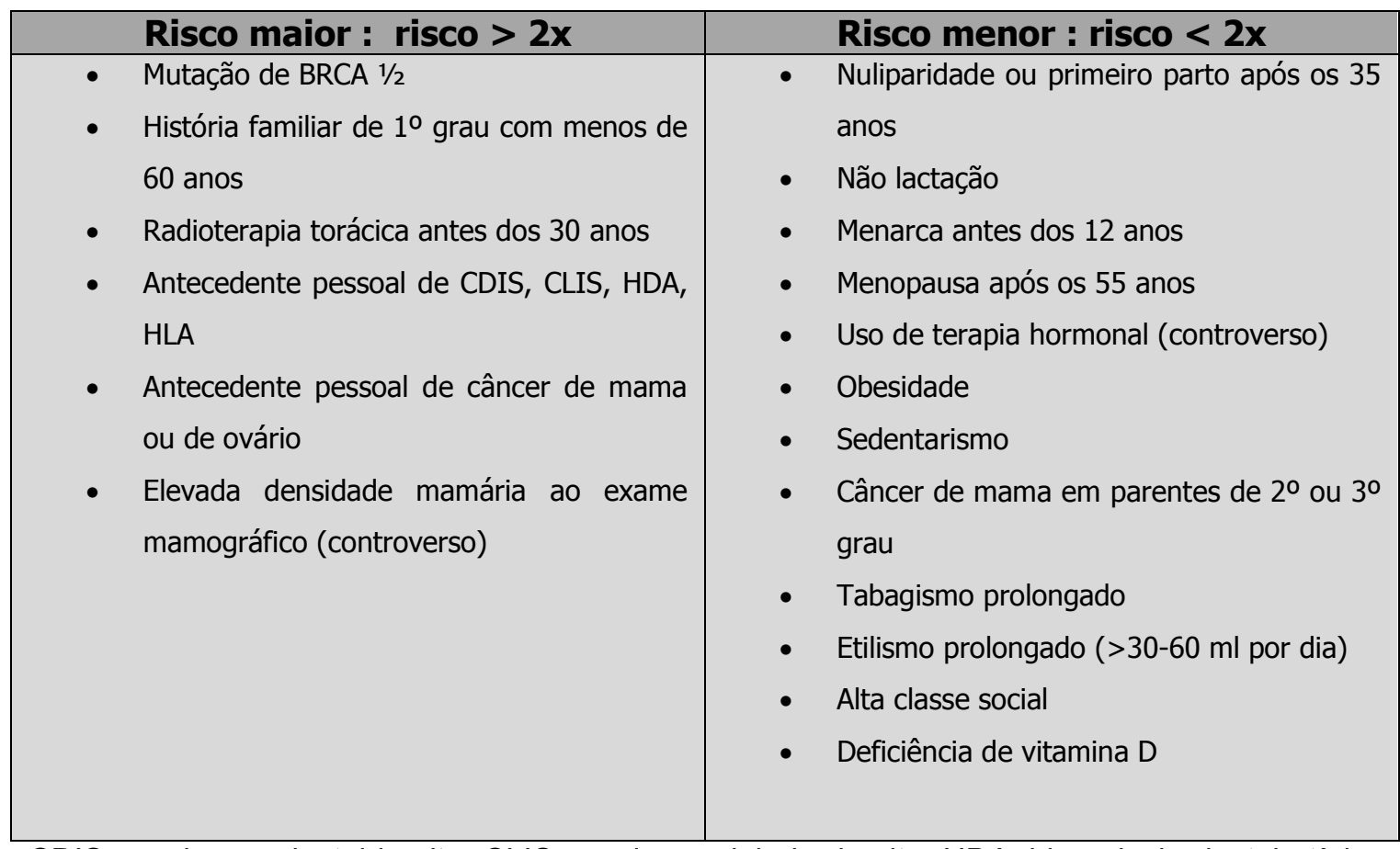

CDIS=carcinoma ductal in situ, CLIS=carcinoma lobular in situ, HDA=hiperplasia ductal atípica, $\mathrm{HLA}=$ hiperplasia lobular atípica.

Além do risco familiar, o mastologista depara-se com o aumento do número de casos de alto risco histopatológico, ou seja, com a expansão dos exames de rastreamento populacional e o avanço das técnicas diagnósticas houve um incremento no diagnóstico de hiperplasia epitelial atípica (padrão ductal ou colunar) e de neoplasia lobular, lesões estas que reconhecidamente acrescentam risco para o desenvolvimento do câncer de mama. 
A tabela 4 relaciona o risco relativo $(R R)$ com os fatores de risco maiores.

Tabela 4 - Risco relativo de câncer de mama para os fatores maiores ${ }^{8}$

\begin{tabular}{|l|l|}
\hline Fator de risco maior & R.R. \\
\hline Idade: 30 anos x 60 anos & 10 \\
\hline CLIS, HLA, HDA & $2-10$ \\
\hline Câncer de mama ou ovário prévio & $2-10$ \\
\hline Parente de 10 grau com câncer de mama antes dos 60 anos & $2-3$ \\
\hline Irradiação torácica com idade < 30 anos & $5-20$ \\
\hline Mutação de alta penetrância (BRCA 1 / 2) & $10-20$ \\
\hline
\end{tabular}

Atualmente coloca-se em dúvida a idéia simplista de progressão linear partindo de hiperplasia usual $\rightarrow$ hiperplasia atípica (HDA ou HLA) $\rightarrow$ carcinoma in situ (CDIS ou CLIS) $\rightarrow$ carcinoma invasivo, estando o surgimento do câncer de mama relacionado à alterações cromossômicas na célula tronco ou em progenitoras ${ }^{14}$ que, possivelmente, não sigam este modelo de desenvolvimento (figura 1). Ainda assim, há evidências de que o achado de lesões mamárias benignas aumente o risco de desenvolver câncer de mama ${ }^{15,16}$.

De acordo com Arpino et al ${ }^{15}$, o risco de desenvolver carcinoma invasor de mama é ainda maior no caso de neoplasia lobular $(6-10)$ e de CDIS (8 10). 
Figura 1: Modelo de metástase de câncer de mama ${ }^{14}$

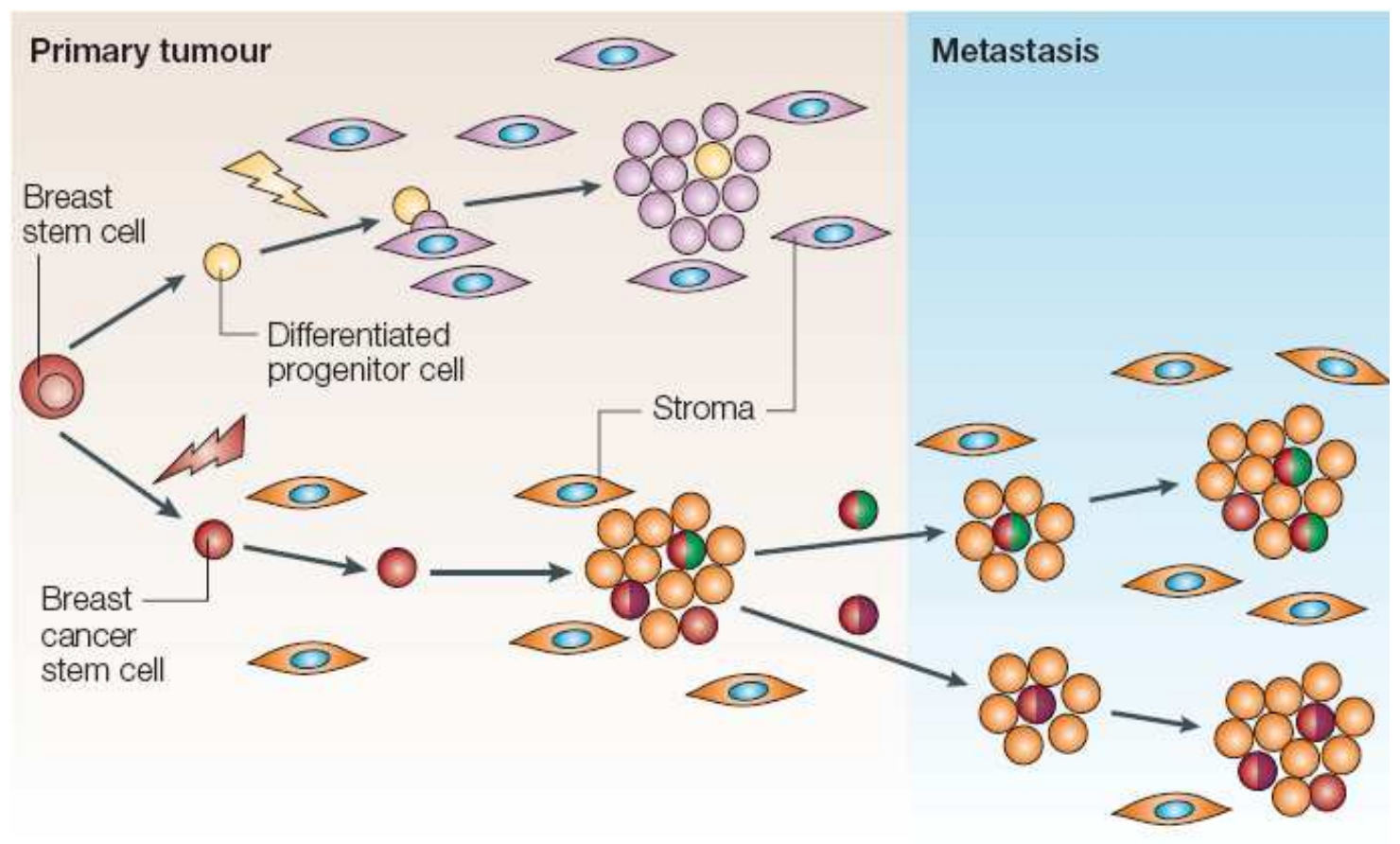

Mutações em oncogenes da célula tronco mamária (em vermelho) podem causar a transformação para uma célula tronco de câncer de mama, gerando um tumor de pobre prognóstico (em laranja). Mutações que ocorrem em células progenitoras diferenciadas (em amarelo) podem formar um câncer de mama de bom prognóstico e não metastático (em rosa). Nos tumores de pobre prognóstico e metastáticos, sob a influência de fibroblastos estromais, somente a população de células tronco de câncer de mama têm a habilidade de metastatizar. Parece que as células tronco de câncer diferem entre si de acordo com o tecido para o qual, seletivamente, darão origem a uma metástase (por exemplo: verde, osso e púrpura, pulmão). No local da metástase a célula tronco de câncer pode induzir uma resposta estromal similar àquela do sítio primário do tumor mamário. Adaptado de Weigelt $\mathrm{B}^{14}$.

A tabela 5 relaciona as diferentes lesões e seus respectivos riscos. 
Tabela 5 - Risco relativo para carcinoma invasivo de mama associado com lesões benignas em biópsia prévia

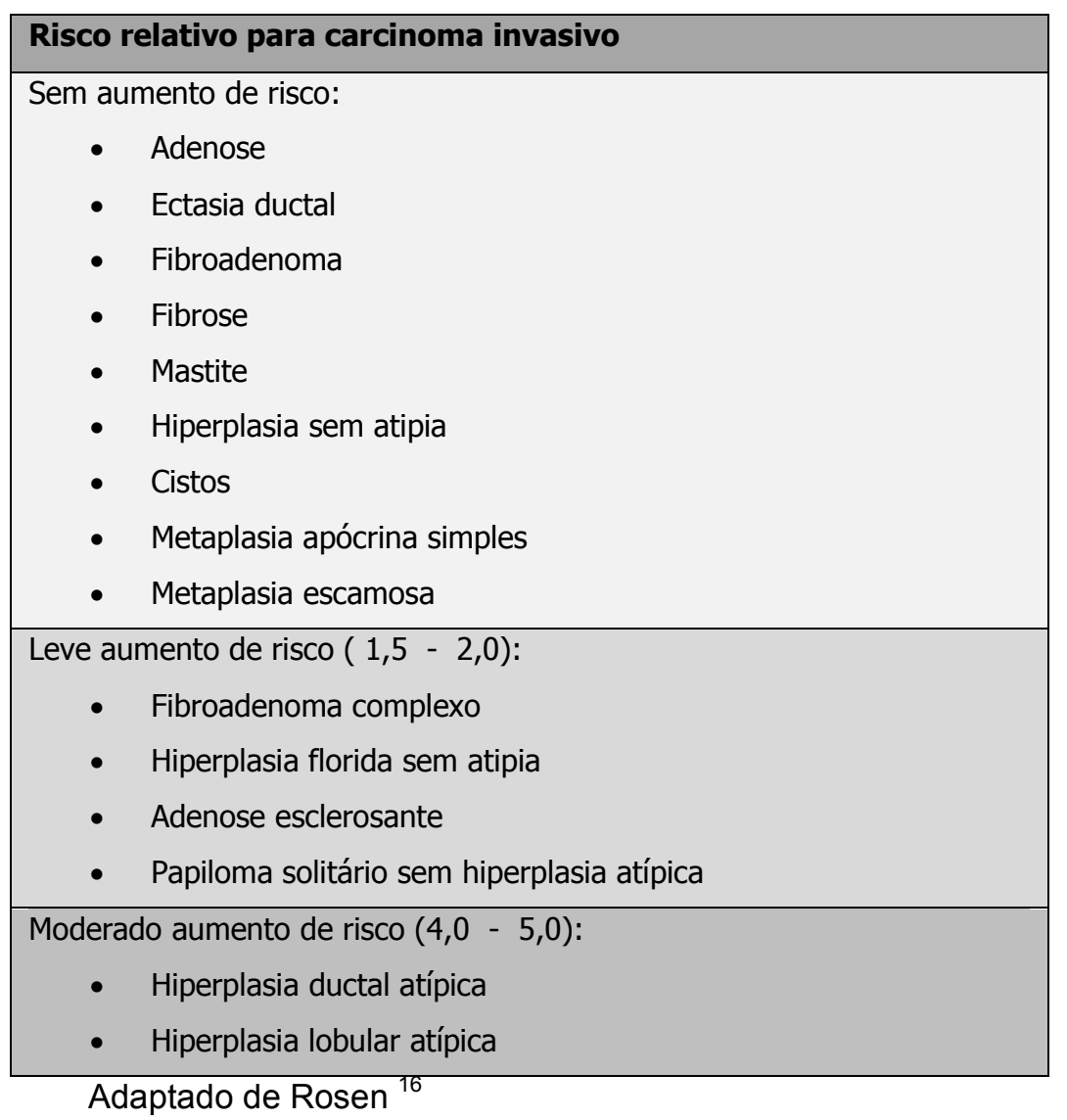

Além destes, Bradbury AR e Olopade OI ${ }^{4}$ mostram outros dados:

- CDIS está associado com 8,2\% de risco em 5 anos de desenvolver um câncer de mama invasivo ipsilateral e 4,3\% contralateral;

- CLIS tem sido considerado um marcador de aumento de risco e confere $1 \%$ de risco de desenvolver câncer de mama por ano;

- mulheres com história familiar e hiperplasia ductal atípica possuem 11 vezes mais risco de desenvolver câncer de mama;

- mamas densas na mamografia têm sido associadas com 4 a 6 vezes de 
aumento no risco de câncer de mama;

- elevados níveis de IGF-1 ou IGFBP-3 na pré menopausa e polimorfismo em genes associados conferem um risco aumentado para câncer de mama.

\subsection{Medidas de vigilância}

A vigilância dos indivíduos testados ou dos considerados de risco elevado leva em conta os resultados obtidos em diferentes estudos ${ }^{4,17,18}$ :

- menor sensibilidade (entre 25 e 56\%) da mamografia em BRCA mutados;

- maior frequência de câncer de intervalo entre mulheres com forte história familiar ou com BRCA mutado;

- maior frequência de mamografia falso negativa entre carreadores de BRCA mutado e mulheres com mamas densas;

- a ressonância magnética parece ser superior à mamografia na capacidade de detectar câncer de mama precoce, com grande ganho de sensibilidade entre mulheres com elevado risco ou com mutação conhecida para BRCA;

- aumento da sensibilidade quando se associa mamografia e ressonância magnética (86 a 96\%);

- ainda não foi demonstrado que programas de rastreamento com ressonância magnética das mamas entre mulheres com risco elevado ou mutadas diminui a mortalidade, mas sabe-se que contribui decisivamente 
para o diagnóstico de câncer de dimensões reduzidas, com menor número de linfonodos positivos, além de contribuir com a redução do câncer de intervalo.

Segundo a National Comprehensive Cancer Network (NCCN) as principais recomendações de vigilância clínica para as diferentes categorias de risco encontram-se na tabela $6{ }^{19}$.

Outras recomendações:

- colonoscopia após os 50 anos nos casos de BRCA mutado;

- evitar o uso de contracepção hormonal por período superior a 5 anos e de preferência trocá-la por DIU em mulheres com BRCA mutado;

- realização de teste pré-natal e diagnóstico genético pré-implantação para as famílias com mutação conhecida. 
Tabela 6 - Medidas de vigilância recomendadas pela $\mathrm{NCCN}^{19}$

\begin{tabular}{|c|c|}
\hline CATEGORIA DE RISCO & RECOMENDAÇÃO \\
\hline $\begin{array}{c}\text { Mutação do BRCA1/2 } \\
\text { ou } \\
\text { síndrome do câncer de mama e ovário } \\
\text { hereditário }\end{array}$ & $\begin{array}{l}\text { - } \text { Auto exame } \\
\text { - } \quad \text { Exame clínico semestral a partir dos } 25 \text { anos } \\
\text { - } \quad \text { Mamografia e ressonância magnética (RM) anual a } \\
\text { partir dos } 25 \text { anos* } \\
\text { - } \text { Considerar estratégias de redução de risco }\end{array}$ \\
\hline $\begin{array}{l}\text { - Mutação do PTEN ou } \\
\text { diagnóstico clínico de Síndrome de Cowden } \\
\text { - } \quad \text { Mutação do TP53 ou Li-Fraumeni clínico }\end{array}$ & $\begin{array}{ll}\text { - } & \text { Auto exame } \\
\text { - } & \text { Exame clínico semestral a partir dos } 25 \text { anos* } \\
\text { - } & \text { Mamografia e RM anual a partir dos } 25 \text { anos* } \\
\text { - } & \text { Considerar estratégias de redução de risco }\end{array}$ \\
\hline $\begin{array}{l}\text { Forte história familiar ou predisposição } \\
\text { genética com idade }<25 \text { anos }\end{array}$ & $\begin{array}{ll}\text { - } & \text { Auto exame } \\
\text { - } & \text { Exame clínico anual } \\
\text { - } & \text { Considerar aconselhamento genético }\end{array}$ \\
\hline Neoplasia lobular ou hiperplasia atípica & $\begin{array}{ll}\text { - } & \text { Auto exame } \\
\text { - } & \text { Exame clínico a cada 6-12 meses } \\
\text { - } & \text { Mamografia anual } \\
\text { - } & \text { RM anual para neoplasia lobular } \\
\text { - } & \text { Considerar estratégias de redução de risco }\end{array}$ \\
\hline $\begin{array}{l}\text { Mulheres com alto risco para câncer de } \\
\text { mama (risco vitalício calculado > } 20 \text { \%) }\end{array}$ & $\begin{array}{l}\text { - } \text { Auto exame } \\
\text { - } \quad \text { Exame clínico a cada 6-12 meses } \\
\text { - } \text { Mamografia anual } \\
\text { - } \quad \text { Considerar RM anual } \\
\text { - } \quad \text { Considerar estratégias de redução de risco }\end{array}$ \\
\hline $\begin{array}{c}\text { Mulheres } \geq 35 \text { anos e com alto risco } \\
\text { baseado em Gail } \geq 1,7 \%\end{array}$ & $\begin{array}{l}\text { - } \text { Auto exame } \\
\text { - } \quad \text { Exame clínico a cada 6-12 meses } \\
\text { - } \quad \text { Mamografia anual } \\
\text { - } \quad \text { Considerar estratégias redutoras de risco }\end{array}$ \\
\hline $\begin{array}{l}\text { Radioterapia torácica prévia e } \\
\text { idade } \geq 25 \text { anos }\end{array}$ & $\begin{array}{l}\text { - } \text { Auto exame } \\
\text { - Exame clínico a cada 6-12 meses } \\
\text { - Mamografia anual começando 8-10anos após a } \\
\text { radioterapia ou aos } 25 \text { anos (qualquer que ocorra } \\
\text { primeiro) } \\
\text { - Considerar RM anual }\end{array}$ \\
\hline
\end{tabular}

*Idade individualizada: 5-10 anos antes do caso de diagnóstico mais jovem. 


\subsection{Procedimentos redutores de risco}

Além destas medidas clínicas pode-se lançar mão de cirurgias profiláticas. A cirurgia profilática de mama reduz em $90 \%$ o risco de desenvolver câncer de mama em mulheres com moderado ou alto risco e naquelas com BRCA 1/2 mutado $^{20 .}$ Assumindo o risco de desenvolver câncer de mama aos 70 anos de idade para a mulher com BRCA $1 / 2$ mutado de $73 \%$, essa redução de $90 \%$ do risco conferida pela cirurgia permite que o risco passe a ser de $7 \%$ aos 70 anos de idade ${ }^{21}$. O ganho em anos de vida depende do grau de risco da paciente e da idade da realização da cirurgia. Muitas mulheres podem sofrer com sequelas psicossociais incluindo depressão e diminuição da libido após esta decisão irreversível.

A ooforectomia bilateral profilática reduz o risco de câncer de mama em mulheres pré-menopausa e mulheres com a síndrome hereditária de câncer de mama e ovário em até $50 \%$ e diminui o risco de câncer de ovário ou de tuba em aproximadamente $80 \%{ }^{20}$. Assim, a ooforectomia profilática é recomendada para portadoras de mutação do BRCA após os 35 anos ou assim que a prole esteja constituída. Evidências preliminares sugerem que a terapia hormonal por curto tempo, especialmente só com estrogênio, não aumenta o risco de câncer de mama em mulheres BRCA1/2 mutadas ${ }^{22}$.

A quimioprevenção é um campo que se desenvolve rapidamente e que oferece às mulheres com elevada probabilidade de desenvolver câncer uma opção para a redução do risco.

O Tamoxifeno (TMX) é um modulador seletivo do receptor de estrogênio 
(SERM) e que reduz em $49 \%$ a incidência de câncer de mama no caso de mulheres com risco em 5 anos determinado pelo modelo de Gail modificado $\geq$ $1,7 \%{ }^{4}$. Sabe-se que somente $10 \%$ dos BRCA1 têm RE positivo, comparado com $65 \%$ de positividade encontrada nos BRCA2 e nos controles. Assim, era de se esperar que o efeito inibitório do TMX nos BRCA1 fosse de apenas 5\% (ou seja, metade dos casos RE+ dos BRCA1), mas Duffy e Nixon ${ }^{23}$ atingem a taxa de $13 \%$ de redução de risco para o BRCA1 e de $27 \%$ para os BRCA2. Julga-se que inicialmente o câncer BRCA1 é estrogênio-dependente e o TMX é eficaz nesta fase. O elevado risco na pré-menopausa e a redução de risco ocasionada pela gravidez ou ooforectomia bilateral sugerem que a influência hormonal é importante, mesmo nos BRCA1. Gronwald et al ${ }^{24}$ relatam efeito protetor do tamoxifeno com redução na incidência de câncer contralateral nas carreadoras de BRCA mutado. A utilidade do tamoxifeno como redutor de risco de câncer de mama em mulheres com idade inferior a 35 anos ainda é desconhecida.

O raloxifeno também é um SERM e vem demonstrando um efeito similar ao do TMX na redução de risco de câncer de mama na pós-menopausa, porém com a vantagem de ter menos efeito tromboembólico e com menor incidência de catarata e de câncer uterino. Segundo o NCCN o raloxifeno é uma opção para redução do risco de câncer de mama em mulheres saudáveis com idade $\geq$ 35 anos e que apresentam risco em cinco anos $\geq 1,7 \%$, calculado pelo modelo de Gail modificado, ou que tenham diagnóstico prévio de carcinoma lobular in situ $^{20}$.

Os inibidores de aromatase mostram-se superiores ao TMX na prevenção 
da recorrência do câncer de mama e na redução do câncer contralateral, porém também são eficazes apenas nos casos de receptores positivos. Estudos estão em curso para definir a utilidade dos inibidores de aromatase na quimioprevenção para mulheres na pós-menopausa, tais como IBIS II (para o anatrozole $)^{25}$ e MAP 3 (para o exemestano) ${ }^{26}$, com resultados esperados para 2012 .

Até o momento não há uma maneira eficaz de se realizar a quimioprevenção de tumores RE negativos.

\subsection{Perspectivas}

De modo geral, o que se procura é uma nova arma terapêutica que aja nas células, bloqueando a multiplicação e/ou estimulando a apoptose de células tumorais.

O ponto de partida é o conhecimento do desenvolvimento mamário e de sua transformação em tecido tumoral. Durante a puberdade, uma onda de estrogênio (força condutora inicial) combinada com progesterona da fase lútea ativam o desenvolvimento da mama desde que exista uma intensa relação com fatores de crescimento (hormônio de crescimento e fator de crescimento insulina-like).

O hipotálamo secreta hormônio liberador de hormônio de crescimento $(\mathrm{GHRH})$, que age na hipófise anterior iniciando a liberação de hormônio de crescimento $(\mathrm{GH})$, o qual, via corrente sanguínea, acoplado à GHBP (proteína carreadora de $\mathrm{GH}$ ) chega ao fígado, ativa seus receptores e desencadeia uma 
cascata de reações as quais culminam com a disponibilização de fator de crescimento insulina-like tipo 1 (IGF-1) pelos hepatócitos e de proteína ligadora ou carreadora de IGF tipo 3 (IGFBP-3) pelas células de Kupffer e pelo endotélio hepático.

Já na mama, o hormônio de crescimento se une ao receptor de $\mathrm{GH}$ no compartimento estromal (fibroblastos e adipócitos) da glândula mamária e induz o RNA mensageiro (mRNA) à produção do IGF-1 que, provavelmente por mecanismo parácrino, liga-se aos receptores de IGF nas células epiteliais, resultando no desenvolvimento da árvore ductal ${ }^{27,28}$, através do estímulo da proliferação e diferenciação celular e inibição da apoptose. Sabe-se que o estrogênio aumenta 2 a 3 vezes a expressão do mRNA do IGF-1 ${ }^{27}$, mediando assim o crescimento das células epiteliais (figura 2).

Na célula neoplásica mamária, o estrogênio aumenta o efeito mitogênico do IGF por induzir a expressão de vários membros da "família IGF", incluindo IGF-1, IGF-2, IGF-1R, IRS-1 ${ }^{27}$. Assim como o estrogênio, a progesterona age estimulando a proliferação celular e reduzindo a apoptose e esta ação também depende da presença de IGF-1. 
Figura 2 - Influência do GH e estrogênios na ação do IGF1

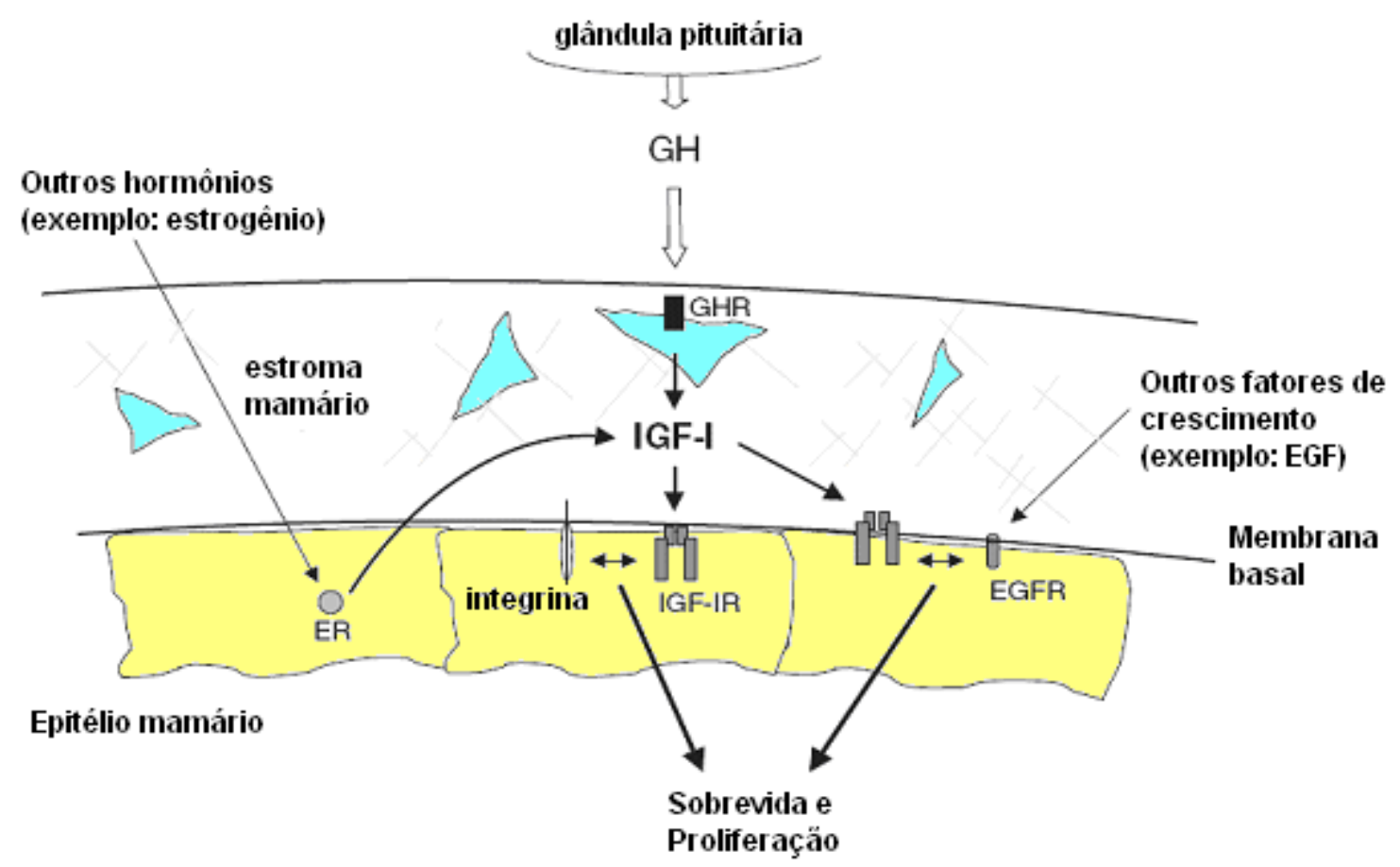

Adaptado de Marshman e Streuli ${ }^{27}$

Quando ocorre um desequilíbrio deste eixo podem se desenvolver lesões hiperplásicas ou lesões precursoras do carcinoma mamário (figura 3).

Figura 3 - Equilíbrio entre proliferação e apoptose

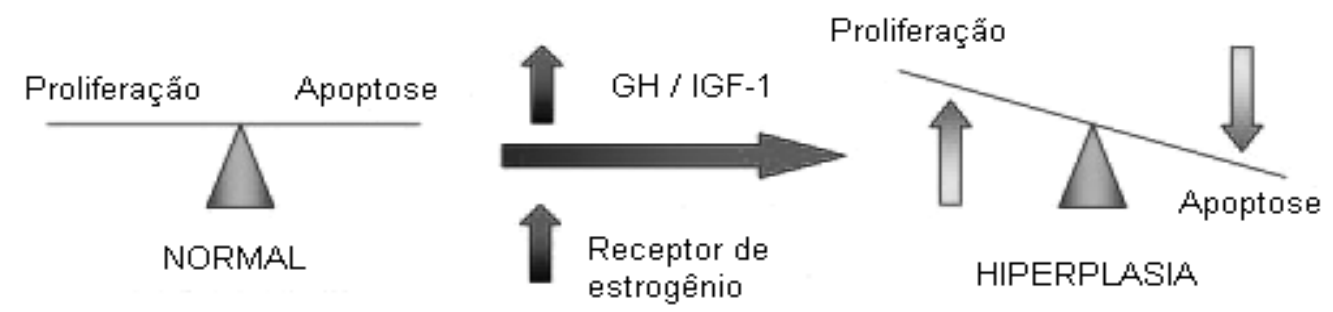

Adaptado de Kleinberg DL et al ${ }^{28}$ 
Os fatores de crescimento insulina-like (IGF) são polipeptídeos de cadeia única que se dividem em 2 tipos (1 e 2) e têm $62 \%$ da sequência de aminoácidos similar. São sintetizados e secretados por vários tecidos e possuem ação local (autócrina ou parácrina) ou à distância (endócrina).

Embora haja dois receptores para IGF, o receptor de IGF-1 é o que possui maior atividade biológica.

As principais funções do IGF são:

- ação anabólica no metabolismo protéico e de carboidrato através do aumento da captação celular de aminoácidos e de glicose e redução da lise

- impacto na proliferação, diferenciação, migração e sobrevida celular (figura 4).

Figura 4 - Representação simplificada dos componentes intracelulares do sistema IGF e suas ações

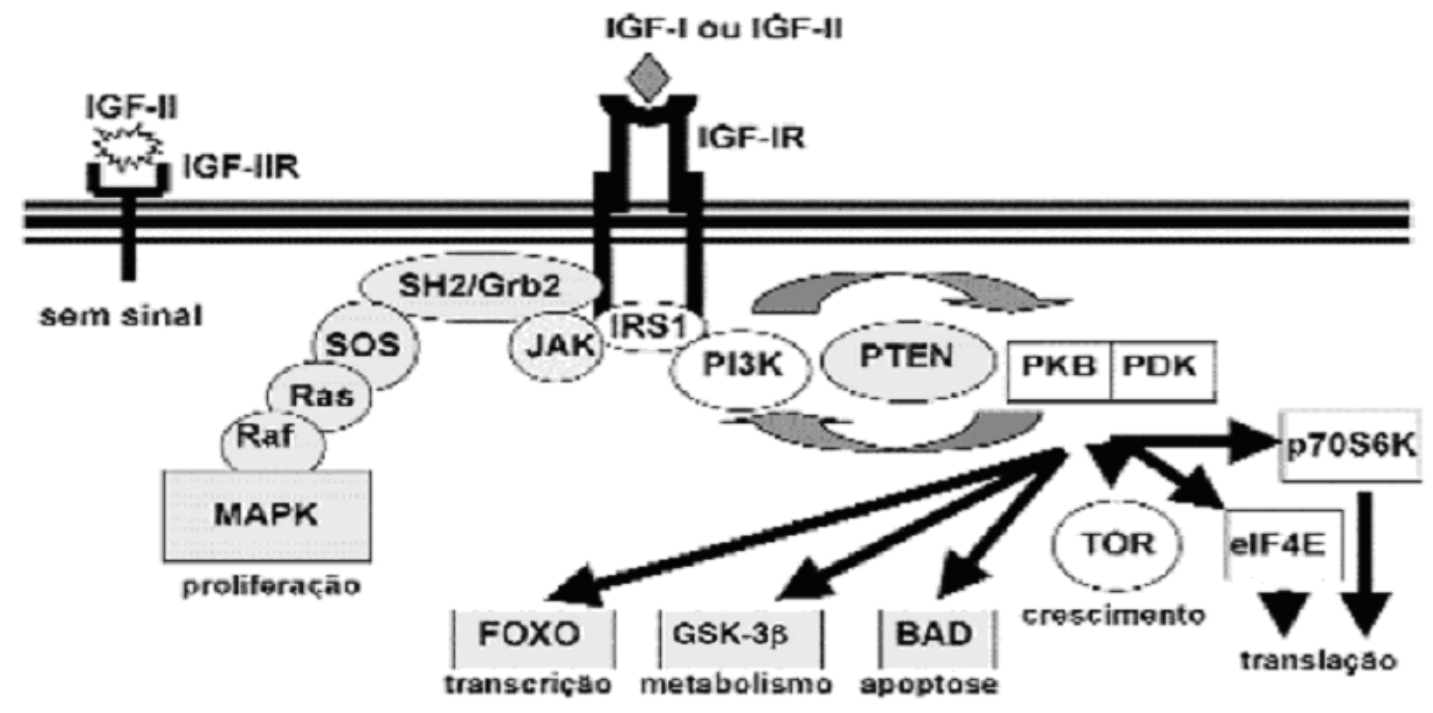

Adaptado de Castro e Guerra-Júnior ${ }^{29}$. 
A complexa rede de reações ${ }^{29}$ em nível intracelular inicia-se com a ligação da IGF-1 ao seu receptor de membrana, que desencadeia a atividade catalítica da tirosina-quinase, levando à fosforilação de substratos intracelulares (proteínas do insulin receptor substrate 1 ou IRS1 e Src homology collagen ou SHC). A IRS1 fosforilada recruta a PI3K (phosphatidylinositol 3-tide-dependent protein kinase) resultando na ativação de PDK (phosphoinositide-dependent protein kinase), PKB (protein kinase B) e p70S6 quinase que, em cascata, irão controlar:

- a transcrição via FOXO (forkhead transcription factors),

- o metabolismo via GSK-3ß (glycogen synthetase kinase $3 \beta$ ),

- a apoptose via BAD (bcl-associated death promoter),

- o crescimento celular via TOR (target of rapamycin),

- a translação via elF4E (eukaryothic initiation factor 4E).

A ativação da proliferação celular é mediada pela ligação da proteína $\mathrm{SH} 2$ ao adaptador Grb2 (growth factor receptor bound protein 2) o que desencadeia a ativação de SOS, Ras, Raf (GTPase-mediated proteins family) e MAPK (mitogen-activated protein kinase).

Reguladores negativos deste sistema incluem a Grb 2, o sistema JAK (janus tyrosine kinase) e a PTEN (fosfatase mutada no cromossomo 10).

No meio extracelular os IGF são transportados por proteínas específicas denominadas proteínas ligadoras de fator de crescimento insulina-like (IGFBP), que são em número de 6 , e que, além de transportar o IGF até os tecidos alvo, 
acabam por prolongar sua meia vida já que o protegem da degradação proteolítica. A principal IGFBP é a IGFBP-3 que transporta próximo a $90 \%$ dos IGFs circulantes ${ }^{30}$ formando um complexo ternário, juntamente com a ALS (acid-labile subunit), e que possui uma afinidade igual ou superior à encontrada no receptor celular de IGF.

As IGFBPs modulam a ação dos IGFs:

- podem liberá-los para que se liguem aos seus receptores celulares;

- podem sequestrá-los, aumentando sua meia vida de 12 minutos para mais de 12 horas, impedindo o acionamento de seus receptores específicos.

$\mathrm{Na}$ circulação, o complexo ternário formado pelo IGF-1+IGFBP-3+ALS permanece intacto graças a presença de proteínas inibidoras de proteases específicas. No extravascular, onde tal inibição encontra-se ausente, proteases específicas reduzem a estabilidade desses complexos e ocorre a liberação da IGF-1 que, então, se conecta ao seu receptor de membrana celular ${ }^{30}$.

O mecanismo que rege esse equilíbrio é extremamente complexo e ainda se encontra em investigação. A IGFBP-3 não só regula a ação mitogênica do IGF e inibe seu efeito antiapoptótico, mas também tem uma ação inibitória do crescimento celular independente do IGF ${ }^{27}$.

Outros fatores de crescimento, como o fator de crescimento epidérmico (EGF), podem ter ação sinérgica ao IGF-1. 
A relação do sistema de IGF com o desenvolvimento de neoplasias vem sendo sugerida por modelos experimentais que mostram que a ativação dos receptores de IGF-1 (IGF-1R), além das funções já assinaladas, pode alterar a adesividade entre as células e dar início à migração celular ${ }^{28}$. No caso das IGFBPs postula-se que as proteases tumorais degradam as proteínas carreadoras de IGF, o que aumenta a fração livre de IGF1 e, consequentemente, a atividade mitogênica no tecido mamário ${ }^{30}$. Graças à possibilidade de um efeito parácrino ou autócrino, as próprias células tumorais passam a produzir IGF e auto-estimular o crescimento das células neoplásicas.

O primeiro estudo que relacionou os níveis circulantes de IGF e risco de câncer de mama foi publicado Peyrat et al em $1993^{31}$. A partir de então, várias outras pesquisas foram realizadas tentando esclarecer essa relação e em uma das mais importantes revisões sistemáticas, publicada por Fletcher et al ${ }^{30} \mathrm{em}$ 2005, conclui-se que há uma possível relação positiva entre níveis prémenopausa de IGF-1 e IGFBP-3 e aumento de risco para câncer de mama, o mesmo não sendo observado na pós-menopausa. Os níveis de IGF-1 e IGFBP3 em mulheres jovens têm uma relação mais exuberante com o risco de câncer de mama devido à ação sinérgica dos hormônios sexuais endógenos.

O aumento de IGF-1 e a diminuição de IGFBP-3 foram observados no soro de mulheres com câncer de mama estádio I ou II já em $1995^{32}$. Vários estudos revistos por Marshman e Streuli ${ }^{27}$ em 2002 mostram relação diretamente proporcional entre IGF-1 e câncer de mama na mulher pré-menopausa. Em 
contraste, a redução de IGFBP-3 no soro é contestada por Rocha et al ${ }^{33}$ que relatam IGFBP-3 três vezes mais prevalente em tumores de pobre prognóstico.

Na literatura há pelo menos quatro revisões sistemáticas e metanálises de estudos prospectivos e caso-controle que mostram que a relação entre risco de câncer de mama e concentrações circulantes de IGF-1 e IGFBP-3 apresenta uma tendência a aumento de risco quando as concentrações estão aumentadas em mulheres na pré-menopausa $30,34,35,36,37$. No entanto, há outras publicações, do tipo caso-controle, que mostram resultados conflitantes de acordo com o estado menopausal ${ }^{38,39,40,41,42}$.

Há inúmeras variáveis envolvidas e apenas deslumbramos o início do caminho, uma vez que, tomados em conjunto, estes dados sugerem novas perspectivas de ação contra a neoplasia que mais acomete as mulheres no mundo. Mudanças do estilo de vida, adaptações da dieta alimentar, perda de peso e novas classes farmacológicas com efeitos antagônicos à fisiologia do IGF (por exemplo: antagonistas ao GHRH, anticorpos monoclonais anti-IGF-1, bloqueadores do receptor IGF-1R, moduladores de IGFBP, inibidores de tirosinaquinase), oferecerão oportunidades ainda inexploradas para prevenir ou modificar a progressão do câncer de mama. 


\section{OBJETIVOS}




\section{OBJETIVOS}

Esta pesquisa tem como objetivo avaliar a variação dos níveis séricos de IGF-1 e IGFBP-3 em mulheres com câncer de mama diagnosticado, comparando-os com os de mulheres com alto risco para câncer de mama e com risco populacional. 
3. MÉTODOS 


\section{MÉTODOS}

\subsection{Casuística}

Foi realizado estudo transversal englobando mulheres atendidas no Setor de Mastologia, da Disciplina de Ginecologia, do Departamento de Obstetrícia e Ginecologia da Faculdade de Medicina da Universidade de São Paulo (FMUSP) e no Instituto do Câncer do Estado de São Paulo.

A partir de 385 mulheres entrevistadas no ambulatório de Mastologia o total de 225 mulheres participantes foi selecionado de acordo com os critérios de inclusão abaixo e distribuído em três grupos (figura 5), a saber:

- Grupo 1: composto por 51 pacientes com câncer de mama (diagnóstico histopatológico sem tratamento prévio);

- Grupo 2: constituído por 108 mulheres com alto risco para câncer de mama, classificadas segundo modelos matemáticos de cálculo de risco de Gail e/ou Tyrer Cuzick , e que apresentam risco vitalício para câncer de mama igual ou superior a $20 \%{ }^{42}$ e sem qualquer indício de neoplasia mamária;

- Grupo 3: : 66 participantes assintomáticas, sem antecedentes pessoal ou familiar ou alteração mamográfica sugestiva de câncer de mama (grupo controle com risco populacional). 
Critérios de inclusão:

a) sexo feminino;

b) idade entre 20 e 70 anos;

c) aceitação do termo de consentimento informado incluindo autorização para coleta de sangue, fornecimento de informações pessoais e familiares para avaliação de risco (anexo $A)$;

d) exame mamográfico realizado há até 180 dias;

e) no grupo com câncer mamário, diagnóstico histopatológico de carcinoma invasivo;

f) no grupo com alto risco: risco vitalício segundo os modelos de Gail e/ou Tyrer-Cuzick igual ou superior a $20 \%$.

Critérios de exclusão:

a) usuária de contraceptivo hormonal ou terapia de reposição hormonal, bem como as mulheres que pararam há menos de três meses;

b) usuária de tamoxifeno ou de raloxifeno;

c) gestante ou lactante;

d) doenças hepáticas ou alteração das enzimas hepáticas;

e) insuficiência renal; 
f) endocrinopatias;

g) uso de antibióticos ou anti-inflamatórios;

h) portadoras de outras neoplasias.

Figura 5: Diagrama de seleção da população estudada

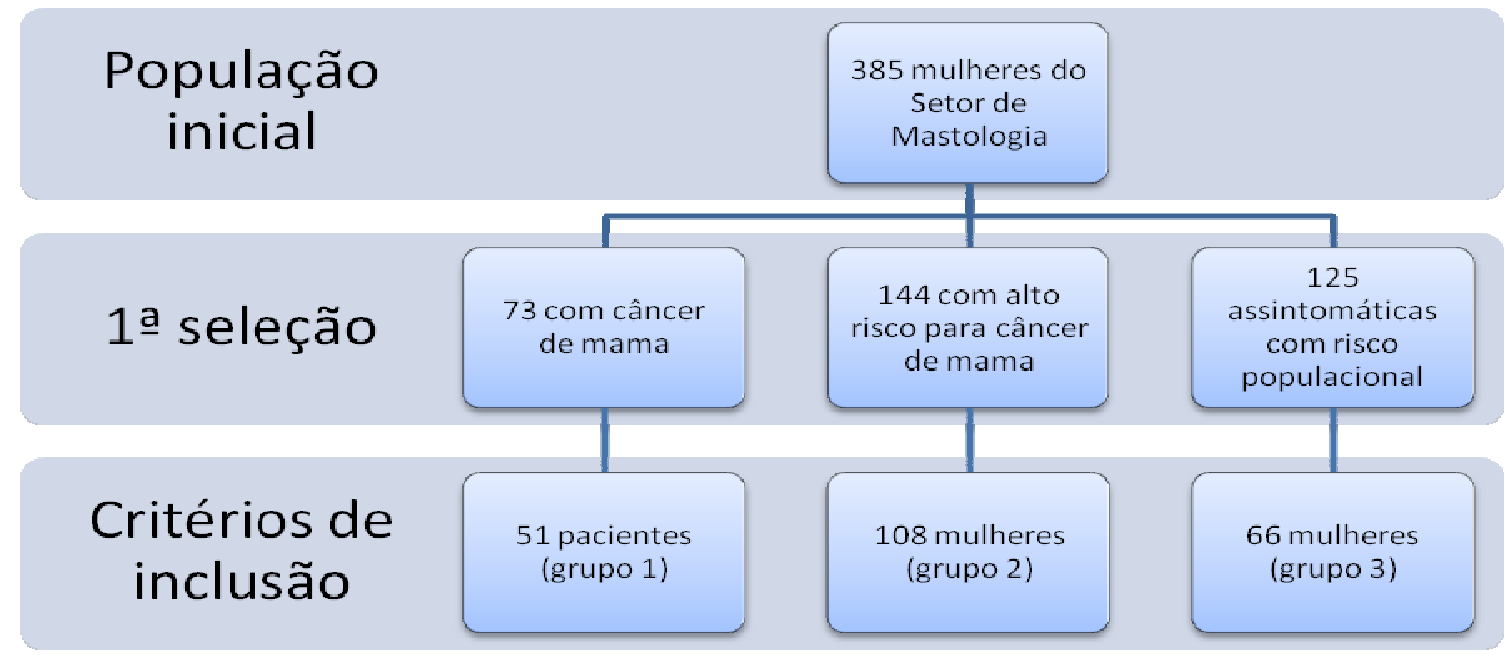

Todas as mulheres selecionadas e que assinaram 0 termo de consentimento livre e esclarecido foram entrevistadas de acordo com formulário próprio (anexo B), examinadas e forneceram amostras de sangue para a realização de dosagem sérica de IGF-1 e de IGFBP-3 pelo método de ensaio imunométrico quimioluminescente.

Houve padronização da coleta de sangue, que foi realizada entre 25 de julho e 27 de novembro de 2009, no período da manhã, observando-se jejum 
mínimo de 8 horas. Foram colhidos $5 \mathrm{ml}$ de sangue em tubo seco que foi enviado de imediato ao Setor de coleta do Laboratório Central do ICHC. Nenhuma amostra foi resfriada ou congelada. As dosagens de IGF-1 e IGFBP-3 foram realizadas pelo Laboratório de Hormônios e Genética Molecular da Disciplina de Endocrinologia do Hospital das Clínicas da FMUSP, utilizando-se técnica padrão para o analisador automático de imunoensaio IMMULITE 2000, pelo ensaio imunométrico quimioluminescente com kits específicos para IGF-1 e IGFBP-3 da marca Siemens.

As mulheres do grupo de alto risco foram reagrupadas de acordo com o grau e o tipo de risco.

Segundo o risco vitalício calculado por Gail e/ou Tyrer-cuzick, passou-se a denominar:

- alto risco A: mulheres com risco entre 20 e $29 \%$;

- alto risco B: mulheres com risco igual ou superior a $30 \%$, ou seja, aquelas classificadas como de altíssimo risco.

De acordo com o tipo de fator de risco as pacientes com alto risco para câncer de mama foram classificadas em:

- alto risco histopatológico: aquelas com diagnóstico de lesões mamárias precursoras ( HDA ou NL); 
- alto risco familiar: aquelas cujos parentes em $1^{\circ}$ e/ou $2^{\circ}$ grau apresentaram câncer de mama e/ou ovário.

\subsection{Metodologia estatística}

Para cada um dos riscos foram ajustados Modelos Multivariados de Análise Discriminante, considerando como variáveis independentes:

- menopausa,

- idade,

- IMC,

- alto risco Familiar,

- alto risco Histopatológico,

- percentual de IGF-1 (\% IGF-1) relativo à mediana,

- percentual de IGFBP-3 (\% IGFBP-3) relativo à mediana,

- razão entre \%|GF-1 / \%IGFBP-3.

Para que se compreendam as variáveis utilizadas na análise dos resultados é fundamental que se tenha em mente a apresentação dos laudos de dosagens de IGF-1 e IGFBP-3 (anexos C e D): não há uma faixa única onde 
valores mínimos e máximos são constantes para todas as mulheres testadas. $\mathrm{O}$ que se observa é uma sucessão de mínimos e máximos que variam de acordo com a idade da paciente. Assim, para que se pudessem valorizar os resultados obtidos, foram estabelecidas curvas medianas para cada uma destas substâncias e os resultados foram interpretados de acordo com a percentagem acima ou abaixo da mediana em que se encontravam. Exemplificando, consideremos duas pacientes com idades de 30 e 50 anos cuja dosagem de IGF-1 foi $200 \mathrm{ng} / \mathrm{ml}$ para ambas. De acordo com as medianas encontradas no anexo $\mathrm{C}$, a mulher de 30 anos encontrava-se muito próximo à normalidade (mediana $=194 \mathrm{ng} / \mathrm{ml})$, enquanto que a senhora de 50 anos possuía dosagem bem superior àquela esperada para sua idade (mediana $=149 \mathrm{ng} / \mathrm{ml}$ ). Quantitativamente, se fossem comparados os valores dosados para ambas encontrar-se-ia igualdade (200: $200=1)$, porém, se fossem estudados os percentuais em relação à mediana $(6 / 194: 51 / 149=894 / 9894 \sim 1 / 10)$ concluirse-ia que o resultado da paciente de 50 anos foi 10 vezes superior ao da paciente de 30 anos. Assim, o percentual elimina as características individuais de cada paciente, permitindo padronização.

Sabendo-se que IGFBP-3 pode alterar a ação do IGF-1, ora como opositor, ora como ativador, o estudo da relação IGF-1 / IGFBP-3 possibilita a análise desta influência de forma quantitativa, o que foi feito no presente estudo através da razão \%IGF-1 / \%IGFBP-3. 
Tabelas de contingência foram elaboradas para testar associação entre variáveis categóricas como Risco Familiar, Risco Histológico, Menopausa, faixa de risco. A estatística empregada nos testes foi o Qui-quadrado de Pearson.

Para as variáveis quantitativas, IMC e Idade, as médias dos grupos foram comparadas usando a técnica de Análise de Variância (ANOVA), com emprego da estatística F-Fischer.

O nível de significância adotado no estudo foi de $5 \%$. Todos os valores de níveis descritivos ( $p$ ) dos testes foram calculados e apresentados no trabalho. O poder calculado da amostra foi de $90 \%$. 
4. RESULTADOS 


\section{RESULTADOS}

Na figura 5 são apresentados os gráficos de correlação entre os valores IGF-1 e IGFBP-3 com os respectivos valores percentuais relativos às medianas.

Figura 6 - Correlações entre as dosagens de IGF-1 e IGFBP-3 e \% relativo à mediana
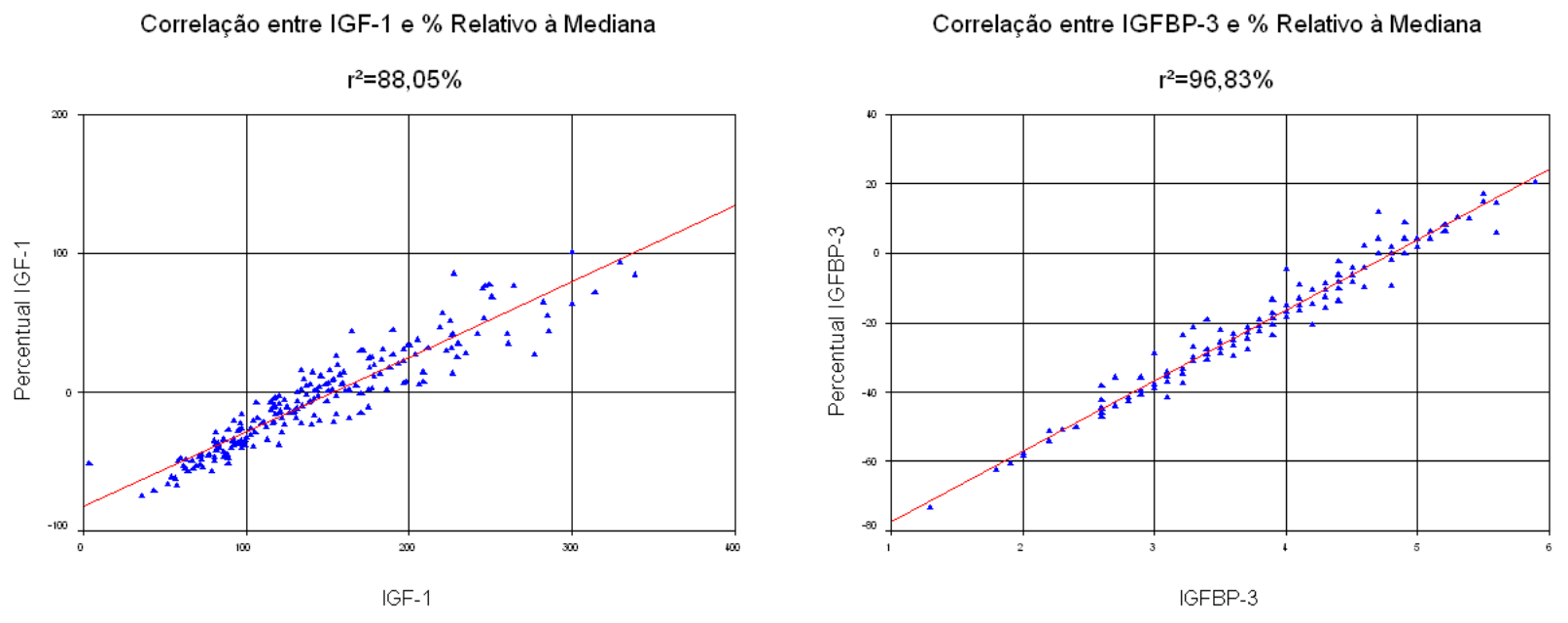

Não foram observados desvios significativos em relação à mediana. A associação observada para o IGF-1 e respectivo percentual (\%) em relação à mediana foi inferior à observada para a dosagem do IGFBP-3.

Na tabela 7 estão apresentados os cálculos estatísticos descritivos para as variáveis quantitativas do estudo, que foram calculadas para cada um dos grupos de risco. 
Tabela 7 - Estatísticas descritivas para as variáveis quantitativas

\begin{tabular}{|c|c|c|c|c|c|c|}
\hline Variáveis & Níveis & $\mathbf{N}$ & Média & Desvio & $\mathbf{F}$ & $\mathbf{P}$ \\
\hline \multirow{4}{*}{ Idade } & Controle & 66 & 50,26 & 8,93 & \multirow{4}{*}{7,982} & \multirow{4}{*}{$<0,001$} \\
\hline & Alto Risco & 108 & 45,82 & 9,09 & & \\
\hline & Câncer & 51 & 51,78 & 12,02 & & \\
\hline & Total & 225 & 48,48 & 10,08 & & \\
\hline \multirow{4}{*}{ Percentual IGFBP-3 } & Controle & 66 & $-18,9008$ & 16,924 & \multirow{4}{*}{0,263} & \multirow{4}{*}{0,769} \\
\hline & Alto Risco & 108 & $-18,8526$ & 15,9165 & & \\
\hline & Câncer & 51 & $-20,8335$ & 19,2511 & & \\
\hline & Total & 225 & $-19,3157$ & 16,9567 & & \\
\hline \multirow{4}{*}{ Percentual IGF-1 } & Controle & 66 & $-11,2051$ & 33,7398 & \multirow{4}{*}{0,979} & \multirow{4}{*}{0,377} \\
\hline & Alto Risco & 108 & $-4,6548$ & 33,805 & & \\
\hline & Câncer & 51 & $-2,9231$ & 40,6454 & & \\
\hline & Total & 225 & $-6,1837$ & 35,4394 & & \\
\hline \multirow{4}{*}{ \% Razão } & Controle & 61 & 1,10 & 6,18 & \multirow{4}{*}{1,402} & \multirow{4}{*}{0,248} \\
\hline & Alto Risco & 105 & 0,04 & 3,66 & & \\
\hline & Câncer & 50 & 1,26 & 5,76 & & \\
\hline & Total & 216 & 0,62 & 5,00 & & \\
\hline \multirow{4}{*}{ IMC } & Controle & 66 & 26,108 & 5,265 & \multirow{4}{*}{0,621} & \multirow{4}{*}{0,538} \\
\hline & Alto Risco & 108 & 25,758 & 4,363 & & \\
\hline & Câncer & 51 & 26,68 & 5,37 & & \\
\hline & Total & 225 & 26,07 & 4,869 & & \\
\hline
\end{tabular}

As diferenças apontadas pela análise discriminante evidenciaram as variações das médias para os grupos com câncer de mama, alto risco e controle. A estatística F-Fischer e respectivo nível descritivo são também apresentados na tabela. O nível de significância foi considerado $p<0,05$.

Apenas a idade apresentou variação estatisticamente significativa nos grupos $(p<0,001)$, mostrando que o grupo de alto risco concentrou pacientes mais jovens. Para todas as demais variáveis quantitativas não foi encontrada variação significativa. 
Foi detectada associação significativa entre estado menopausal e os diferentes grupos (tabela 8). A estatística do teste foi igual a $\chi^{2}=16,90 \mathrm{com}$ $p<0,001$. A proporção de pacientes em pós-menopausa foi maior no grupo com câncer (58,8\%), correspondendo a apenas $25,9 \%$ das mulheres do grupo com alto risco.

Tabela 8 - Associação menopausa e grupos

\begin{tabular}{|c|c|c|c|c|c|}
\hline \multirow{2}{*}{ Menopausa } & \multicolumn{3}{|c|}{ Grupo } & \multirow{2}{*}{ Total } \\
\cline { 3 - 6 } & & controle & alto risco & Câncer & \\
\hline \multirow{2}{*}{ Não } & $\mathrm{n}$ & 37 & 80 & 21 & 138 \\
\cline { 2 - 5 } & $\%$ & $56,10 \%$ & $74,10 \%$ & $41,20 \%$ & $61,30 \%$ \\
\hline \multirow{2}{*}{ Sim } & $\mathrm{n}$ & 29 & 28 & 30 & 87 \\
\cline { 2 - 5 } & $\%$ & $43,90 \%$ & $25,90 \%$ & $58,80 \%$ & $38,70 \%$ \\
\hline \multirow{2}{*}{ Total } & $\mathrm{n}$ & 66 & 108 & 51 & 225 \\
\cline { 2 - 5 } & $\%$ & $100,00 \%$ & $100,00 \%$ & $100,00 \%$ & $100,00 \%$ \\
\hline
\end{tabular}

Nas tabelas 9 e 10 são apresentadas as distribuições dos percentuais de IGF-1 (\%IGF-1) e IGFBP-3 (\%IGFBP-3) em relação às respectivas medianas para cada um dos três grupos pesquisados.

Tabela 9 - Distribuição dos \% IGFBP-3 em relação à mediana nos diferentes grupos

\begin{tabular}{|c|c|c|c|c|c|}
\hline \multirow{2}{*}{\multicolumn{2}{|c|}{ \%IGFBP-3 X mediana }} & \multicolumn{3}{|c|}{ Grupo } & \multirow{3}{*}{$\begin{array}{c}\text { Total } \\
195\end{array}$} \\
\hline & & \multirow{2}{*}{$\begin{array}{c}\text { controle } \\
57\end{array}$} & \multirow{2}{*}{$\frac{\text { alto risco }}{95}$} & \multirow{2}{*}{$\begin{array}{c}\text { câncer } \\
43\end{array}$} & \\
\hline & $\mathrm{n}$ & & & & \\
\hline Abaixo & $\%$ & $86,40 \%$ & $88,00 \%$ & $84,30 \%$ & $86,70 \%$ \\
\hline \multirow{2}{*}{ Acima } & $\mathrm{n}$ & 9 & 13 & 8 & 30 \\
\hline & $\%$ & $13,60 \%$ & $12,00 \%$ & $15,70 \%$ & $13,30 \%$ \\
\hline \multirow{2}{*}{ Total } & $\mathrm{n}$ & 66 & 108 & 51 & 225 \\
\hline & $\%$ & $100,00 \%$ & $100,00 \%$ & $100,00 \%$ & $100,00 \%$ \\
\hline
\end{tabular}

A maior parte das pacientes $(86,7 \%)$ ficou abaixo da mediana para o IGFBP-3. Essa proporção é praticamente constante se considerarmos os diferentes grupos $(p=0,816)$. 
Tabela 10 - Distribuição dos \%IGF-1 em relação à mediana nos diferentes grupos

\begin{tabular}{|c|c|c|c|c|c|}
\hline \multirow{2}{*}{\multicolumn{2}{|c|}{ \%IGF-1 X mediana }} & \multicolumn{3}{|c|}{ Grupo } & \multirow{3}{*}{$\begin{array}{c}\text { Total } \\
133\end{array}$} \\
\hline & & controle & alto risco & Câncer & \\
\hline \multirow{2}{*}{ Abaixo } & $\mathrm{n}$ & 43 & 59 & 31 & \\
\hline & $\%$ & $65,20 \%$ & $54,60 \%$ & $60,80 \%$ & $59,10 \%$ \\
\hline \multirow{2}{*}{ Acima } & $\mathrm{n}$ & 23 & 49 & 20 & 92 \\
\hline & $\%$ & $34,80 \%$ & $45,40 \%$ & $39,20 \%$ & $40,90 \%$ \\
\hline \multirow{2}{*}{ Total } & $\mathrm{n}$ & 66 & 108 & 51 & 225 \\
\hline & $\%$ & $100,00 \%$ & $100,00 \%$ & $100,00 \%$ & $100,00 \%$ \\
\hline
\end{tabular}

Quanto à relação com a mediana para o \%IGF-1, 59,1\% do total de mulheres ficou abaixo, sendo que a proporção demonstrou-se constante para os três grupos estudados $(p=0,377)$.

Nas tabelas 11, 12 e 13 estão expostas as distribuições dos percentuais de IGFBP-3, IGF-1 e razão \%IGF-1 / \%IGFBP-3 em relação à mediana e risco familiar.

Os resultados dos percentuais de IGFBP-3, IGF-1 e a razão \%IGF-1 / \%IGFBP-3 puderam ser considerados independentes do risco familiar $(p=0,777$, $p=0,600$ e $p=0,945$ respectivamente).

Tabela 11 - Distribuição do \% IGFBP-3 em relação à mediana e risco familiar

\begin{tabular}{|c|c|c|c|c|}
\hline \multirow{2}{*}{ \%IGFBP-3 X mediana } & \multicolumn{3}{|c|}{ Risco Familiar } \\
\cline { 2 - 5 } Abaixo & $\mathrm{n}$ & $\mathbf{N a ̃ o}$ & Sim & Total \\
\cline { 2 - 5 } & $\%$ & $89,20 \%$ & 62 & 95 \\
\hline \multirow{2}{*}{ Acima } & $\mathrm{n}$ & 4 & 9 & 13 \\
\cline { 2 - 5 } & $\%$ & $10,80 \%$ & $12,70 \%$ & $12,00 \%$ \\
\hline \multirow{2}{*}{ Total } & $\mathrm{n}$ & 37 & 71 & 108 \\
\cline { 2 - 5 } & $\%$ & $100,00 \%$ & $100,00 \%$ & $100,00 \%$ \\
\hline
\end{tabular}


Tabela 12 - Distribuição dos \%IGF-1 em relação à mediana e risco familiar

\begin{tabular}{|c|c|c|c|c|}
\hline \multirow{2}{*}{\multicolumn{2}{|c|}{ \%IGF-1 X mediana }} & \multicolumn{3}{|c|}{ Risco Familiar } \\
\hline & & \multirow{2}{*}{$\begin{array}{c}\text { Não } \\
22\end{array}$} & \multirow{2}{*}{$\begin{array}{c}\text { Sim } \\
37\end{array}$} & \multirow{2}{*}{\begin{tabular}{|c|} 
Total \\
59
\end{tabular}} \\
\hline & $\mathrm{n}$ & & & \\
\hline Abaixo & $\%$ & $59,50 \%$ & $52,10 \%$ & $54,60 \%$ \\
\hline \multirow{2}{*}{ Acima } & $\mathrm{n}$ & 15 & 34 & 49 \\
\hline & $\%$ & $40,50 \%$ & $47,90 \%$ & $45,40 \%$ \\
\hline \multirow{2}{*}{ Total } & $\mathrm{n}$ & 37 & 71 & 108 \\
\hline & $\%$ & $100,00 \%$ & $100,00 \%$ & $100,00 \%$ \\
\hline
\end{tabular}

Tabela 13 - Distribuição dos resultados da razão \%IGF-1 / \%IGFBP-3 em relação à mediana e risco familiar

\begin{tabular}{|c|c|c|c|c|}
\hline \multirow{2}{*}{\multicolumn{2}{|c|}{$\begin{array}{c}\text { \%IGF-1 / \%IGFBP-3 } \\
\text { X mediana }\end{array}$}} & \multicolumn{3}{|c|}{ Risco Familiar } \\
\hline & & \multirow{2}{*}{$\begin{array}{c}\text { Não } \\
16\end{array}$} & \multirow{2}{*}{$\begin{array}{c}\text { Sim } \\
30\end{array}$} & \multirow{2}{*}{$\begin{array}{c}\text { Total } \\
46\end{array}$} \\
\hline & $\mathrm{n}$ & & & \\
\hline Abaixo & $\%$ & $45,70 \%$ & $42,90 \%$ & $43,80 \%$ \\
\hline \multirow{2}{*}{ Acima } & $\mathrm{n}$ & 19 & 40 & 59 \\
\hline & $\%$ & $54,30 \%$ & $57,10 \%$ & $56,20 \%$ \\
\hline \multirow{2}{*}{ Total } & $n$ & 35 & 70 & 105 \\
\hline & $\%$ & $100,00 \%$ & $100,00 \%$ & $100,00 \%$ \\
\hline
\end{tabular}

As próximas tabelas $(14,15$ e 16) mostram as distribuições dos percentuais de IGFBP-3, IGF-1 e a razão \%IGF-1 / \%IGFBP-3 em relação à mediana e risco histopatológico.

O percentual de IGFBP-3 foi considerado independente do risco histopatológico $(p=0,748)$, bem como o percentual de IGF-1 $(p=0,592)$ e a razão \%IGF-1 / \%IGFBP-3 ( $p=0,539)$. 
Tabela 14 - Distribuição dos \%IGFBP-3 em relação à mediana e risco histopatológico

\begin{tabular}{|c|c|c|c|c|}
\hline \multirow{2}{*}{ \%IGFBP-3 X mediana } & \multicolumn{3}{|c|}{ Risco Histopatológico } \\
\cline { 3 - 5 } & & Não & Sim & Total \\
\hline \multirow{2}{*}{ Abaixo } & $\mathrm{n}$ & 54 & 41 & 95 \\
\cline { 2 - 5 } & $\%$ & $87,10 \%$ & $89,10 \%$ & $88,00 \%$ \\
\hline \multirow{2}{*}{ Acima } & $\mathrm{n}$ & 8 & 5 & 13 \\
\cline { 2 - 5 } & $\%$ & $12,90 \%$ & $10,90 \%$ & $12,00 \%$ \\
\hline \multirow{2}{*}{ Total } & $\mathrm{n}$ & 62 & 46 & 108 \\
\cline { 2 - 5 } & $\%$ & $100,00 \%$ & $100,00 \%$ & $100,00 \%$ \\
\hline
\end{tabular}

Tabela 15 - Distribuição dos \% IGF-1 em relação à mediana e risco histopatológico

\begin{tabular}{|c|c|c|c|c|}
\hline \multirow{2}{*}{ \%IGF-1 X mediana } & \multicolumn{3}{|c|}{ Risco Histopatológico } \\
\cline { 2 - 5 } & $\mathrm{Não}$ & Sim & Total \\
\hline \multirow{2}{*}{ Abaixo } & $\mathrm{n}$ & 32 & 27 & 59 \\
\cline { 2 - 5 } & $\%$ & $51,60 \%$ & $58,70 \%$ & $54,60 \%$ \\
\hline \multirow{2}{*}{ Acima } & $\mathrm{n}$ & 30 & 19 & 49 \\
\cline { 2 - 5 } & $\%$ & $48,40 \%$ & $41,30 \%$ & $45,40 \%$ \\
\hline \multirow{2}{*}{ Total } & $\mathrm{n}$ & 62 & 46 & 108 \\
\cline { 2 - 5 } & $\%$ & $100,00 \%$ & $100,00 \%$ & $100,00 \%$ \\
\hline
\end{tabular}

Tabela 16 - Distribuição da razão \%IGF-1 / \%IGFBP-3 em relação à mediana e risco histopatológico

\begin{tabular}{|c|c|c|c|c|}
\hline \multirow{2}{*}{$\begin{array}{c}\text { \%IGF-1 / \%IGFBP-3 } \\
\text { X mediana }\end{array}$} & \multicolumn{3}{|c|}{ Risco Histopatológico } \\
\cline { 2 - 5 } Abaixo & $\mathrm{n}$ & $\mathbf{N a ̃ o}$ & Sim & Total \\
\cline { 2 - 5 } & $\%$ & $44,30 \%$ & $43,20 \%$ & $43,80 \%$ \\
\hline \multirow{2}{*}{ Acima } & $\mathrm{n}$ & 34 & 25 & 59 \\
\cline { 2 - 5 } & $\%$ & $55,70 \%$ & $56,80 \%$ & $56,20 \%$ \\
\hline \multirow{2}{*}{ Total } & $\mathrm{n}$ & 61 & 44 & 105 \\
\cline { 2 - 5 } & $\%$ & $100,00 \%$ & $100,00 \%$ & $100,00 \%$ \\
\hline
\end{tabular}

Definiu-se como mulher com alto risco para câncer de mama aquela cujo risco vitalício calculado pelos modelos de Gail e/ou Tyrer-Cuzick foi superior a $20 \%$. Visando apurar a análise dos resultados obtidos serão avaliados separadamente os subgrupos: 
- alto risco A: risco vitalício entre 20 e $29 \%$, total de 65 mulheres;

- alto risco B: risco vitalício igual ou superior a $30 \%$, total de 41 mulheres.

\subsection{Avaliação do subgrupo de alto risco A}

As tabelas 17, 18 e 19 apresentam as médias observadas de idade e IMC segundo a condição do \%IGF-1, do \%IGFBP-3 e da razão \%IGF-1 / \%IGFBP-3 em relação às suas respectivas medianas.

Não foram significativas as diferenças entre as médias de idade e IMC segundo a condição do \%IGF-1, do \%IGFBP-3 e da razão \%IGF-1 / \%IGFBP-3 estarem acima ou abaixo da mediana $(p>0,05)$.

Tabela 17 - Médias de idade e IMC para o grupo de alto risco A segundo \%IGF-1 em relação à mediana

\begin{tabular}{|c|c|c|c|c|c|c|}
\hline Alto Risco A & $\begin{array}{c}\% \text { IGF-1 } \\
\quad \mathbf{x} \\
\text { mediana } \\
\end{array}$ & $\mathbf{N}$ & Média & Desvio & $\mathbf{F}$ & $p$ \\
\hline \multirow{3}{*}{ Idade (anos) } & Abaixo & 39 & 46,95 & 9,33 & \multirow{3}{*}{2,332} & \multirow{3}{*}{0,132} \\
\hline & Acima & 26 & 43,38 & 9,04 & & \\
\hline & Total & 65 & 45,52 & 9,31 & & \\
\hline \multirow{3}{*}{ IMC (kg/m²) } & Abaixo & 39 & 26,3 & 4,623 & \multirow{3}{*}{1,167} & \multirow{3}{*}{0,284} \\
\hline & Acima & 26 & 25,114 & 3,859 & & \\
\hline & Total & 65 & 25,825 & 4,342 & & \\
\hline
\end{tabular}


Tabela 18 - Médias de idade e IMC para o grupo de alto risco A segundo \%IGFBP-3 em relação à mediana

\begin{tabular}{|c|c|c|c|c|c|c|}
\hline Alto Risco A & $\begin{array}{c}\text { \%IGFBF-3 } \\
x \\
\text { mediana }\end{array}$ & $\mathbf{N}$ & Média & Desvio & $\mathbf{F}$ & $\mathbf{p}$ \\
\hline \multirow{3}{*}{ Idade (anos) } & Abaixo & 60 & 45,62 & 9,11 & \multirow{3}{*}{0,078} & \multirow{3}{*}{0,781} \\
\hline & Acima & 5 & 44,4 & 12,7 & & \\
\hline & Total & 65 & 45,52 & 9,31 & & \\
\hline \multirow{3}{*}{ IMC $\left(\mathrm{kg} / \mathrm{m}^{2}\right)$} & Abaixo & 60 & 25,786 & 4,457 & \multirow{3}{*}{0,063} & \multirow{3}{*}{0,803} \\
\hline & Acima & 5 & 26,297 & 2,883 & & \\
\hline & Total & 65 & 25,825 & 4,342 & & \\
\hline
\end{tabular}

Tabela 19 - Médias de idade e IMC para o grupo de alto risco A segundo a razão \%IGF-1 / \%IGFBP-3 em relação à mediana

\begin{tabular}{|c|c|c|c|c|c|c|}
\hline Alto Risco A & $\begin{array}{c}\text { Razão } \\
X \\
\text { mediana }\end{array}$ & $\mathbf{N}$ & Média & Desvio & $\mathbf{F}$ & $\mathbf{p}$ \\
\hline \multirow{3}{*}{ Idade (anos) } & Abaixo & 24 & 44,04 & 8,24 & \multirow{3}{*}{0,685} & \multirow{3}{*}{0,411} \\
\hline & Acima & 39 & 46,05 & 9,98 & & \\
\hline & Total & 63 & 45,29 & 9,34 & & \\
\hline \multirow{3}{*}{ IMC (kg/m²) } & Abaixo & 24 & 24,651 & 3,757 & \multirow{3}{*}{2,198} & \multirow{3}{*}{0,143} \\
\hline & Acima & 39 & 26,262 & 4,426 & & \\
\hline & Total & 63 & 25,648 & 4,227 & & \\
\hline
\end{tabular}

De acordo com os dados contidos nas tabelas 20, 21 e 22, não foi significativa a associação entre \%IGF-1, \%IGFBP-3 ou razão \%IGF-1 / \%IGFBP-3 e menopausa no caso de alto risco A. Estas variáveis foram consideradas independentes. A estatística do teste foi:

- $\chi^{2}=2,334$ com $p=0,127$ para $\%$ IGF-1,

- $\chi^{2}=0,015$ com $p=0,904$ para \%IGFBP-3,

- $\chi^{2}=1,334$ com $p=0,248$ para a razão. 
Tabela 20 - Distribuição do \%IGF-1 em relação à mediana e condição de menopausa no alto risco $\mathrm{A}$

\begin{tabular}{|c|c|c|c|c|}
\hline \multicolumn{2}{|c|}{$\begin{array}{c}\text { Alto Risco A } \\
\text { \%IGF1 x mediana }\end{array}$} & \multicolumn{2}{|c|}{ Menopausa } & \multirow{2}{*}{ Total } \\
\cline { 2 - 4 } Abaixo & $\mathrm{n}$ & 25 & 14 & \\
\cline { 2 - 4 } & $\%$ & $53,20 \%$ & $77,80 \%$ & $60,00 \%$ \\
\hline \multirow{2}{*}{ Acima } & $\mathrm{n}$ & 22 & 4 & 26 \\
\cline { 2 - 5 } & $\%$ & $46,80 \%$ & $22,20 \%$ & $40,00 \%$ \\
\hline \multirow{2}{*}{ Total } & $\mathrm{n}$ & 47 & 18 & 65 \\
\cline { 2 - 4 } & $\%$ & $100,00 \%$ & $100,00 \%$ & $100,00 \%$ \\
\hline
\end{tabular}

Tabela 21 - Distribuição do \%IGFBP-3 em relação à mediana e condição de menopausa no alto risco $\mathrm{A}$

\begin{tabular}{|c|c|c|c|c|}
\hline \multirow{2}{*}{$\begin{array}{c}\text { Alto Risco A } \\
\text { \%IGFBP-3 x mediana }\end{array}$} & \multicolumn{2}{|c|}{ Menopausa } & \multirow{2}{*}{ Total } \\
\cline { 2 - 4 } Abaixo & $\mathrm{n}$ & 44 & 16 & 60 \\
\cline { 2 - 4 } & $\%$ & $93,60 \%$ & $88,90 \%$ & $92,30 \%$ \\
\hline \multirow{2}{*}{ Acima } & $\mathrm{n}$ & 3 & 2 & 5 \\
\cline { 2 - 5 } & $\%$ & $6,40 \%$ & $11,10 \%$ & $7,70 \%$ \\
\hline \multirow{2}{*}{ Total } & $\mathrm{n}$ & 47 & 18 & 65 \\
\cline { 2 - 4 } & $\%$ & $100,00 \%$ & $100,00 \%$ & $100,00 \%$ \\
\hline
\end{tabular}

Tabela 22 - Distribuição da razão \%IGF-1 / \%IGFBP-3 em relação à mediana e condição de menopausa no alto risco $A$

\begin{tabular}{|c|c|c|c|c|}
\hline \multicolumn{2}{|c|}{$\begin{array}{c}\text { Alto Risco A } \\
\text { Razão X mediana }\end{array}$} & \multicolumn{2}{|c|}{ Menopausa } & \multirow{2}{*}{ Total } \\
\cline { 2 - 4 } Abaixo & $\mathrm{n}$ & 20 & 4 & 24 \\
\cline { 2 - 4 } & $\%$ & $43,50 \%$ & $23,50 \%$ & $38,10 \%$ \\
\hline \multirow{2}{*}{ Acima } & $\mathrm{n}$ & 26 & 13 & 39 \\
\cline { 2 - 4 } & $\%$ & $56,50 \%$ & $76,50 \%$ & $61,90 \%$ \\
\hline \multirow{2}{*}{ Total } & $\mathrm{n}$ & 46 & 17 & 63 \\
\cline { 2 - 4 } & $\%$ & $100,00 \%$ & $100,00 \%$ & $100,00 \%$ \\
\hline
\end{tabular}




\subsection{Avaliação do subgrupo de alto risco $B$}

As tabelas 23,24 e 25 revelam as médias observadas de idade e IMC segundo a condição do \%IGF-1, \%IGFBP-3 e razão \%IGF-1 / \%IGFBP-3, respectivamente em relação à sua mediana, para as mulheres de alto risco $\mathrm{B}$.

Tabela 23 - Médias de idade e IMC para o grupo de alto risco B segundo \%IGF-1 em relação à mediana

\begin{tabular}{|c|c|c|c|c|c|c|}
\hline Alto Risco B & $\begin{array}{c}\% \text { IGF-1 } \\
\mathbf{x} \\
\text { mediana }\end{array}$ & $\mathbf{N}$ & Média & Desvio & $\mathbf{F}$ & $p$ \\
\hline \multirow{3}{*}{ Idade (anos) } & Abaixo & 20 & 47,45 & 7,12 & \multirow{3}{*}{0,953} & \multirow{3}{*}{0,335} \\
\hline & Acima & 21 & 44,71 & 10,43 & & \\
\hline & Total & 41 & 46,05 & 8,96 & & \\
\hline \multirow{3}{*}{ IMC $\left(\mathrm{kg} / \mathrm{m}^{2}\right)$} & Abaixo & 20 & 26,233 & 4,295 & \multirow{3}{*}{0,708} & \multirow{3}{*}{0,405} \\
\hline & Acima & 21 & 25,048 & 4,698 & & \\
\hline & Total & 41 & 25,626 & 4,489 & & \\
\hline
\end{tabular}

Tabela 24 - Médias de idade e IMC para o grupo de alto risco B segundo \%IGFBP-3 em relação à mediana

\begin{tabular}{|c|c|c|c|c|c|c|}
\hline Alto Risco B & $\begin{array}{c}\text { \%IGFBF-3 } \\
x \\
\text { mediana }\end{array}$ & $\mathbf{N}$ & Média & Desvio & $\mathbf{F}$ & $\mathbf{p}$ \\
\hline \multirow{3}{*}{ Idade (anos) } & Abaixo & 34 & 45,74 & 9,54 & \multirow{3}{*}{0,239} & \multirow{3}{*}{0,628} \\
\hline & Acima & 7 & 47,57 & 5,65 & & \\
\hline & Total & 41 & 46,05 & 8,96 & & \\
\hline \multirow{3}{*}{ IMC $\left(\mathbf{k g} / \mathrm{m}^{2}\right)$} & Abaixo & 34 & 25,907 & 4,767 & \multirow{3}{*}{0,774} & \multirow{3}{*}{0,384} \\
\hline & Acima & 7 & 24,263 & 2,601 & & \\
\hline & Total & 41 & 25,626 & 4,489 & & \\
\hline
\end{tabular}


Tabela 25 - Médias de idade e IMC para o grupo de alto risco B segundo a razão \%IGF-1 / \%IGFBP-3 em relação à mediana

\begin{tabular}{|c|c|c|c|c|c|c|}
\hline Alto Risco B & $\begin{array}{c}\text { Razão } \\
\text { X } \\
\text { Mediana } \\
\end{array}$ & $\mathbf{N}$ & Média & Desvio & $\mathbf{F}$ & $\mathbf{p}$ \\
\hline \multirow{3}{*}{ Idade (anos) } & Abaixo & 21 & 45,33 & 10,25 & \multirow{3}{*}{0,310} & \multirow{3}{*}{0,581} \\
\hline & Acima & 19 & 46,95 & 7,76 & & \\
\hline & Total & 40 & 46,1 & 9,07 & & \\
\hline \multirow{3}{*}{ IMC $\left(\mathbf{k g} / \mathrm{m}^{2}\right)$} & Abaixo & 21 & 25,362 & 4,746 & \multirow{3}{*}{0,152} & \multirow{3}{*}{0,699} \\
\hline & Acima & 19 & 25,93 & 4,425 & & \\
\hline & Total & 40 & 25,632 & 4,547 & & \\
\hline
\end{tabular}

Não foi significativa a diferença entre as médias de idade e IMC, segundo a condição do \%IGF-1, do \%IGFBP-3 e da razão \%IGF-1 / \%IGFBP-3 estarem acima ou abaixo da mediana no subgrupo de alto risco B.

Nas tabelas 26, 27 e 28 são apontados os dados referentes à distribuição de \%IGF-1, \%IGFBP-3 e da razão \%IGF-1 / \%IGFBP-3 em relação à mediana segundo o estado menopausal para o subgrupo de alto risco $B$. Sua análise permitiu inferir que não foi significativa a associação entre estas variáveis e menopausa, caracterizando-as como variáveis independentes da menopausa. A estatística do teste foi:

- $\chi^{2}=0,212$ com $p=0,645$ para \%IGF-1,

- $\chi^{2}=0,290$ com $p=0,591$ para \%IGFBP-3,

- $\chi^{2}=0,043$ com $p=0,835$ para a razão. 
Tabela 26 - Distribuição do \%IGF-1 em relação à mediana e condição de menopausa no alto risco $B$

\begin{tabular}{|c|c|c|c|c|}
\hline \multicolumn{2}{|c|}{$\begin{array}{c}\text { Alto Risco B } \\
\text { \%IGF1 x mediana }\end{array}$} & \multicolumn{2}{|c|}{ Menopausa } & \multirow{2}{*}{ Total } \\
\cline { 2 - 4 } Abaixo & $\mathrm{n}$ & 15 & 5 & 20 \\
\cline { 2 - 4 } & $\%$ & $46,90 \%$ & $55,60 \%$ & $48,80 \%$ \\
\hline \multirow{2}{*}{ Acima } & $\mathrm{n}$ & 17 & 4 & 21 \\
\cline { 2 - 5 } & $\%$ & $53,10 \%$ & $44,40 \%$ & $51,20 \%$ \\
\hline \multirow{2}{*}{ Total } & $\mathrm{n}$ & 32 & 9 & 41 \\
\cline { 2 - 4 } & $\%$ & $100,00 \%$ & $100,00 \%$ & $100,00 \%$ \\
\hline
\end{tabular}

Tabela 27 - Distribuição do \%IGFBP-3 em relação à mediana e condição de menopausa no alto risco $B$

\begin{tabular}{|c|c|c|c|c|}
\hline \multirow{2}{*}{$\begin{array}{c}\text { Alto Risco B } \\
\text { \%IGFBP-3 x mediana }\end{array}$} & \multicolumn{2}{|c|}{ Menopausa } & \multirow{2}{*}{ Total } \\
\cline { 2 - 4 } Abaixo & $\mathrm{n}$ & 26 & 8 & 34 \\
\cline { 2 - 4 } & $\%$ & $81,30 \%$ & $88,90 \%$ & $82,90 \%$ \\
\hline \multirow{2}{*}{ Acima } & $\mathrm{n}$ & 6 & 1 & 7 \\
\cline { 2 - 4 } & $\%$ & $18,80 \%$ & $11,10 \%$ & $17,10 \%$ \\
\hline \multirow{2}{*}{ Total } & $\mathrm{n}$ & 32 & 9 & 41 \\
\cline { 2 - 4 } & $\%$ & $100,00 \%$ & $100,00 \%$ & $100,00 \%$ \\
\hline
\end{tabular}

Tabela 28 - Distribuição da razão \%IGF1 / \%IGFBP3 em relação à mediana e condição de menopausa no alto risco $B$

\begin{tabular}{|c|c|c|c|c|}
\hline \multicolumn{2}{|c|}{$\begin{array}{c}\text { Alto Risco B } \\
\text { Razão x mediana }\end{array}$} & \multicolumn{2}{|c|}{ Menopausa } & \multirow{2}{*}{ Total } \\
\cline { 2 - 4 } Abaixo & $\mathrm{n}$ & 16 & 5 & 21 \\
\cline { 2 - 4 } & $\%$ & $51,60 \%$ & $55,60 \%$ & $52,50 \%$ \\
\hline \multirow{2}{*}{ Acima } & $\mathrm{n}$ & 15 & 4 & 19 \\
\cline { 2 - 4 } & $\%$ & $48,40 \%$ & $44,40 \%$ & $47,50 \%$ \\
\hline \multirow{2}{*}{ Total } & $\mathrm{n}$ & 31 & 9 & 40 \\
\cline { 2 - 4 } & $\%$ & $100,00 \%$ & $100,00 \%$ & $100,00 \%$ \\
\hline
\end{tabular}


5. DISCUSSÃO 


\section{DISCUSSÃO}

Conviver com fantasma já foi tema de filmes ganhadores do Oscar, mas, fora das telas, isso perde o traço trágico-cômico e transforma-se em fardo angustiante. No ambulatório de acompanhamento de mulheres com alto risco para câncer de mama encontram-se mulheres que periodicamente retornam ao atendimento médico com a finalidade de confirmarem que continuam livres da doença que tanto as amedronta, uma vez que grande parte delas já vivenciou o drama de mães, irmãs ou filhas na batalha contra o câncer de mama. Além das portadoras de risco familiar, há as portadoras de risco histopatológico e que comparecem à consulta para se certificarem de que não necessitarão de novo procedimento cirúrgico e que nenhuma nova lesão mamária surgiu.

Além das recomendações editadas pela NCCN ${ }^{19,20}$ e pela $\operatorname{ACS}^{43}$ de que se realizem mamografia e ressonância magnética das mamas anualmente em mulheres com alto risco para câncer de mama (secundário à mutações ou a risco calculado), seria de especial interesse a possibilidade de se acrescentar novo exame que enfatizasse a necessidade de prosseguir a pesquisa diagnóstica, agregando risco aos cálculos matemáticos ora vigentes.

O primeiro estudo epidemiológico visando relacionar IGF-1 e câncer de mama foi publicado em 1993 por Peyrat ${ }^{31}$ que, levando em conta o efeito "in vitro" do IGF-1 nas células tumorais mamárias e a presença de receptores de 
IGF-1 no câncer de mama, demonstra um possível envolvimento do IGF-1 plasmático com o desenvolvimento do câncer de mama.

Até o momento não há estudos publicados que relacionem as dosagens de IGF-1 e IGFBP-3 em população com alto risco para câncer de mama.

Baseado nessas conclusões e nas pesquisas que se seguiram utilizando os fatores de crescimento insulinóides IGF-1 e IGFBP-3, este trabalho procurou adicionar dados que mostrem essa possível relação na população brasileira, particularmente nas mulheres com alto risco para câncer de mama.

A análise das variáveis quantitativas levantadas para os três grupos pesquisados mostrou que houve uma diferença estatisticamente significante $(p<0,001)$ entre as médias de idade, sendo que no grupo de alto risco as mulheres eram mais jovens do que nos grupos controle e com câncer de mama, com média de idade de 45,92, o que se explica em parte por ser a população com alto risco familiar composta por filhas ou irmãs de mulheres portadoras de câncer de mama e que temem a possibilidade de desenvolver a doença no futuro. Soma-se a esta a possibilidade de que as lesões mamárias que definem o alto risco histopatológico surgem, em geral, em idade inferior àquela observada em pacientes portadoras de câncer de mama. A diferença das médias de idade nos grupos não interferiu na análise de IGF-1 e IGFBP-3, pois o estudo dos percentuais em relação à mediana elimina a influência de características individuais, como a idade. 
Apesar de ser freqüentemente apontada, a associação entre dosagem de IGF-1 e pré-menopausa não foi confirmada, uma vez que no grupo com alto risco, onde a grande maioria $(74,1 \%)$ das mulheres encontrava-se no menacme, não houve variação dos percentuais de IGF-1 quando comparados aos encontrados no grupo de pacientes portadoras de câncer de mama, no qual $58,8 \%$ das mulheres encontravam-se pós-menopausa.

Da mesma forma, não se verificou variação nos percentuais de IGF-1 entre o grupo de mulheres com alto risco, predominantemente mais jovem (média de idade $=45,82$ anos), e o grupo de pacientes com câncer de mama (média de idade $=51,78$ anos), em desacordo com os dados de Johansson et al ${ }^{39}$, que em 2004, mostram a redução dos níveis de IGF-1 de 1,2\% ao ano, com o aumento da idade.

Comparados os percentuais de IGF-1 e IGFBP-3 em relação à mediana nos três grupos, sem se levar em conta variáveis como idade, IMC ou menopausa, foram encontrados $86,70 \%$ dos \%IGFBP-3 abaixo da mediana e $59,10 \%$ dos \%IGF-1 abaixo da mediana, sendo que as variações observadas nos três grupos estudados (tabelas 9 e 10) não foram estatisticamente significantes ( $p=0,816$ e $p=0,377$ respectivamente).

Muitos estudos $40,41,44,46,51,52$ apesar de casuística extensa, serviram-se de amostras colhidas muito tempo antes da análise, congeladas ou criopreservadas, utilizando metodologias com variados graus de automatização (teste imunoenzimático ou ELISA, radioimunoensaio, ensaio 
radioimunométrico), o que talvez possa influenciar os resultados, uma vez que o processo de congelamento e degelo pode levar à desnaturação proteica, com possibibilidade de redução dos níveis de IGFBP-3 e aumento do IGF-1. Quanto ao método de escolha para a dosagem, quanto maior o grau de automação menor a possibilidade de erro na dosagem, visto que esta independerá do profissional executante. O método atual que permite dosagens de modo totalmente automatizado é o ensaio imunométrico quimioluminescente, o qual dispensa a necessidade de outras dosagens de confirmação para cada amostra e que foi empregado no presente estudo. A publicação de Rinaldi et al ${ }^{38}$ elenca mulheres de vários países como França, Holanda, Reino Unido, Alemanha, Espanha, Itália, Dinamarca e Grécia, com diferentes etnias, perfis antropométricos, hábitos alimentares e de vida que sabidamente influenciam a liberação de fatores insulinóides. No caso do estudo de Gunter et al ${ }^{42}$, em que a casuística foi tirada do estudo WHI, muitas foram usuárias de terapia hormonal, o que também pode ser um viés, pois de acordo com Marshman e Streuli ${ }^{27}$ o estrogênio pode induzir a expressão de IGF-1 e aumentar o nível de IGFBP protease, que consequentemente resulta em elevação de IGF-1. O estudo cuja casuística foi retirada do Nurses' Health Study ${ }^{45}$ contou com amostras de sangue colhidas em domicílio pelas próprias participantes e enviadas congeladas pelo correio, o que provavelmente não permitiu homogeneidade metodológica. 
Baglietto et al $^{40}$ realizaram estudo do tipo caso-controle em que 19.347 mulheres entre 27 e 75 anos colheram amostras de sangue no intervalo 1990 1994. Em 2002 as participantes foram recontatadas, sendo que destas, 423 foram diagnosticadas com câncer de mama no período. Realizaram-se, então, dosagens de IGF-1 e IGFBP-3 por ELISA nos soros criopreservados destas pacientes e de 1.903 controles. Não se observa relevante aumento no risco de câncer de mama associado com elevados níveis de IGF-1 ou IGFBP-3 na prémenopausa (os resultados obtidos nesta tese foram similares), mas, no entanto, se encontra aumento de risco quando há níveis elevados dos fatores insulinóides em amostras colhidas de mulheres com idade superior a 60 anos ou pós-menopusa.

Vatten et al ${ }^{41}$ conduziram estudo de tipo caso-controle com desenho semelhante ao de Baglietto et al ${ }^{40}$, publicado em 2008, onde 35.105 mulheres entre 40 e 42 anos foram acompanhadas pelo período médio de 4,3 anos. Durante esse período, 325 mulheres foram diagnosticadas com câncer de mama e 647 sem câncer foram selecionadas como controles. IGF-1 e IGFBP-3 foram dosados por radioimunoensaio (amostras congeladas). Conclusão do estudo: apenas uma modesta associação positiva entre IGF-1 e câncer de mama pôde ser observada em mulheres com idade inferior a 50 anos.

Em 2009 Gunter et al ${ }^{42}$ publicaram estudo do tipo caso-controle com as pacientes do Women's Health Initiative Observational Study (WHI-OS) e avaliaram as dosagens de amostras colhidas de 835 mulheres com diagnóstico 
de câncer de mama e de 816 controles randomicamente escolhidos. Foram dosados (em amostras descongeladas) insulina, glicose, IGF-1 total, IGF-1 livre, IGFBP-3 e estradiol. Somente os níveis de insulina são positivamente associados com o risco de câncer de mama, não se observando relação com os fatores de crescimento insulina like, o que foi ratificado neste estudo.

Conforme exposto nos Resultados, esta pesquisa passou a avaliar os dados obtidos de acordo com as principais características qualitativas ou quantitativas de cada grupo, visando refinar a análise. Verificou-se que para as pacientes com alto risco familiar para câncer de mama os percentuais de IGF-1, IGFBP-3 e a razão \%IGF-1 / \%IGFBP-3 não variaram de modo significante em relação às suas respectivas medianas, demonstrando que o risco familiar não interfere com a concentração sérica destas substâncias.

De acordo com Barnes et al ${ }^{43}$, IGF-1 ou IGFBP-3 não estão envolvidos no aumento do risco para câncer de mama devido ao antecedente familiar, independente do estado menopausal. Assim como no presente estudo, outros autores ${ }^{38,44}$ não encontram associação entre IGF e história familiar de câncer de mama. Também Diorio et al ${ }^{45}$ não detectam a combinação de aumento de IGFBP-3 com antecedente familiar em mulheres na pré menopausa.

Quanto à influência do alto risco histopatológico, não foi demonstrada relação entre \%IGF-1, \%IGFBP-3 ou razão \%IGF-1 / \%IGFBP-3 e patologias ditas precursoras. A grande maioria dos estudos já publicados refere-se apenas 
à doença benigna da mama, de forma ampla, como no estudo publicado por Barnes et $\mathrm{al}^{43}$, no qual houve associação positiva entre altos níveis de IGF-1 (tanto na pré como na pós-menopausa) e mulheres com diagnóstico prévio de patologia mamária benigna (sem outras especificações). De acordo com publicação de Singer et al ${ }^{46}$ tumores mamários malignos não podem ser distinguidos de lesões mamárias benignas através dos níveis séricos de IGF, o que parece estar de acordo com os achados desta tese.

Há estudos, como o de Bolke et al ${ }^{47}$, que se focam em carcinoma ductal in situ e concluem que a combinação de elevado IGF-1 e reduzido IGFBP-3 pode aumentar o risco de CDIS na pré-menopausa. Visto que os casos de CDIS foram excluídos da casuística, este trabalho não acrescenta informações nesse sentido.

Com o foco na "população alvo" desta pesquisa, ou seja, pacientes com alto risco para câncer de mama, a casuística foi dividida de acordo com a quantificação do risco em 2 subgrupos (A e B), conforme já descrito.

Apesar da reconhecida relação inversa entre IGF-1 e idade ${ }^{43,44,48}$ e de os estudos publicados apresentarem uma relação controversa entre IGFBP-3 e idade, não foi encontrada relação de dependência nos grupos de alto risco A e B entre idade e \%IGF-1, \%IGFBP-3 e razão \%IGF-1 / \%IGFBP-3. De acordo com Fletcher et al ${ }^{30}$, os níveis de IGF-1 e IGFBP-3 em mulheres mais jovens são regulados pelos hormônios sexuais endógenos, o que é sugerido pelos 
achados de que os níveis de IGF-1 declinam com a idade e são mais elevados na pré-menopausa.

Neste estudo não foram consideradas significativas as diferenças de IMC nos grupos controle, câncer de mama e alto risco $(p=0,538)$ bem como não se encontrou relação entre IMC e \%IGF-1, \%IGFBP-3 e razão \%IGF-1 / \%IGFBP-3 nos dois subgrupos de Alto Risco A e B. Esses dados diferem daqueles publicados por Barnes et al ${ }^{43}$ em 2009, que associa maior IMC a níveis mais elevados de IGF-1 e IGFBP-3 na pós-menopausa. Holmes, Pollak e Hankinson ${ }^{44}$ encontram associação positiva entre IGFBP-3 e IMC, o que pode estar relacionado à diminuição do nível de IGF-1 biologicamente ativo, sinalizando a favor da hipótese de que níveis baixos de IGF-1 estão associados com a diminuição da massa muscular e aumento da gordura corpórea (aumento do IMC). Já na publicação de Diorio et al ${ }^{45}$ não se encontra correlação entre o nível de IGF-1 e IMC, o que é confirmado em artigo de Johansson et al ${ }^{38}$ que não observa associação entre os níveis de IGF-1 e IGFBP-3 e IMC, altura e razão cintura/quadril.

Uma dos pontos mais discutíveis é a influência do estado menopausal e níveis de fatores insulinóides. O presente estudo não encontrou conexão entre percentuais de IGF-1 e IGFBP-3 e sua razão com estado menopausal nos três grupos avaliados e nem mesmo quando houve a subdivisão do alto risco em A e B. Toniolo et al ${ }^{49}$, em estudo prospectivo de tipo coorte, observam que o risco de câncer de mama pré-menopausa aumenta com a elevação dos níveis 
circulantes de IGF-1, o que parece estar limitado ao câncer que se desenvolve antes dos 50 anos de idade. De modo diferente, Bruning ${ }^{31}$, em estudo do tipo caso-controle, encontra em portadoras de câncer de mama na pré-menopausa concentrações elevadas de IGF-1, reduzidas de IGFBP-3 e aumento da razão IGF-1 / IGFBP-3.

Schenhammer et al ${ }^{50}$ em 2005 publicaram um estudo prospectivo tipo caso-controle baseado no Nurses' Health Study (iniciado em 1976). Amostras de sangue foram colhidas pelo menos 6 anos antes do diagnóstico de câncer em 800 participantes (671 com CDI e 129 com CDIS) e em 1129 controles e o estudo conclui que há relação entre IGF-1 e risco para câncer de mama apenas nas mulheres na pré-menopausa e com idade inferior a 50 anos; nos demais casos (pós-menopausa ou pré-menopausa com idade superior a 50anos) não se observa qualquer relação entre IGFBP-3, IGFBP-1 ou IGF-1. A mesma autora publicou (em 2006) outro levantamento similar tomando por base as mulheres do Nurses' Health Study II (iniciado em 1989), sendo 317 portadoras de câncer de mama (237 CDI e 80 CDIS) e 634 controles ${ }^{51}$. A análise dos dados obtidos não mostra variação entre IGF-1, IGFBP-3, IGFBP-1 ou GH entre casos e controles, nem mesmo se selecionados em pré ou pós-menopausa demonstrando o conflito de resultados da literatura em geral. Este segundo estudo apresenta concordância com os dados obtidos nesta tese.

Com resultados que diferem dos relatados, em revisão sistemática de 13 estudos, Fletcher et $\mathrm{al}^{30}$ concluem haver consistência na associação entre 
níveis pré-menopausa de IGF-1 e IGFBP-3 e subseqüente risco de câncer de mama. Na pós-menopausa, não se confirma esta relação ${ }^{39}$.

As principais revisões sistemáticas e metanálises separam as mulheres quanto ao seu estado menopausal, sendo que 4 delas ${ }^{30,33,34,36}$ concluem que IGF-1 e IGFBP-3 aumentam o risco na pré-menopausa. Rinaldi et al ${ }^{37}$, por sua vez, confirmam que, em extenso estudo multicêntrico europeu publicado em 2006, há associação entre a elevação de IGF-1 e IGFBP-3 e o risco de câncer de mama apenas em mulheres idosas. Aumentando a controvérsia, Sugumar et al ${ }^{35}$, em 2004, em meta-análise de 7 estudos encontram apenas uma possível associação $(p=0,062)$ entre elevação dos níveis de IGF-1 e risco de desenvolver câncer de mama na pré-menopausa.

Johansson et al ${ }^{38}$ estudaram os níveis circulantes de IGF-1 e IGFBP-3 em 364 mulheres portadoras de neoplasia mamária intraepitelial ou câncer de mama precoce, comparando-os aos resultados encontrados no grupo controle (376 mulheres) e a conclusão é de que há aumento estatisticamente significante de IGF-1 no grupo de mulheres com câncer de mama precoce ou com neoplasia intraepitelial quando comparado com o grupo controle.

Em 2009, Chen et al ${ }^{36}$ publicou meta-análise de 96 estudos dos quais 20 relacionavam IGF-1 e IGFBP-3 e câncer de mama. Seus dados comprovam uma relação positiva entre IGF-1 e IGFBP-3 e risco de câncer de mama na prémenopausa. 
De forma sintética são apresentadas na tabela 29 as conclusões finais das principais publicações sobre o tema.

Tabela 29 : Estudos que relacionam IGF-1 e/ou IGFBP-3 e risco de câncer de mama

\begin{tabular}{|l|l|l|l|}
\hline AUTOR & ANO & ESTUDO & CONCLUSÃO \\
\hline Sugumar A et al ${ }^{35}$ & 2004 & MA & $\begin{array}{l}\text { IGF-1: associação discreta na préM } \\
\text { IGFBP-3: não significante }\end{array}$ \\
\hline Renehan AG et al & 2004 & RS e MA & IGF-1 e IGFBP-3 aumentam o risco na préM \\
\hline Shi R et al ${ }^{34}$ & 2004 & MA & IGF-1 e IGFBP-3 aumentam o risco na préM \\
\hline Fletcher O et al ${ }^{30}$ & 2005 & RS & IGF-1 e IGFBP-3 aumentam o risco na préM \\
\hline Chen W et al ${ }^{36}$ & 2009 & MA & IGF-1 e IGFBP-3 aumentam o risco na préM \\
\hline Johansson H et al ${ }^{38}$ & 2004 & CC & $\begin{array}{l}\text { IGF-1 e IGFBP-3 aumentam o risco e } \\
\text { IGF-1 significante no CaM precoce }\end{array}$ \\
\hline Rinaldi S et al ${ }^{37}$ & 2006 & CC & IGF-1 e IGFBP-3 aumentam o risco na pósM \\
\hline Baglietto L et al ${ }^{39}$ & 2007 & CC & $\begin{array}{l}\text { Não associação de IGF-1 e IGFBP-3 na préM, mas } \\
\text { aumento significativo após os 50 anos de idade }\end{array}$ \\
\hline Vatten LJ et al ${ }^{40}$ & 2008 & CC & Associação modesta entre IGF-1 e risco antes dos 50 anos \\
\hline Gunter MJ et al ${ }^{41}$ & 2009 & CC & Não encontrou relação entre IGF-1 e risco de CaM \\
\hline
\end{tabular}

RS = revisão sistemática, $\mathrm{MA}=$ meta-análise, $\mathrm{CC}=$ caso-controle, pré-M = pré menopausa, pós-M = pós menopausa

Nesta tese foram avaliadas as dosagens de IGF-1 e IGFBP-3 em pacientes portadoras de câncer de mama sem qualquer tipo de tratamento prévio. Uma vez que não se observou diferenças estatisticamente significantes entre os três grupos avaliados, pode-se afirmar que os fatores insulinóides não são marcadores tumorais na população estudada. 
Há evidências, demonstradas por Fletcher et al ${ }^{30}$, de que os níveis circulantes de IGFs são determinados tanto pela produção quanto pelo clearence, sofrendo a influência da complexa relação IGF e suas proteinas carreadoras (IGFBP). O mesmo autor também sugere que talvez a concentração destas substâncias no tecido mamário possa ser mais fidedigna que sua dosagem sérica. Em artigo publicado em 2006, Renehan, Harvie e Howell ${ }^{33}$, após a análise de estudos publicados desde 1998, avaliam que a capacidade dos níveis de IGF de predizer o risco de câncer de mama parece desencorajadora, pois, apesar da comprovada ação das IGF na oncogênese, sua concentração no sangue sofre a influência de dietas, estilo de vida e interações farmacológicas e conclui que no futuro os fatores insulinóides poderão colaborar na prevenção de alguns tipos de câncer. Nesta tese apenas foram consideradas as influências exercidas pela idade, IMC e estado menopausal.

Petridou et al ${ }^{53}$ concluem sua publicação afirmando que seus resultados não confirmam os trabalhos prévios que associam IGF-1 com risco de câncer de mama na pré-menopausa e que seu objetivo não é modificar a evidência coletiva, mas mostrar que são claramente necessárias investigações adicionais, o que vem de encontro com os achados desta tese. 
Há que se ressaltar que este é o primeiro estudo a avaliar IGF-1 e IGFBP3 na população brasileira, em pacientes com alto risco para câncer de mama, uma vez que todos os trabalhos já publicados correlacionam apenas mulheres com diagnóstico de câncer de mama e controles.

Pontos relevantes:

- Os casos de câncer de mama inclusos são todos virgens de tratamento, eliminando a possibilidade de alteração das dosagens realizadas por influência de tratamento quimio e/ou hormonioterápico ou modificação desencadeada pela prévia retirada da neoplasia.

- Foram excluídos todos os casos de CDIS.

- Todas as amostras foram coletadas em intervalo de 4 meses e as dosagens realizadas sem que houvesse resfriamento ou congelamento de amostras, reduzindo possíveis viéses metodológicos por provável desnaturação proteica.

- Trata-se do primeiro estudo em população brasileira, a qual se caracteriza pela miscigenação racial, acrescida de fatores climáticos, hábitos alimentares e de vida ímpares, que distinguem esta população das demais já estudadas, predominantemente de mulheres caucasianas, habitantes de países do hemisfério norte. 
Apesar de os resultados finais não mostrarem tratar-se de substâncias que podem influir sobre o cálculo de risco para o câncer de mama na população estudada, não se pode deixar de considerar a complexa via do $\mathrm{GH}$ e dos fatores de crescimento insulinóides como peça fundamental na ativação e aceleração do processo tumoral. Outros estudos serão necessários para estabelecer substâncias que possam sinalizar o desenvolvimento do câncer de mama, possibilitando novas terapias preventivas ou tratamentos precoces, principais objetivos da mastologia atual. 


\section{CONCLUSÃO}




\section{CONCLUSÃO}

Não foram observadas diferenças significantes nos níveis séricos de IGF-1 e IGFBP-3 nas pacientes com câncer de mama, nas mulheres com alto risco para câncer de mama e naquelas com risco populacional. 


\section{ANEXOS}




\section{ANEXOS}

\section{Anexo A - Termo de consentimento livre e esclarecido}

HOSPITAL DAS CLÍNICAS DA

FACULDADE DE MEDICINA DA UNIVERSIDADE DE SÃO PAULO

DIRETORIA CLÍNICA

COMISSÃO DE ÉTICA PARA ANÁLISE DE PROJETOS DE PESQUISA - CAPPesq

\section{TERMO DE CONSENTIMENTO LIVRE E ESCLARECIDO}

I - DADOS DE IDENTIFICAÇÃO DO SUJEITO DA PESQUISA OU RESPONSÁVEL LEGAL

1. NOME DO PACIENTE .:

DOCUMENTO DE IDENTIDADE N N $^{\circ}$ SEXO:.$M \square F$ DATA NASCIMENTO: .......................

ENDEREÇO $N^{\circ}$ APTO:

BAIRRO. CIDADE

CEP: TELEFONE:DDD ( .)

2.RESPONSÁVEL LEGAL NATUREZA (grau de parentesco, tutor, curador, etc.) DOCUMENTO DE IDENTIDADE : SEXO: $M \square F$ DATA NASCIMENTO.: ....................

ENDEREÇO:

$\mathrm{N}^{\circ}$ APTO:

BAIRRO: CIDADE: CEP: TELEFONE:DDD 


\section{II - DADOS SOBRE A PESQUISA CIENTÍFICA}

1. TÍTULO DO PROTOCOLO DE PESQUISA: Avaliação dos fatores de crescimento insulinóides IGF-I e IGFBP-3 em pacientes de alto risco para câncer de mama

2. PESQUISADOR: José Roberto Filassi

CARGO/FUNÇÃO: Médico Assistente INSCRIÇÃO CONSELHO REGIONAL Nº 31182

UNIDADE DO HCFMUSP: .Disciplina de Ginecologia HCFMUSP

3. AVALIAÇÃO DO RISCO DA PESQUISA:

SEM RISCO RISCO MÍNIMO $X \quad$ RISCO MÉDIO

RISCO BAIXO RISCO MAIOR

(probabilidade de que o indivíduo sofra algum dano como consequência imediata ou tardia do estudo)

4.DURAÇÃO DA PESQUISA : 12 meses

\section{III - REGISTRO DAS EXPLICAÇÕES DO PESQUISADOR AO PACIENTE OU SEU REPRESENTANTE LEGAL SOBRE A PESQUISA CONSIGNANDO:}

1. Justificativa e os objetivos da pesquisa

Esta pesquisa tem por objetivo verificar o risco de mulheres que têm parentes (mães, irmãs) portadoras de câncer de mama para desenvolver esta doença também. Esta pesquisa terá três grupos: um grupo com mulheres com câncer de mama, outro grupo com mulheres que têm parentes que tiveram câncer de mama (ou seja, alto risco familiar) ou que já tiveram alguma doença na mama que aumente o risco de desenvolver câncer de mama e o terceiro grupo com mulheres que não têm doença na mama e nem risco familiar.

2. Procedimentos que serão utilizados e propósitos, incluindo a identificação dos procedimentos experimentais.

Será feito exame físico, coleta de sangue, mamografia e também será preciso responder a um questionário. As mulheres com câncer de mama continuarão seu tratamento no Setor de Mastologia. Nesta pesquisa só será feita a coleta de sangue, exame físico e questionário, sendo que o tratamento do câncer não é nosso objetivo.

\section{Desconfortos e riscos esperados}

A coleta de sangue causa alguma dor pela picada da agulha; a mamografia aperta a mama e pode causar dor também. 
4. Benefícios que poderão ser obtidos.

O benefício maior é que o médico poderá entender melhor quais são as mulheres com risco elevado para câncer de mama. Assim, as mulheres poderão ser beneficiadas já que serão futuramente melhor estudadas e acompanhadas para que o câncer de mama seja detectado no início, com maior chance de cura.

5. Procedimentos alternativos que possam ser vantajosos para o indivíduo

Se a Senhora não quiser participar desta pesquisa continuará a ser acompanhada normalmente no Ambulatório de Ginecologia. Não há procedimentos alternativos, visto que a Senhora não tem doença na mama. Se a Senhora faz parte do grupo com câncer de mama poderá ser tratada normalmente pelo Setor de Mastologia mesmo que não participe desta pesquisa.

\section{ESCLARECIMENTOS DADOS PELO PESQUISADOR SOBRE GARANTIAS DO SUJEITO DA PESQUISA CONSIGNANDO:}

1. Acesso a qualquer tempo às informações sobre procedimentos, riscos e benefícios relacionados à pesquisa, inclusive para dirimir eventuais dúvidas.

2. Liberdade de retirar seu consentimento a qualquer momento e de deixar de participar do estudo, sem que isto traga prejuízo a continuidade da assistência.

3. Salvaguarda da confidencialidade, sigilio e privacidade.

\section{INFORMAÇÕES DE NOMES, ENDEREÇOS E TELEFONES DOS RESPONSÁVEIS PELO ACOMPANHAMENTO DA PESQUISA PARA CONTATO EM CASO DE INTERCORRÊNCIAS CLÍNICAS E REAÇÕES ADVERSAS}

Dra Angela F. Trinconi - Tel: 2604-4014

\section{OBSERVAÇÕES COMPLEMENTARES}

\section{CONSENTIMENTO PÓS-ESCLARECIDO}

Declaro que, após convenientemente esclarecido pelo pesquisador e ter entendido o que me foi explicado, consinto em participar do presente Protocolo de Pesquisa.

São Paulo, de de 2009.

Assinatura do sujeito da pesquisa ou

responsável legal
Assinatura do pesquisador

(carimbo ou nome legível) 


\section{Anexo B - Formulário de anamnese}

ETIQUETA

AMBULATÓRIO DE CONDUTAS ESPECIAIS PARA ALTO RISCO

NOME

DATA

$N^{\circ}$

ENDEREÇO

FONE RES:

CEL:

CONTATO:

PROFISSÃO

EST CIVIL ( )S ( )C ( )V ( )D

RAÇA ( )B ( )N ( )A ( )ASHK NACIONALIDADE ( )BR ( )OUTRA RADICADO EM SP HÁ NO BRASIL HÁ DATA NASC

\section{ANTECEDENTES PESSOAIS}

PATOLOGIAS

TABAGISMO ( )S ( )N ( )PAROU HÁ

CIRURGIAS ( ) OOFORECTOMIA ETILISMO ( ) S ( ) N ( ) PAROU HÁ

( )MAMA DROGA ( )S ( )N ( )PAROU HÁ

( )OUTRAS

MEDICAMENTOS

NEO PRÉVIA

\section{ANT. GINECO-OBSTÉTRICOS} MENARCA CICLOS ( )REG ( )IRREG

$\mathrm{G} \_\mathrm{P} \_\mathrm{A} \_$10 PARTO

( ) NUNCA USOU

AMAMENTAÇÃO( ) $<1$ ANO ( ) > 1 ANO ( ) N

MENOPAUSA COM ANOS

TH: EM USO HÁ PAROU HÁ

( ) NUNCA USOU 


\section{ANT. MAMÁRIOS}

LESÃO ( )NÃO ( )SIM:

( )CISTOS ( )NÓDULOS ( )MICROCALC ( )ALT MG

BIÓPSIA ( )NÃO ( )SIM:

( )PAAF ( )CORE ( )MAMOTOMIA ( )CIRURGIA

ANAT. PATOL. ( )HIPERPLASIA ATÍPICA ( )NEOPLASIA LOBULAR ( )OUTRO

- ÍNDICES
GAIL:
\begin{tabular}{|c|l|}
\hline $5 \mathrm{a}$ & \\
\hline $90 \mathrm{a}$ &
\end{tabular}

BRCAPRO BRCA1

BRCA2

BRCA1 e 2

\section{- EXAME FÍSICO}

PESO : ALTURA:

IMC :

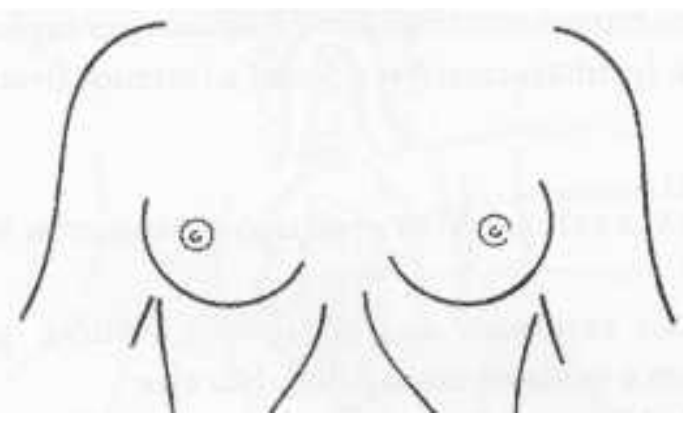

\section{RESULTADOS DE EXAMES}

MG: $1 / 1=$

USG:

$\mathrm{RM}: \ldots$

OUTROS:

- CONDUTA: 
4. ANT. FAMILIARES:

\begin{tabular}{|l|l|l|l|}
\hline \multirow{2}{*}{ MÃE } & \multicolumn{3}{|c|}{ IDADE } \\
\cline { 2 - 4 } & CA & ATUAL & ÓBITO \\
\hline OVÁRIO & & & \\
\hline MAMA UNI & & & \\
\hline MAMA BIL & & & \\
\hline INTESTINO & & & \\
\hline NÃO AFET & & & \\
\hline
\end{tabular}

\begin{tabular}{|c|c|c|c|c|c|c|}
\hline \multirow{3}{*}{ AVós } & \multicolumn{6}{|c|}{ IDADE } \\
\hline & \multicolumn{3}{|c|}{ MATERNA } & \multicolumn{3}{|c|}{ PATERNA } \\
\hline & $\mathrm{CA}$ & $\overline{A T L}$ & ÓBT & $\mathrm{CA}$ & ATL & ÓBT \\
\hline \multicolumn{7}{|l|}{ OVÁRIO } \\
\hline \multicolumn{7}{|l|}{ MM UNI } \\
\hline \multicolumn{7}{|l|}{ MM BIL } \\
\hline \multicolumn{7}{|l|}{ INTEST } \\
\hline N AFET & & & & & & \\
\hline
\end{tabular}

\begin{tabular}{|l|l|l|l|l|l|l|l|l|l|}
\hline \multirow{3}{*}{ IRMÃS } & \multicolumn{9}{|c|}{ IDADE } \\
\cline { 2 - 10 } & \multicolumn{3}{|c|}{ IRMÃ 1 } & \multicolumn{3}{c|}{ IRMÃ 2 } & \multicolumn{3}{c|}{ IRMÃ 3 } \\
\cline { 2 - 10 } & CA & ATL & ÓBT & CA & ATL & ÓBT & CA & ATL & ÓBT \\
\hline OVÁRIO & & & & & & & & & \\
\hline MM UNI & & & & & & & & & \\
\hline MM BIL & & & & & & & & & \\
\hline INTEST & & & & & & & & & \\
\hline N AFET & & & & & & & & & \\
\hline
\end{tabular}

\begin{tabular}{|l|c|c|c|c|c|c|c|c|c|}
\hline \multirow{2}{*}{ FILHAS } & \multicolumn{9}{|c|}{ IDADE } \\
\cline { 2 - 10 } & \multicolumn{3}{|c|}{ FILHA 1 } & \multicolumn{3}{c|}{ FILHA 2 } & \multicolumn{3}{c|}{ FILHA 3 } \\
\cline { 2 - 10 } & CA & ATL & ÓBT & CA & ATL & ÓBT & CA & ATL & ÓBT \\
\hline OVÁRIO & & & & & & & & & \\
\hline MM UNI & & & & & & & & & \\
\hline MM BIL & & & & & & & & & \\
\hline INTEST & & & & & & & & & \\
\hline N AFET & & & & & & & & & \\
\hline
\end{tabular}




\begin{tabular}{|c|c|c|c|c|c|c|c|c|c|}
\hline \multirow{4}{*}{$\begin{array}{l}\text { TIAS } \\
\text { OU } \\
\text { PRIMAS }\end{array}$} & \multicolumn{9}{|c|}{ IDADE } \\
\hline & \multicolumn{3}{|c|}{ ( )M ( )P } & \multicolumn{3}{|c|}{ ( )M ( )P } & \multicolumn{3}{|c|}{ ( )M ( )P } \\
\hline & $\mathrm{CA}$ & ATL & ÓBT & CA & ATL & ÓBT & CA & ATL & ÓBT \\
\hline & & & & & & & & & \\
\hline \multicolumn{10}{|l|}{ OVÁRIO } \\
\hline \multicolumn{10}{|l|}{ MM UNI } \\
\hline \multicolumn{10}{|l|}{ MM BIL } \\
\hline INTEST & & & & & & & & & \\
\hline
\end{tabular}

OUTROS GRAUS DE PARENTESCO: ( )MEIA-IRMÃ MATERNA (M) ( )MEIA-IRMÃ PATERNA (P) ( )SOBRINHA-IRMÃ (A) ( )SOBRINHA-IRMÃO (O)

\begin{tabular}{|c|c|c|c|c|c|c|c|c|c|}
\hline & \multicolumn{9}{|c|}{ IDADE } \\
\hline & \multicolumn{3}{|c|}{ ( ) } & \multicolumn{3}{|c|}{$($ ( ) } & \multicolumn{3}{|c|}{$($ ( ) } \\
\hline & CA & ATL & ÓBT & CA & ATL & ÓBT & CA & ATL & ÓBT \\
\hline OVÁRIO & & & & & & & & & \\
\hline MM UNI & & & & & & & & & \\
\hline MM BIL & & & & & & & & & \\
\hline INTEST & & & & & & & & & \\
\hline
\end{tabular}

CA DE MAMA MASCULINO: ( )PAI （ )IRMÃO ( )AVÔ （ )TIO ( )SOBRINHO(irmão) ( )SOBRINHO (irmã)( )MEIO-IRMÃO (M) ( )MEIO-IRMÃO (P)

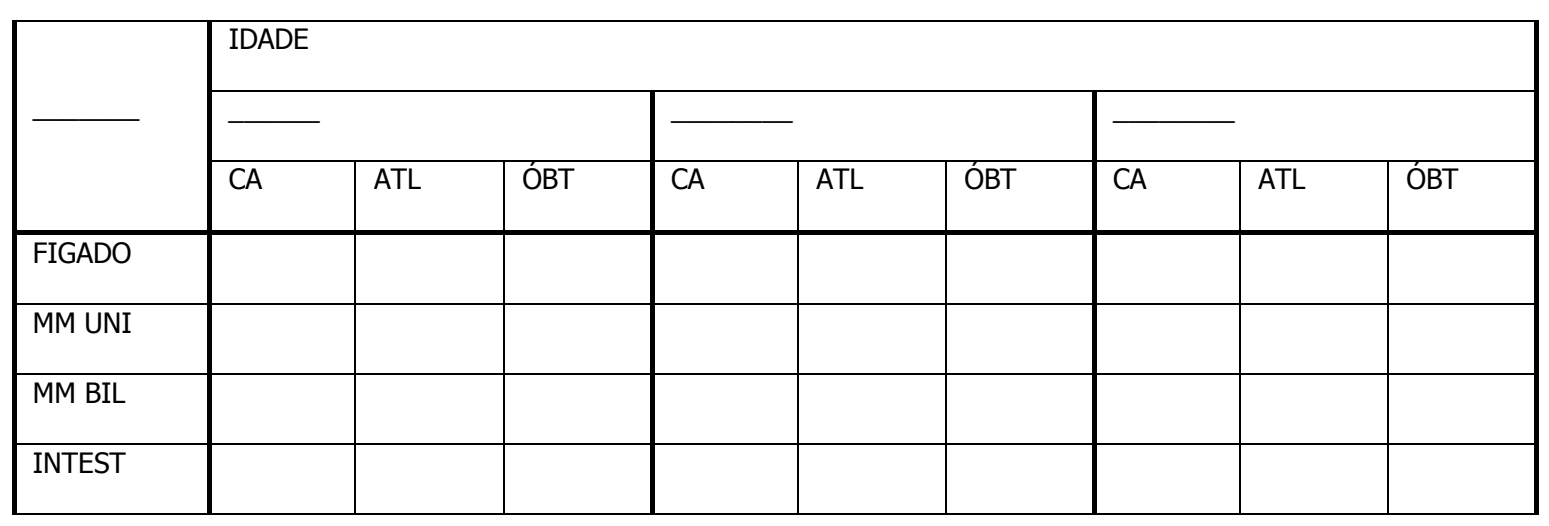

\section{RETORNOS:}




\section{Anexo C - Modelo de laudo de dosagem de IGFBP-3}

\begin{tabular}{|c|c|c|c|}
\hline $\begin{array}{c}\text { INSULIN-LIKE GROWTH } \\
\text { FACTOR BINDING } \\
\text { PROTEIN (IGFBP-3), } \\
\text { soro }\end{array}$ & $\mathrm{mg} / \mathrm{L}$ & Valores de referência & Método \\
\hline & & 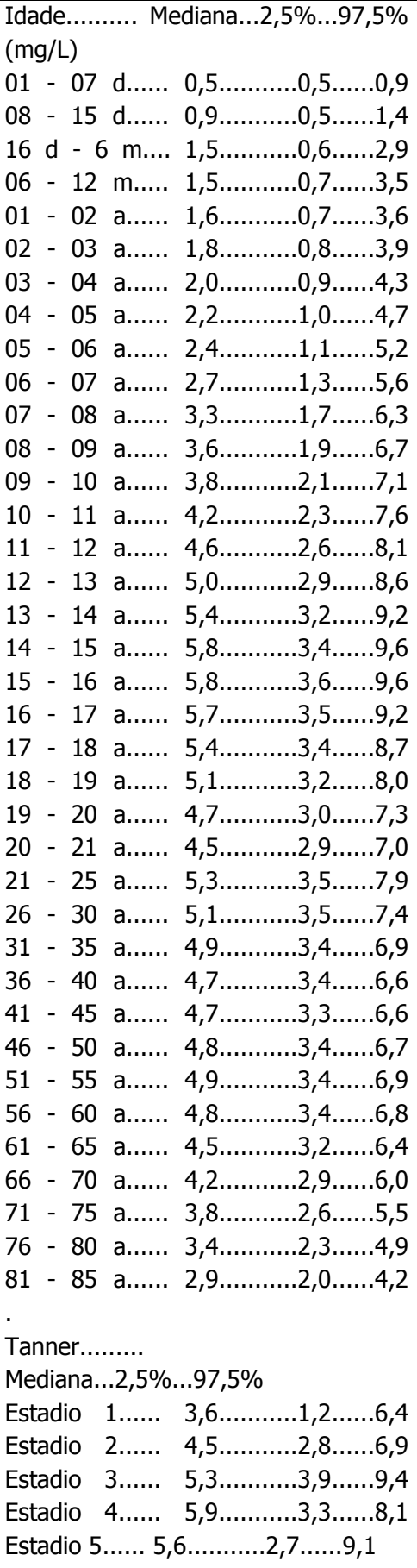 & 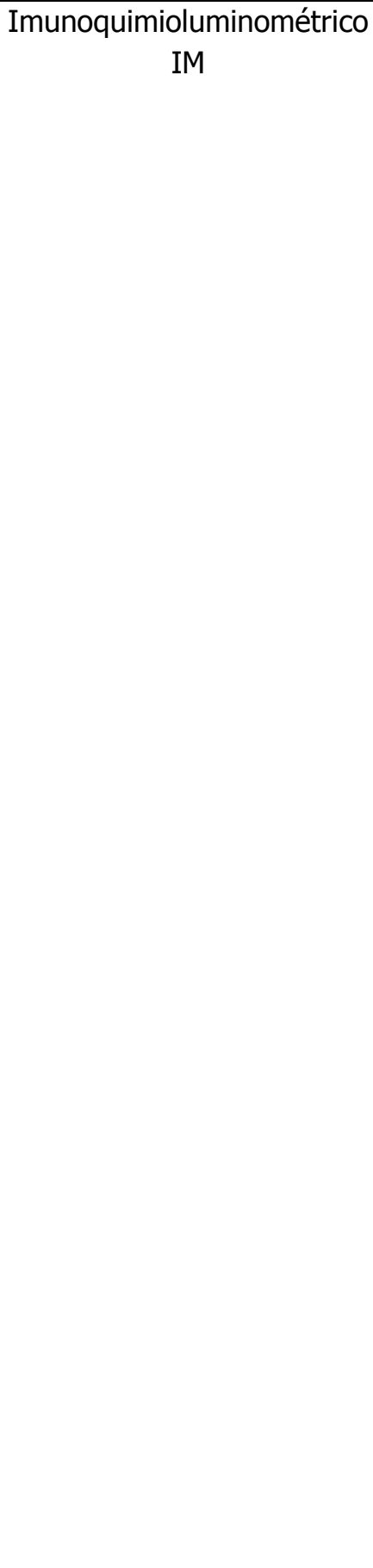 \\
\hline
\end{tabular}




\section{Anexo D - Modelo de laudo de dosagem de IGF-1}

\begin{tabular}{|c|c|c|c|}
\hline $\begin{array}{c}\text { INSULIN-LIKE } \\
\text { GROWTH FACTOR } 1 \\
\text { (IGF-1), soro }\end{array}$ & $\mathrm{ng} / \mathrm{mL}$ & Valores de referência & Método \\
\hline & & 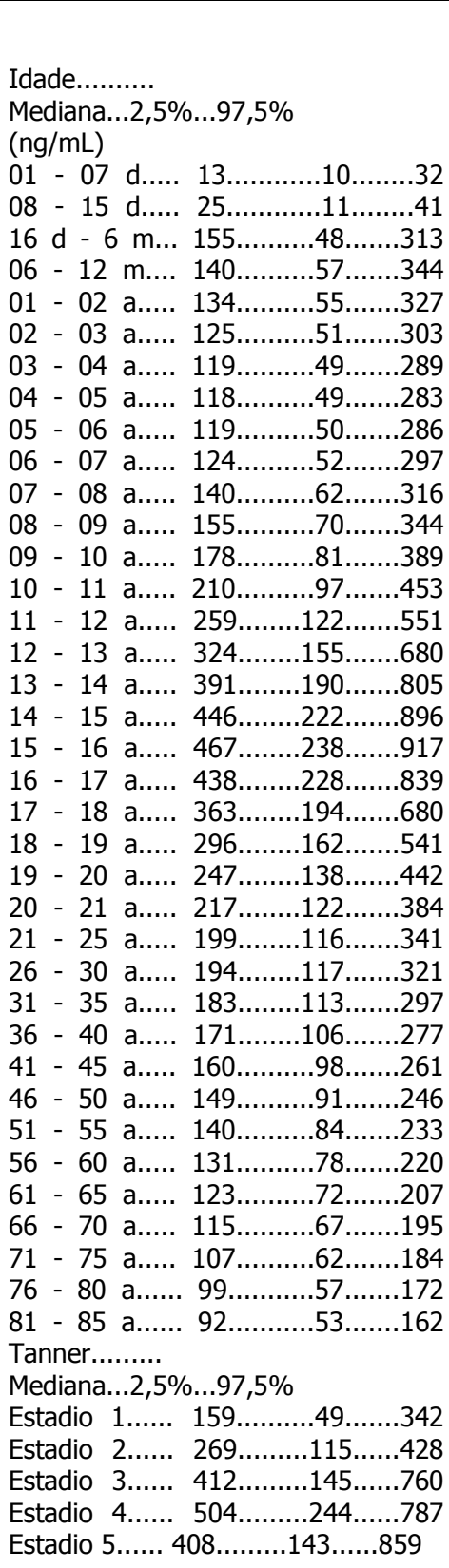 & $\begin{array}{c}\text { Imunoquinioluminométrico } \\
\text { IM }\end{array}$ \\
\hline
\end{tabular}


Anexo E - Casos estudados

- Mulheres com diagnóstico de câncer de mama

\begin{tabular}{|c|c|c|c|c|c|c|c|}
\hline FICHA & $\begin{array}{l}\text { IDADE } \\
\text { (anos) }\end{array}$ & $\begin{array}{l}\text { MENO- } \\
\text { PAUSA }\end{array}$ & $\begin{array}{c}\text { IMC } \\
\left(\mathrm{kg} / \mathrm{m}^{2}\right)\end{array}$ & $\begin{array}{c}\text { IGFBP-3 } \\
(\mathrm{mg} / \mathrm{l})\end{array}$ & \begin{tabular}{|c|} 
MEDIANA \\
$(\mathrm{mg} / \mathrm{l})$
\end{tabular} & $\begin{array}{c}\text { IGF-1 } \\
\text { (ng/ml) }\end{array}$ & $\begin{array}{c}\text { MEDIANA } \\
(\mathrm{ng} / \mathrm{ml})\end{array}$ \\
\hline 1 & 62 & $S$ & 31,6 & 3,5 & 4,5 & 118 & 123 \\
\hline 2 & 60 & $S$ & 23,7 & 4 & 4,8 & 117 & 131 \\
\hline 3 & 29 & $\mathbf{N}$ & 19,9 & 3,7 & 5,1 & 261 & 194 \\
\hline 4 & 64 & $\mathbf{S}$ & 31,6 & 4,4 & 4,5 & 80 & 123 \\
\hline 5 & 56 & 5 & 30,8 & 3,5 & 4,8 & 72 & 131 \\
\hline 6 & 53 & $\mathbf{S}$ & 25,3 & 1,3 & 4,9 & 36 & 140 \\
\hline 7 & 36 & $\mathbf{N}$ & 24,1 & 2,3 & 4,7 & 104 & 171 \\
\hline 8 & 61 & $S$ & 31,2 & 3,3 & 4,5 & 89 & 123 \\
\hline 9 & 35 & $\mathbf{N}$ & 25,3 & 3,4 & 4,9 & 89 & 183 \\
\hline 10 & 70 & $\mathbf{S}$ & 32 & 4 & 4,9 & 79 & 184 \\
\hline 11 & 37 & $\mathbf{N}$ & 15 & 2 & 4,7 & 57 & 171 \\
\hline 12 & 38 & $\mathbf{N}$ & 19,6 & 4,2 & 4,7 & 226 & 171 \\
\hline 13 & 34 & $\mathbf{N}$ & 24,8 & 5 & 4,9 & 260 & 183 \\
\hline 14 & 35 & $\mathbf{N}$ & 23,4 & 4,1 & 4,9 & 338 & 183 \\
\hline 15 & 60 & $\mathbf{S}$ & 27,7 & 2,4 & 4,8 & 120 & 131 \\
\hline 16 & 69 & $S$ & 32,7 & 2,6 & 4,2 & 60 & 115 \\
\hline 17 & 62 & $S$ & 20,1 & 4,9 & 4,5 & 141 & 123 \\
\hline 18 & 46 & $\mathbf{N}$ & 21,5 & 4,5 & 4,8 & 199 & 149 \\
\hline 19 & 51 & $\mathbf{S}$ & 25,5 & 3,9 & 4,9 & 120 & 140 \\
\hline 20 & 63 & $\mathbf{S}$ & 36,7 & 2,6 & 4,5 & 63 & 123 \\
\hline 21 & 53 & $\mathrm{~s}$ & 28,5 & 5,1 & 4,9 & 249 & 140 \\
\hline 22 & 53 & $\mathbf{N}$ & 26,1 & 5,9 & 4,9 & 150 & 140 \\
\hline 23 & 45 & $\mathbf{N}$ & 29 & 3,5 & 4,7 & 163 & 160 \\
\hline 24 & 46 & $\mathbf{N}$ & 27,4 & 3 & 4,8 & 117 & 149 \\
\hline 25 & 49 & $\mathbf{N}$ & 16,4 & 3,9 & 4,8 & 138 & 149 \\
\hline 26 & 40 & $\mathbf{N}$ & 24,8 & 4,8 & 4,7 & 142 & 171 \\
\hline 27 & 30 & $\mathbf{N}$ & 37,1 & 4,3 & 5,1 & 285 & 183 \\
\hline 28 & 67 & $S$ & 22,8 & 4,7 & 4,2 & 165 & 115 \\
\hline 29 & 57 & $S$ & 27,7 & 5 & 4,8 & 82 & 131 \\
\hline 30 & 46 & $\mathbf{N}$ & 28,1 & 3,5 & 4,8 & 105 & 149 \\
\hline 31 & 56 & $S$ & 23,4 & 1,8 & 4,8 & 64 & 149 \\
\hline 32 & 56 & $\mathbf{S}$ & 21,7 & 3,5 & 4,8 & 94 & 131 \\
\hline 33 & 32 & $\mathbf{N}$ & 24,3 & 4,9 & 4,9 & 300 & 183 \\
\hline 34 & 56 & $S$ & 19,5 & 4 & 4,8 & 171 & 131 \\
\hline 35 & 56 & $\mathbf{S}$ & 35,7 & 4 & 4,8 & 95 & 131 \\
\hline 36 & 48 & $\mathbf{N}$ & 27,5 & 3,8 & 4,8 & 251 & 149 \\
\hline 37 & 54 & $S$ & 34,1 & 4,4 & 4,9 & 137 & 140 \\
\hline 38 & 68 & $\mathbf{S}$ & 32,3 & 3,3 & 4,2 & 133 & 115 \\
\hline 39 & 62 & $S$ & 30,5 & 3,9 & 4,5 & 135 & 123 \\
\hline 40 & 68 & S & 23 & 2,7 & 4,2 & 106 & 115 \\
\hline
\end{tabular}




\begin{tabular}{|c|c|c|c|c|c|c|c|} 
FICHA & $\begin{array}{c}\text { IDADE } \\
\text { (anos) }\end{array}$ & $\begin{array}{c}\text { MENO- } \\
\text { PAUSA }\end{array}$ & $\begin{array}{c}\text { IMC } \\
\left(\mathrm{kg} / \mathrm{m}^{2}\right)\end{array}$ & $\begin{array}{c}\text { IGFBP-3 } \\
(\mathrm{mg} / \mathrm{l})\end{array}$ & $\begin{array}{c}\text { MEDIANA } \\
(\mathrm{mg} / \mathrm{l})\end{array}$ & $\begin{array}{c}\text { IGF-1 } \\
(\mathrm{ng} / \mathrm{ml})\end{array}$ & $\begin{array}{c}\text { MEDIANA } \\
(\mathrm{ng} / \mathrm{ml})\end{array}$ \\
\hline 41 & 48 & $\mathrm{~S}$ & 18,4 & 3,8 & 4,8 & 139 & 149 \\
\hline 42 & 61 & $\mathrm{~S}$ & 28,6 & 3,3 & 4,5 & 120 & 123 \\
\hline 43 & 70 & $\mathrm{~S}$ & 27,1 & 3 & 4,2 & 81 & 115 \\
\hline 44 & 62 & $\mathrm{~S}$ & 22,1 & 4,7 & 4,5 & 228 & 123 \\
\hline 45 & 65 & $\mathrm{~S}$ & 30,9 & 4,1 & 4,5 & 115 & 123 \\
\hline 46 & 35 & $\mathrm{~N}$ & 26,9 & 3 & 4,9 & 196 & 183 \\
\hline 47 & 53 & $\mathrm{~S}$ & 40,9 & 2,6 & 4,9 & 62 & 140 \\
\hline 48 & 45 & $\mathrm{~N}$ & 25,3 & 4,1 & 4,7 & 97 & 160 \\
\hline 49 & 34 & $\mathrm{~N}$ & 25,8 & 4,1 & 4,9 & 209 & 183 \\
\hline 50 & 65 & $\mathrm{~S}$ & 26,5 & 3,9 & 4,5 & 114 & 123 \\
\hline 51 & 40 & $\mathrm{~N}$ & 25,7 & 3,7 & 4,7 & 242 & 171 \\
\hline
\end{tabular}

- Mulheres com alto risco para câncer de mama

\begin{tabular}{|c|c|c|c|c|c|c|c|c|c|c|}
\hline FICHA & $\begin{array}{c}\text { IDADE } \\
\text { (anos) }\end{array}$ & $\begin{array}{c}\text { MENO- } \\
\text { PAUSA }\end{array}$ & $\begin{array}{c}\text { IMC } \\
(\mathrm{kg} / \mathrm{ml})\end{array}$ & $\begin{array}{c}\text { ALTO } \\
\text { RISCO }\end{array}$ & GAIL & $\begin{array}{c}\text { TYRER- } \\
\text { CUZICK }\end{array}$ & $\begin{array}{c}\text { IGFBP-3 } \\
\text { (mg/l) }\end{array}$ & $\begin{array}{c}\text { MEDIANA } \\
\text { (mg/l) }\end{array}$ & $\begin{array}{c}\text { IGF-1 } \\
\text { (ng/mI) }\end{array}$ & $\begin{array}{c}\text { MEDIANA } \\
\text { (ng/mI) }\end{array}$ \\
\hline 52 & 51 & N & 24,34 & H & 18,5 & 22,701 & 4,5 & 4,9 & 153 & 140 \\
\hline 53 & 51 & N & 19,05 & F+H & 33,1 & 59,39 & 2,9 & 4,9 & 84 & 140 \\
\hline 54 & 49 & S & 29,64 & F & 10,4 & NC & 4,6 & 4,8 & 158 & 149 \\
\hline 55 & 54 & S & 26,64 & H & 17,7 & 21,381 & 3,1 & 4,9 & 81 & 140 \\
\hline 56 & 51 & N & 25,30 & F & 20,8 & 22,47 & 3,8 & 4,9 & 148 & 140 \\
\hline 57 & 50 & S & 25,15 & H & 16,8 & 29,881 & 5,5 & 4,8 & 300 & 149 \\
\hline 58 & 42 & N & 25,59 & F & 22,4 & 18,76 & 4 & 4,7 & 161 & 160 \\
\hline 59 & 50 & N & 26,06 & H & 15,6 & 21,746 & 3,2 & 4,8 & 144 & 149 \\
\hline 60 & 38 & N & 22,52 & F & 24,7 & 21,76 & 3,9 & 4,7 & 89 & 171 \\
\hline 61 & 48 & N & 24,39 & F & 31,8 & 24,48 & 5,1 & 4,8 & 142 & 149 \\
\hline 62 & 59 & S & 27,99 & F & 27,6 & 14,19 & 4 & 4,8 & 107 & 131 \\
\hline 63 & 52 & N & 21,63 & F & 34 & 21,83 & 5,6 & 4,9 & 247 & 140 \\
\hline 64 & 45 & N & 30,00 & F & 19,9 & 20,65 & 3,3 & 4,7 & 80 & 160 \\
\hline 65 & 46 & N & 22,76 & F & 17,5 & 20,25 & 3,6 & 4,8 & 99 & 149 \\
\hline 66 & 41 & N & 23,86 & H & 12,6 & 25,268 & 4,5 & 4,7 & 167 & 160 \\
\hline 67 & 47 & N & 27,05 & F & 17,1 & 24,48 & 2,9 & 4,8 & 64 & 149 \\
\hline 68 & 28 & N & 25,88 & F & 20 & 22,561 & 3,2 & 5,1 & 120 & 194 \\
\hline 69 & 49 & N & 26,22 & H & 21 & 23,192 & 3,3 & 4,8 & 97 & 149 \\
\hline 70 & 23 & N & 16,53 & F & 20 & 31,935 & 4,8 & 5,3 & 286 & 199 \\
\hline 71 & 47 & N & 24,46 & H & 18,1 & 26,832 & 4 & 4,8 & 139 & 149 \\
\hline 72 & 47 & N & 23,71 & F & 26 & 29,18 & 3,6 & 4,8 & 178 & 149 \\
\hline 73 & 31 & N & 37,25 & F & 21,7 & 23,423 & 3,4 & 4,9 & 234 & 183 \\
\hline 74 & 51 & N & 28,73 & F & 17,9 & 20,63 & 2,9 & 4,9 & 63 & 140 \\
\hline 75 & 49 & N & 28,52 & F & 25,7 & 17,672 & 4,5 & 4,8 & 100 & 149 \\
\hline 76 & 50 & N & 33,06 & H & 28,6 & 37,827 & 4 & 4,8 & 56 & 149 \\
\hline
\end{tabular}




\begin{tabular}{|c|c|c|c|c|c|c|c|c|c|c|}
\hline FICHA & $\begin{array}{l}\text { IDADE } \\
\text { (anos) }\end{array}$ & $\begin{array}{l}\text { MENO- } \\
\text { PAUSA }\end{array}$ & $\underset{\left(\mathrm{kg} / \mathrm{m}^{2}\right)}{I M C}$ & $\begin{array}{c}\text { ALTO } \\
\text { RISCO }\end{array}$ & GAIL & $\begin{array}{l}\text { TYRER } \\
\text { CUZICK }\end{array}$ & $\begin{array}{l}\text { IGFBP-3 } \\
\text { (mg/l) }\end{array}$ & $\begin{array}{c}\text { MEDIANA } \\
(\mathrm{mg} / \mathrm{l})\end{array}$ & $\begin{array}{c}\text { IGF-1 } \\
\text { (ng/ml) }\end{array}$ & $\begin{array}{c}\text { MEDIANA } \\
(\mathrm{ng} / \mathrm{ml})\end{array}$ \\
\hline 77 & 43 & $\mathbf{N}$ & 23,59 & $\mathbf{H}$ & 17,5 & 29,07 & 3,9 & 4,7 & 167 & 160 \\
\hline 78 & 21 & $\mathbf{N}$ & 19,14 & $\mathbf{F}$ & 12,9 & 21,654 & 3,3 & 4,5 & 163 & 199 \\
\hline 79 & 51 & $\mathbf{N}$ & 29,72 & $\mathbf{F}$ & 19,5 & 22,011 & 2,8 & 4,9 & 76 & 140 \\
\hline 80 & 49 & $S$ & 35,60 & $\mathbf{F}$ & 24,2 & 14,947 & 1,9 & 4,8 & 64 & 149 \\
\hline 81 & 46 & $\mathbf{N}$ & 26,81 & $\mathbf{F}$ & 34,3 & 23,33 & 5,1 & 4,8 & 131 & 149 \\
\hline 82 & 47 & $\mathbf{N}$ & 22,77 & $\mathrm{H}$ & 12,4 & 28,626 & 3 & 4,8 & 116 & 149 \\
\hline 83 & 44 & $\mathbf{N}$ & 25,39 & $\mathbf{H}$ & 38,4 & 31,25 & 4,7 & 4,7 & 193 & 160 \\
\hline 84 & 58 & $S$ & 23,83 & $\mathrm{~F}+\mathrm{H}$ & 23 & 16,835 & 3,4 & 4,8 & 66 & 131 \\
\hline 85 & 39 & $\mathbf{N}$ & 23,05 & $\mathbf{F}$ & 21,3 & 24,998 & 4,4 & 4,7 & 282 & 171 \\
\hline 86 & 45 & $\mathbf{N}$ & 28,96 & $\mathrm{H}$ & 17,7 & 24,205 & 3,7 & 4,7 & 149 & 160 \\
\hline 87 & 52 & $\mathbf{N}$ & 27,06 & $\mathrm{H}$ & 19 & 38,936 & 4,1 & 4,9 & 220 & 140 \\
\hline 88 & 22 & $\mathbf{N}$ & 31,23 & $\mathbf{F}$ & 21,7 & 26,465 & 5,6 & 5,3 & 227 & 199 \\
\hline 89 & 36 & $\mathbf{N}$ & 22,83 & $\mathbf{F}$ & 11,3 & 25,196 & 3,8 & 4,7 & 170 & 171 \\
\hline 90 & 53 & $S$ & 20,32 & $\mathbf{H}$ & 18,7 & 20,523 & 3,2 & 4,9 & 77 & 140 \\
\hline 91 & 53 & $S$ & 28,35 & $\mathbf{F}$ & 39,2 & 12,16 & 5 & 4,9 & 77 & 140 \\
\hline 92 & 49 & $S$ & 21,26 & $\mathrm{H}$ & 21,9 & 26,486 & 2,6 & 4,8 & 43 & 149 \\
\hline 93 & 38 & $\mathbf{N}$ & 23,63 & $\mathbf{F}$ & 12,3 & 21,027 & 3,9 & 4,7 & 133 & 171 \\
\hline 94 & 54 & $\mathrm{~S}$ & 21,40 & $\mathbf{H}$ & 47,4 & 23,443 & 4,2 & 4,9 & 184 & 140 \\
\hline 95 & 47 & $\mathbf{N}$ & 22,94 & $\mathrm{~F}+\mathrm{H}$ & 23,4 & 47,642 & 4,1 & 4,8 & 200 & 149 \\
\hline 96 & 46 & $\mathbf{N}$ & 35,88 & $\mathbf{F}$ & 23,2 & 16,468 & 3,8 & 4,8 & 105 & 149 \\
\hline 97 & 47 & $\mathbf{N}$ & 29,33 & $\mathbf{F}$ & 13,8 & 24,005 & 3,2 & 4,8 & 127 & 149 \\
\hline 98 & 50 & $\mathbf{N}$ & 30,38 & $\mathbf{F}$ & 31,4 & 26,781 & 4,4 & 4,8 & 205 & 149 \\
\hline 99 & 57 & $S$ & 35,56 & $\mathrm{H}$ & 20,7 & 23,527 & 4,8 & 4,8 & 123 & 131 \\
\hline 100 & 21 & $\mathbf{N}$ & 20,42 & $\mathrm{H}$ & 27,7 & 44,65 & 4,2 & 5,3 & 277 & 217 \\
\hline 101 & 47 & $\mathbf{N}$ & 27,39 & $\mathbf{H}$ & 16,8 & 23,218 & 4,1 & 4,8 & 183 & 149 \\
\hline 102 & 54 & $\mathbf{N}$ & 24,39 & $\mathbf{H}$ & 22,3 & 31,764 & 3,7 & 4,9 & 103 & 140 \\
\hline 103 & 46 & $\mathbf{N}$ & 24,01 & H & 19,1 & 20,609 & 4,3 & 4,8 & 159 & 149 \\
\hline 104 & 40 & $\mathbf{N}$ & 24,44 & $\mathrm{~F}+\mathrm{H}$ & 20 & 42,749 & 3,5 & 4,7 & 86 & 160 \\
\hline 105 & 45 & $\mathbf{N}$ & 35,76 & $\mathbf{F}$ & 13,6 & 36,716 & 3,1 & 4,7 & 88 & 160 \\
\hline 106 & 34 & $\mathbf{N}$ & 28,72 & $\mathbf{F}$ & 18,9 & 35,843 & 4,1 & 4,9 & 140 & 183 \\
\hline 107 & 46 & $\mathbf{N}$ & 23,44 & $\mathrm{H}$ & 17,1 & 56,696 & 4,6 & 4,8 & 116 & 149 \\
\hline 108 & 49 & $\mathbf{N}$ & 27,24 & $\mathbf{F}$ & 18 & 23,923 & 4,8 & 4,8 & 175 & 149 \\
\hline 109 & 50 & $\mathbf{N}$ & 22,86 & $\mathrm{~F}+\mathrm{H}$ & 21 & 31,01 & 5,5 & 4,8 & 196 & 149 \\
\hline 110 & 34 & $\mathbf{N}$ & 24,03 & $\mathbf{F}$ & 21,6 & 22,061 & 4 & 4,9 & 314 & 183 \\
\hline 111 & 40 & $\mathbf{N}$ & 27,01 & $\mathbf{F}$ & 34,1 & 25,957 & 4,5 & 4,7 & 176 & 171 \\
\hline 112 & 51 & $\mathbf{N}$ & 30,43 & $\mathrm{~F}+\mathrm{H}$ & 49,7 & 31,868 & 3,9 & 4,9 & 142 & 140 \\
\hline 113 & 37 & $\mathbf{N}$ & 22,27 & $\mathbf{F}$ & 17,2 & 22,943 & 4 & 4,7 & 230 & 171 \\
\hline 114 & 54 & $S$ & 26,77 & $\mathrm{H}$ & 5,4 & 24,69 & 4,1 & 4,9 & 110 & 140 \\
\hline 115 & 50 & $\mathbf{N}$ & 26,40 & $\mathbf{F}$ & 25,4 & 23,12 & 5,2 & 4,8 & 178 & 149 \\
\hline 116 & 48 & $\mathbf{N}$ & 21,36 & $\mathrm{H}$ & 29,5 & 34,403 & 5,2 & 4,8 & 144 & 149 \\
\hline 117 & 24 & $\mathbf{N}$ & 19,38 & $\mathbf{F}$ & 15,1 & 21,93 & 3,1 & 5,3 & 170 & 199 \\
\hline 118 & 52 & $S$ & 30,10 & $\mathrm{H}$ & 15,7 & 32,388 & 4,1 & 4,9 & 145 & 140 \\
\hline 119 & 47 & $\mathbf{N}$ & 28,34 & $\mathbf{H}$ & 4,6 & 25,574 & 3,1 & 4,8 & 67 & 149 \\
\hline
\end{tabular}




\begin{tabular}{|c|c|c|c|c|c|c|c|c|c|c|}
\hline FICHA & $\begin{array}{l}\text { IDADE } \\
\text { (anos) }\end{array}$ & $\begin{array}{l}\text { MENO- } \\
\text { PAUSA }\end{array}$ & $\underset{\left(\mathrm{kg} / \mathrm{m}^{2}\right)}{I M C}$ & $\begin{array}{c}\text { ALTO } \\
\text { RISCO }\end{array}$ & GAIL & $\begin{array}{l}\text { TYRER } \\
\text { CUZICK }\end{array}$ & $\begin{array}{l}\text { IGFBP-3 } \\
\text { (mg/l) }\end{array}$ & $\begin{array}{c}\text { MEDIANA } \\
(\mathrm{mg} / \mathrm{l})\end{array}$ & $\begin{array}{c}\text { IGF-1 } \\
\text { (ng/ml) }\end{array}$ & $\begin{array}{c}\text { MEDIANA } \\
\text { (ng/ml) }\end{array}$ \\
\hline 120 & 41 & $\mathbf{N}$ & 22,77 & $\mathbf{H}$ & 6,3 & 29,041 & 4,5 & 4,7 & 227 & 160 \\
\hline 121 & 53 & $\mathbf{N}$ & 35,25 & $\mathbf{F}$ & 39,2 & 23,538 & 3,9 & 4,9 & 175 & 140 \\
\hline 122 & 56 & $\mathbf{S}$ & 22,21 & $\mathbf{F}$ & 23 & 20,272 & 3,9 & 4,8 & 151 & 131 \\
\hline 123 & 44 & $\mathbf{N}$ & 23,24 & $\mathbf{H}$ & 21,6 & 24,828 & 3,9 & 4,7 & 226 & 160 \\
\hline 124 & 52 & $\mathbf{N}$ & 22,04 & $\mathrm{H}$ & 26,9 & 60,6 & 2,8 & 4,9 & 91 & 140 \\
\hline 125 & 54 & $S$ & 31,63 & $\mathbf{F}$ & 31,2 & 15,455 & 4,2 & 4,9 & 125 & 140 \\
\hline 126 & 47 & $\mathbf{N}$ & 32,00 & $\mathrm{H}$ & 13,1 & 23,914 & 3,3 & 4,8 & 138 & 149 \\
\hline 127 & 59 & $\mathbf{S}$ & 34,13 & $\mathbf{F}$ & 19,1 & 28,61 & 3,2 & 4,8 & 71 & 131 \\
\hline 128 & 51 & $S$ & 28,13 & $\mathrm{~F}+\mathrm{H}$ & 10,7 & 23,966 & 4 & 4,9 & 92 & 140 \\
\hline 129 & 53 & $S$ & 32,87 & $\mathbf{H}$ & 14,1 & 35,527 & 4,5 & 4,9 & 157 & 140 \\
\hline 130 & 59 & $\mathbf{S}$ & 20,81 & $\mathbf{F}$ & 30,4 & 11,995 & 3,1 & 4,8 & 97 & 131 \\
\hline 131 & 35 & $\mathbf{N}$ & 19,10 & $\mathbf{F}$ & 10,8 & 20,05 & 4 & 4,9 & 186 & 183 \\
\hline 132 & 60 & $\mathbf{S}$ & 26,84 & $\mathbf{F}$ & 22,5 & 13,614 & 3,1 & 4,8 & 146 & 131 \\
\hline 133 & 26 & $\mathbf{N}$ & 17,26 & $\mathbf{F}$ & 27,8 & 24,735 & 3,6 & 5,1 & 153 & 194 \\
\hline 134 & 53 & $\mathbf{S}$ & 24,46 & $\mathbf{H}$ & 7,7 & 23,809 & 5,4 & 4,9 & 118 & 140 \\
\hline 135 & 60 & $S$ & 21,09 & $\mathrm{~F}+\mathrm{H}$ & 37,1 & 34,849 & 3,8 & 4,8 & 170 & 131 \\
\hline 136 & 58 & $S$ & 24,84 & $\mathbf{F}$ & 29,1 & 11,833 & 3,6 & 4,8 & 190 & 131 \\
\hline 137 & 52 & $\mathbf{N}$ & 26,16 & $\mathbf{F}$ & 43,6 & 16,858 & 3,6 & 4,9 & 121 & 140 \\
\hline 138 & 50 & $\mathbf{N}$ & 21,72 & $\mathrm{H}$ & 20 & 22,113 & 2,8 & 4,8 & 128 & 149 \\
\hline 139 & 51 & $\mathbf{S}$ & 30,85 & $\mathbf{F}$ & 17,8 & 30,526 & 3,5 & 4,9 & 137 & 140 \\
\hline 140 & 51 & $S$ & 21,71 & $\mathbf{F}$ & 22,8 & 10,656 & 3 & 4,9 & 81 & 140 \\
\hline 141 & 60 & $S$ & 31,53 & $\mathrm{H}$ & 20,2 & 23,586 & 2,7 & 4,8 & 70 & 131 \\
\hline 142 & 53 & $\mathbf{N}$ & 22,94 & $\mathbf{F}$ & 12,1 & NC & 5,2 & 4,9 & 160 & 140 \\
\hline 143 & 43 & $\mathbf{N}$ & 27,60 & $\mathbf{F}$ & 31,2 & 25,148 & 4,4 & 4,7 & 130 & 160 \\
\hline 144 & 32 & $\mathbf{N}$ & 22,21 & $\mathbf{F}$ & 18,4 & 33,468 & 4 & 4,9 & 198 & 183 \\
\hline 145 & 53 & $S$ & 23,63 & $\mathrm{~F}+\mathrm{H}$ & 39,9 & 40,686 & 2,8 & 4,9 & 92 & 140 \\
\hline 146 & 41 & $\mathbf{N}$ & 31,25 & $\mathbf{F}$ & 10,9 & 23,12 & 4,1 & 4,7 & 246 & 160 \\
\hline 147 & 47 & $\mathbf{N}$ & 24,24 & $\mathrm{H}$ & 18,6 & 22,727 & 5 & 4,8 & 122 & 149 \\
\hline 148 & 28 & $\mathbf{N}$ & 18,38 & $\mathbf{F}$ & 23,7 & 18,321 & 4,6 & 5,1 & 206 & 194 \\
\hline 149 & 47 & $\mathbf{N}$ & 27,68 & $\mathbf{F}$ & 20,1 & 24,326 & 2,2 & 4,8 & 150 & 149 \\
\hline 150 & 55 & $S$ & 24,45 & $\mathrm{H}$ & 29 & 21,648 & 4 & 4,9 & 92 & 140 \\
\hline 151 & 33 & $\mathbf{N}$ & 27,55 & $\mathbf{F}$ & 41,5 & 26,401 & 4,3 & 4,9 & 229 & 183 \\
\hline 152 & 38 & $\mathbf{N}$ & 22,22 & $\mathbf{F}$ & 24 & 17,348 & 4,1 & 4,7 & 174 & 171 \\
\hline 153 & 45 & $\mathbf{N}$ & 22,52 & $F$ & 21,5 & 32,26 & 4,2 & 4,7 & 182 & 160 \\
\hline 154 & 42 & $\mathbf{N}$ & 22,77 & $\mathbf{H}$ & 24,5 & 32,69 & 3,1 & 4,7 & 188 & 160 \\
\hline 155 & 36 & $\mathbf{N}$ & 24,44 & $\mathbf{F}$ & 19,8 & 41,019 & 4,8 & 4,7 & 223 & 171 \\
\hline 156 & 39 & $\mathbf{N}$ & 27,27 & $\mathbf{F}$ & 18,1 & 32,816 & 4,5 & 4,7 & 113 & 171 \\
\hline 157 & 47 & $\mathbf{N}$ & 25,89 & $\mathbf{F}$ & 10 & 21,553 & 4,3 & 4,8 & 92 & 149 \\
\hline 158 & 31 & $\mathbf{N}$ & 24,88 & $F$ & 19,5 & 37,519 & 3 & 4,9 & 145 & 183 \\
\hline 159 & 49 & $\mathbf{N}$ & 21,17 & F & 38,2 & 22,372 & 4,3 & 4,8 & 219 & 149 \\
\hline
\end{tabular}


- População controle

\begin{tabular}{|c|c|c|c|c|c|c|c|}
\hline FICHA & $\begin{array}{l}\text { IDADE } \\
\text { (anos) }\end{array}$ & $\begin{array}{l}\text { MENO- } \\
\text { PAUSA }\end{array}$ & $\begin{array}{c}\text { IMC } \\
\left(\mathrm{kg} / \mathrm{m}^{2}\right)\end{array}$ & $\begin{array}{c}\text { IGFBP-3 } \\
(\mathrm{mg} / \mathrm{l})\end{array}$ & $\begin{array}{c}\text { MEDIANA } \\
(\mathrm{mg} / \mathrm{l})\end{array}$ & $\begin{array}{c}\text { IGF-1 } \\
\text { (ng/ml) }\end{array}$ & $\begin{array}{c}\text { MEDIANA } \\
\text { (ng/ml) }\end{array}$ \\
\hline 160 & 48 & $\mathbf{N}$ & 24,44 & 3,7 & 4,8 & 80 & 149 \\
\hline 161 & 59 & $\mathrm{~S}$ & 25,57 & 3,6 & 4,8 & 137 & 131 \\
\hline 162 & 55 & $\mathrm{~S}$ & 29,64 & 4,8 & 4,8 & 115 & 131 \\
\hline 163 & 43 & $\mathbf{N}$ & 32,46 & 4,7 & 4,7 & 130 & 160 \\
\hline 164 & 64 & $\mathbf{S}$ & 23,95 & 3,4 & 4,2 & 97 & 115 \\
\hline 165 & 58 & $S$ & 21,45 & 4 & 4,8 & 83 & 131 \\
\hline 166 & 51 & $S$ & 22,94 & 3,7 & 4,9 & 109 & 140 \\
\hline 167 & 41 & $\mathbf{N}$ & 29,03 & 3,3 & 4,7 & 73 & 160 \\
\hline 168 & 48 & $\mathbf{N}$ & 27,89 & 5,3 & 4,8 & 264 & 149 \\
\hline 169 & 65 & $\mathbf{S}$ & 33,3 & 4,6 & 4,5 & 155 & 123 \\
\hline 170 & 49 & $\mathbf{N}$ & 22,96 & 5,3 & 4,8 & 129 & 149 \\
\hline 171 & 49 & $\mathbf{N}$ & 25 & 5,1 & 4,8 & 152 & 149 \\
\hline 172 & 44 & $\mathbf{N}$ & 21,26 & 2,6 & 4,7 & 99 & 160 \\
\hline 173 & 51 & $\mathbf{N}$ & 26,22 & 3,6 & 4,9 & 82 & 140 \\
\hline 174 & 45 & $\mathbf{N}$ & 19,1 & 4,3 & 4,7 & 162 & 160 \\
\hline 175 & 59 & $S$ & 26,93 & 2,7 & 4,8 & 118 & 131 \\
\hline 176 & 51 & $S$ & 24,98 & 3,9 & 4,9 & 131 & 140 \\
\hline 177 & 47 & $\mathbf{N}$ & 23,53 & 3,1 & 4,8 & 94 & 149 \\
\hline 178 & 38 & $\mathbf{N}$ & 24,65 & 3,4 & 4,7 & 113 & 171 \\
\hline 179 & 57 & $S$ & 33,75 & 4,4 & 4,8 & 86 & 131 \\
\hline 180 & 48 & $\mathbf{N}$ & 30,85 & 5,3 & 4,8 & 190 & 149 \\
\hline 181 & 66 & $S$ & 25,28 & 4 & 4,2 & 92 & 115 \\
\hline 182 & 44 & $\mathbf{N}$ & 31,11 & 5,5 & 4,7 & 211 & 160 \\
\hline 183 & 33 & $\mathbf{N}$ & 20,5 & 2,9 & 4,9 & 155 & 183 \\
\hline 184 & 46 & $\mathbf{N}$ & 29,32 & 2,7 & 4,8 & 69 & 149 \\
\hline 185 & 70 & $\mathrm{~S}$ & 29,73 & 3,3 & 4,2 & 58 & 115 \\
\hline 186 & 54 & $S$ & 25,96 & 4,8 & 4,9 & 245 & 140 \\
\hline 187 & 46 & $\mathbf{N}$ & 33,32 & 4,5 & 4,8 & 90 & 149 \\
\hline 188 & 48 & $\mathbf{N}$ & 25,24 & 4,8 & 4,8 & 86 & 149 \\
\hline 189 & 70 & $S$ & 26,67 & 3,2 & 4,2 & 2,9 & 6 \\
\hline 190 & 48 & $\mathbf{N}$ & 24,61 & 4,8 & 4,8 & 225 & 149 \\
\hline 191 & 42 & $\mathbf{N}$ & 18,13 & 4,8 & 4,7 & 204 & 160 \\
\hline 192 & 54 & $S$ & 25,64 & 5,4 & 4,9 & 152 & 140 \\
\hline 193 & 63 & $\mathbf{S}$ & 29,38 & 2,2 & 4,5 & 117 & 123 \\
\hline 194 & 42 & $\mathbf{N}$ & 28,76 & 3,9 & 4,7 & 161 & 160 \\
\hline 195 & 45 & $\mathbf{N}$ & 22,86 & 4 & 4,7 & 86 & 160 \\
\hline 196 & 51 & $\mathbf{S}$ & 27,56 & 3,6 & 4,9 & 72 & 140 \\
\hline 197 & 41 & $\mathbf{N}$ & 24,34 & 3,6 & 4,7 & 178 & 160 \\
\hline 198 & 48 & $\mathbf{N}$ & 19,23 & 3,6 & 4,8 & 134 & 149 \\
\hline 199 & 52 & $\mathbf{N}$ & 29,72 & 3,5 & 4,9 & 54 & 140 \\
\hline 200 & 56 & $\mathbf{S}$ & 31,11 & 2,8 & 4,8 & 61 & 131 \\
\hline 201 & 48 & $\mathbf{N}$ & 28,4 & 2 & 4,8 & 51 & 149 \\
\hline
\end{tabular}




\begin{tabular}{|c|c|c|c|c|c|c|c|}
\hline FICHA & $\begin{array}{l}\text { IDADE } \\
\text { (anos) }\end{array}$ & $\begin{array}{l}\text { MENO- } \\
\text { PAUSA }\end{array}$ & $\underset{\left(\mathrm{kg} / \mathrm{m}^{2}\right)}{\operatorname{IMC}}$ & $\begin{array}{c}\text { IGFBP-3 } \\
(\mathrm{mg} / \mathrm{l})\end{array}$ & \begin{tabular}{|c} 
MEDIANA \\
$(\mathrm{mg} / \mathrm{l})$
\end{tabular} & $\begin{array}{c}\text { IGF-1 } \\
\text { (ng/ml) }\end{array}$ & $\begin{array}{c}\text { MEDIANA } \\
\text { (ng/ml) }\end{array}$ \\
\hline 202 & 53 & $\mathbf{N}$ & 35,34 & 4,9 & 4,9 & 176 & 140 \\
\hline 203 & 59 & $\mathbf{S}$ & 31,14 & 3,4 & 4,8 & 104 & 131 \\
\hline 204 & 60 & $S$ & 30,13 & 3,2 & 4,8 & 133 & 131 \\
\hline 205 & 59 & $S$ & 26,91 & 4,5 & 4,8 & 156 & 131 \\
\hline 206 & 41 & $\mathbf{N}$ & 22,66 & 3,7 & 4,7 & 196 & 160 \\
\hline 207 & 49 & $S$ & 22,76 & 3,9 & 4,8 & 112 & 149 \\
\hline 208 & 27 & $\mathbf{N}$ & 22,94 & 3,9 & 5,1 & 209 & 194 \\
\hline 209 & 43 & $\mathbf{N}$ & 18,97 & 3,4 & 4,7 & 155 & 160 \\
\hline 210 & 54 & $S$ & 22,15 & 3,1 & 4,9 & 121 & 140 \\
\hline 211 & 60 & $S$ & 29,71 & 4 & 4,8 & 131 & 131 \\
\hline 212 & 56 & $S$ & 30,86 & 2,9 & 4,8 & 81 & 131 \\
\hline 213 & 51 & S & 25,78 & 4,5 & 4,9 & 143 & 140 \\
\hline 214 & 62 & $S$ & 28,33 & 2,9 & 4,5 & 96 & 123 \\
\hline 215 & 45 & $\mathbf{N}$ & 20,7 & 3,4 & 4,7 & 123 & 160 \\
\hline 216 & 56 & $\mathbf{S}$ & 25,39 & 3,4 & 4,8 & 139 & 131 \\
\hline 217 & 37 & $\mathbf{N}$ & 29,71 & 4,9 & 4,7 & 330 & 171 \\
\hline 218 & 54 & $\mathrm{~S}$ & 24,24 & 4,5 & 4,9 & 174 & 140 \\
\hline 219 & 47 & $\mathbf{N}$ & 24,45 & 3,3 & 4,8 & 105 & 149 \\
\hline 220 & 47 & $\mathbf{N}$ & 25,81 & 3,1 & 4,8 & 103 & 149 \\
\hline 221 & 58 & $\mathbf{S}$ & 23,74 & 3,9 & 4,8 & 170 & 131 \\
\hline 222 & 50 & $\mathbf{N}$ & 29,43 & 3,1 & 4,8 & 71 & 149 \\
\hline 223 & 28 & $\mathbf{N}$ & 20,81 & 4,4 & 5,1 & 174 & 194 \\
\hline 224 & 38 & $\mathbf{N}$ & 33,79 & 4 & 4,7 & 122 & 171 \\
\hline 225 & 46 & $\mathbf{N}$ & 33,53 & 3,5 & 4,8 & 96 & 149 \\
\hline
\end{tabular}


8. REFERÊNCIAS 


\section{REFERÊNCIAS}

1. Brasil - Instituto Nacional do Câncer (INCA). Incidência de câncer no Brasil - Estimativa 2008 [on line]. Brasília: Ministério da Saúde; 2008.

$\begin{array}{lll}\text { Disponível em abr/2008: } & \text { em }\end{array}$ www.inca.gov.br/estimativa/2008/index.asp?link=conteudo view.asp\&ID=

2. Estados Unidos da América - National Cancer Institute (NCl). Breast cancer home page [on line]. Disponível em abr/2008: www.cancer.gov/cancertopics/types/breast

3. Estados Unidos da América - National Cancer Institute (NCl). Probability of breast cancer in American women [on line]. Disponível em abr/2008:

www.cancer.gov/cancertopics/factsheet/Detection/probability-breast-cancer

4. Bradbury AR, Olopade OI. Genetic susceptibility to breast cancer. Rev Endocr Metab Disord. 2007;8:255-267.

5. Thompson d, Easton D. The genetic epidemiology of breast cancer genes. J Mammary Gland Biol Neoplasia. 2004;9:221-36. 
6. De Grève J, Sermijn E, Brakeleer SD, et al. Hereditary breast cancer: from bench to bedside. Cur Opin Oncol. 2008;20:605-13.

7. Allain DC. Genetic counseling and testing for common hereditary breast cancer syndromes. J Mol Diagn. 2008;10(5):383-95.

8. Schwartz GF, Hughes KS, Lynch HT, et al. Proceedings of international consensus conference on breast cancer risk, genetics, \& risk management, April, 2007. Breast J. 2009;15(1):4-16.

9. Offit K, Bertagnolli MM, Bombard AT, et al. American Society of Clinical Oncology policy statement update: genetic testing for cancer susceptibility. J Clin Oncol. 2003;21:2397-406.

10. Estados Unidos da América - National Cancer Institute (NCI). Genetics of breast and ovarian cancer [on line]. Disponível em abr/2008: www.cancer.gov/cancertopics/pdq/genetics/breast-andovarian/HealthProfessional/page2 
11. Amir E, Evans DG, Shenton A, et al. Evaluations of breast cancer risk assessment packages in the family history evaluation and screening programme. J Med Genet. 2003;40(11):807-14.

12. Alberts DS, Hess LM. Fundamental of cancer prevention. In: Thompson PA. Breast Cancer Prevention. Springer Berlin Heidelberg New York; 2005.271

13. Weigelt B, Peterse JL, van't Veer LJ. Breast cancer metastasis: markers and models. Nat Rev Cancer. 2005:5:591-602.

14. Arpino G, Laucinica R, Elledge RM. Premalignant and in situ breast disease: biology and clinical implications. Ann Intern Med. 2005;143:44657.

15. Rosen PP. Precancerous breast disease: epidemiological, pathological, and clinical considerations. In: Rosen PP et al. Rosen's Breast Pathology. Lippincott Williams et Wilkins. 2009;264-84. 
16. Hartmann LC, Sellers TA, Frost MH, et al. Benign breast disease and risk of breast cancer. N Engl J Med. 2005;353:229-37.

17.Schrading S, Kuhl CK. Mammographic, US, and MR imaging phenotypes of familial breast cancer. Radiology. 2008;246(1):58-70.

18. Hartman AR, Daniel BL, Kurian AW, et al. Breast magnetic resonance image screening and ductal lavage in women at high genetic risk for breast carcinoma. Cancer. 2004;100(3):479-89.

19. Estados Unidos da América - National Comprehensive Cancer Network (NCCN). Genetic/familial high risk assessment: breast and ovarian. Practice guidelines in oncology - v1. 2009 [on line]. Disponível em abr/2008:

www.nccn.org/professionals/physician gls/PDF/genetics screening.pdf

20. Rebbeck TR, Friebel T, Lynch HT, et al. Bilateral prophylactic mastectomy reduces breast cancer risk in BRCA1 and BRCA2 mutation carriers: the PROSE Study Group. J Clin Oncol. 2004;22:1055-62. 
21. Rebbeck TR, Friebel T, Wagner T, et al. Effect of short-term hormone replacement therapy on breast cancer risk reduction after bilateral prophylactic oophorectomy in BRCA1 and BRCA2 mutation carries: the PROSE Study Group. J Clin Oncol. 2005;23:7804-10.

22. Duffy SW, Nixon RM. Estimates of likely prophylactic effect of tamoxifen in women with high risk BRCA1 and BRCA2 mutations. Br J Cancer. 2002;86(2):218-21.

23. Gronwald J, Tung N, Foulkes WD, et al. Tamoxifen and contralateral breast cancer in BRCA1 and BRCA2 carriers: an update. Int $J$ Cancer. 2006;118: 2281-4.

24. Foulkes WD, Goffin J, Brunet JS, et al. Tamoxifen may be an effective adjuvant treatment for BRCA1 - related breast cancer irrespective of estrogen receptor status. J Nacl Cancer Inst. 2002;94(19):1504-06.

25. Jenkins VA, Ambroisine LM, Atkins L, et al. Effects of anastrozole on cognitive performance in postmenopausal women: a randomized, doubleblind chemoprevention trial (IBIS II). Lancet Oncol. 2008;9(10):953-61. 
26. Richardson H, Johnston D, Pater J, et al. The National Cancer Institute of Canada Clinical Trials Group MAP.3 trial: an international breast cancer prevention trial. Curr Oncol. 2007;14(3):89-96.

27. Marshman E, Streuli $\mathrm{CH}$. Insulin-like growth factors and insulin-like growth factor binding proteins in mammary gland fuction. Breast Cancer Res. 2002;4(6):231-9.

28. Castro AMS, Guerra-Junior G. GH/IGF e neoplasia: o que há de novo nesta associação. Arq Bras Endocrinol Metab. 2005;49:833-42.

29. Peyrat JP, Bonneterre J, Hecquet B, et al. Plasma insulin-like growth factor-1 (IGF-1) concentrations in human breast cancer. Eur J Cancer. 1993;29(4):492-7.

30. Fletcher O, Gibson L, Johnson N, et al. Polymorphisms and circulating levels in the insulin-like growth factor system and risk of breast cancer: a systematic review. Cancer Epidemiol Biomarkers Prev. 2005;14(1):2-19. 
31. Bruning PF, Van Doorn J, Bonfrer IMG, et al. Insulin-like growth-factorbinding protein 3 is decreased in early-stage operable pre-menopausal breast cancer. Int J Cancer.1995;62(3):266-70.

32. Rocha RL, Hilsenbeck SG, Jackson JG, et al. Correlation of insulin-like growth factor-binding protein-3 messenger RNA with protein expression in primary breast cancer tissues: detection of higher levels in tumors with poor prognostic features. J Natl Cancer Inst. 1996;88:601-6.

33. Renehan AG, Zwahlen M, Minder $C$, et al. Insulin-like growth factor (IGF)-I, IGF binding protein-3, and cancer risk: systematic review and meta-regression analysis. Lancet. 2004;363:1346-53.

34. Shi R, Yu H, McLarty J, Glass J. IGF-I and breast cancer: a metaanalysis. Int J Cancer. 2004;111:418-23.

35. Sugumar A, Liu YC, Xia Q, et al. Insulin-like growth factor(IGF)-I and IGF-binding protein 3 and the risk of premenopausal breast câncer: a meta-analysis of literature. Int J Cancer. 2004;111:293-7. 
36. Chen W, Wang S, Tiam T et al. Phenotypes and genotypes of insulin-like growth factor-1, IGF-binding protein-3 and cancer risk: evidence from 96 studies. Eur J Hum Genet. 2009 Jun:1-8.

37. Rinaldi S, Peeters PH, Berrino F, et al. IGF-I, IGFBP-3 and breast cancer risk in women: The European Prospective Investigation into Cancer and Nutrition (EPIC). Endocr Relat Cancer. 2006;13:593-605.

38. Johansson H, Baglietto L, Guerriri-Gonzaga A, et al. factors associated with circulating levels of insulis-like growth factor-I and insulin-like growth factor binding protein-3 in 740 womwn at risk for breast cancer. Breast Cancer Res Treat. 2004;88(1):63-73.

39. Baglietto L, English DR, Hopper JL et al. Circulating insulin-like growth factor-I and binding protein-3 and the risk of breast cancer. Environmental Cancer Epidemiol Biomarkers Prev. 2007;16(4):763-68.

40. Vatten LJ, Holly JM, Gunnell D et al. Nested case-control study of the association of circulating levels of serum insulin-like growth factor I and insulin-like growth factor binding protein 3 with breast cancer in young 
women in Norway. Cancer Epidemiol Biomarkers Prev. 2008;17(8):2097100.

41. Gunter MJ, Hoover DR, Yu H et al. Insulin, insulin-like growth factor-I, and risk of breast cancer in postmenopausal women. J Natl Cancer Inst. 2009;101:48-60.

42. Estados Unidos da América - American Cancer Society (ACS). Cancer screening in the United States, 2008: a review of current American Cancer Society guidelines and cancer screening issues [on line]. Disponível em out/2009:

http://caonline.amcancersoc.org/cgi/content/full/58/3/161

43. Barnes BB, Chang-Claude J, Flesch-Janys D et al. Cancer risk factors associated with insulin-like growth factor (IGF)-1 and IGF-binding protein3 levels in healthy women: effect modification by menopausal status. Cancer Causes Control. 2009;20(10):1985-96. 
44. Holmes MD, Pollak MN, Hankinson SE. Lifestyle correlates of plasma insulin-like growth factor I and insulin-like growth factor binding protein 3 concentrations. Cancer Epidemiol Biomakers Prev. 2002; 11(9):862-7.

45. Diorio C, Brisson J, Bérubé S, Pollak M. Intact and total insulin-like growth factor-binding protein-3 (IGFBP-3) levels in relation to breast cancer risk factor: a cross-sectional study. Breast Cancer Res. 2008;10(3):R42.

46. Singer CF, Mogg M, Koestler W, et al. Insulin-like growth factor (IGF)-I and IGF-II serum concentrations in patients with benign and malignant breast lesions: free IGF-II is correlated with breast cancer size. Clin Cancer Res. 2004;10:4003-9.

47. Bohlke K, Cramer DW, Trichopoulos D, Mantzoros CS. Insulin-like growth factor-I in relation to premenopausal ductal carcinoma in situ of the breast. Epidemiology. 1998;9(5):570-3.

48. Sherlock M, Toogood AA. Aging and the growth hormone / insulin like growth factor-1 axis. Pituitary. 2007;10(2):189-203. 
49. Toniolo P, Bruning PF, Akhmedkhanov $A$ et al. Serum insulin-like growth factor-1 and breast cancer. Int J Cancer. 2000; 88:828-32.

50. Schernhamer ES, Holly JM, Pollak MN, et al. Circulating levels of insulinlike growth factors, their binding proteins, and breast cancer risk. Cancer Epidemiol Biomarkers Prev. 2005;14(3):699-704.

51. Schernhammer ES, Holly MJ, Hunter DJ et al. Insulin-like growth factor-1, its binding proteins (IGFBP-1 and IGFBP-3), and growth hormone and breast cancer risk in The Nurses Health Study II. Endocrine Related Cancer. 2006;13:583-92.

52. Renehan AG, Harvie M, Howell A. Insulin-like growth factor (IGF)-I, IGF binding protein-3, and breast cancer risk: eight years on. EndocrineRelated Cancer. 2006;13:273-8.

53. Petridou E, Papadiamantis $Y$, Markopoulos C, et al. Leptin and insulin growth factor I in relation to breast câncer (Greece). Cancer Causes Control. 2000;11:383-8. 